\title{
ANÁLISE DAS OPERAÇÕES DE HEDGING EM MERCADOS FUTUROS: O CASO DO CAFÉ ARÁBICA NO BRASIL
}

\author{
Felipe Bertinatto Pelizari Pacheco \\ Engenheiro Agrônomo
}

Orientador: Prof. Dr. RICARDO SHIROTA

Dissertaçãó apreseñtadà à Escola-Superior de Agricultura "Luiz de Queiroz", Universidade de São Paulo, para a obtenção do título de Mestre em Ciências, Área de Concentração: Economia Aplicada.

\section{PIRACICABA}

Estado de São Paulo - Brasil

Janeiro - 2000 
Dados Internacionais de Catalogação na Publicação (CIP) DIVISÃO DE BIBLIOTECA E DOCUMENTAÇÃO - Campus "Luiz de Queiroz"/USP

\author{
Pacheco, Felipe Bertinato Pelizari \\ Análise das operaçōes de hedging em mercados futuros: o caso do café Arábica \\ do Brasil / Felipe Bertinatto Pelizari Pacheco. - - Piracicaba, 2000. \\ $79 \mathrm{p}$. \\ Dissertação (mestrado) - - Escola Superior de Agricultura Luiz de Queiroz, 1998. \\ Bibliografia.
}

1. Agribusiness 2. Café 3. Economia agrícola 4. Flutuação econômica 5. Mercado de futuros 6. Preço agrícola I. Título

CDD 338.17373

"Permitida a cópia total ou parcial deste documento, desde que citada a fonte - 0 Autor" 
Dedico este trabalho para os meus pais Eunice e Hugo. 


\section{AGRADECIMENTOS}

Gostaria de agradecer todos os funcionários do Departamento de Economia e Sociologia Rural que, direta ou indiretamente, ajudaram na minha caminhada dentro desse departamento.

Especial agradecimento aos meus amigos Augusto, Mauricio, Fábio, Pedro, Valter, Renato, Marcelo e Sérgio que foram de fundamental importância na minha vida acadêmica em Piracicaba e tornaram a minha convivência em Piracicaba ainda mais agradável.

Ao meu orientador e amigo Ricardo Shirota, pelas orientações nessa dissertação e por todo apoio dispensado a minha pessoa em mais de 5 anos de convivência.

A todos os colegas de trabalho e amigos do Centro de Estudos Avançados em Economia Aplicada (CEPEA), que sempre me incentivaram nessa escalada.

Aos meus pais Eunice e Hugo que, tenho certeza, sempre acreditaram no meu futuro e não pouparam esforços para que pudesse chegar até aqui e conquistar esse titulo. Aos meus irmãos Rogério e Mauricio, pelos exemplos de sucesso que são, mostrando que tudo que conseguimos é fruto de nossa dedicação e perseverança.

A minha namorada Tarcila, que sempre incentivou minha carreira e meus estudos, sendo cúmplice da minha dedicação e muito paciente em vários momentos nesses últimos meses que antecederam a entrega desse trabalho. 


\section{SUMÁRIO}

Página

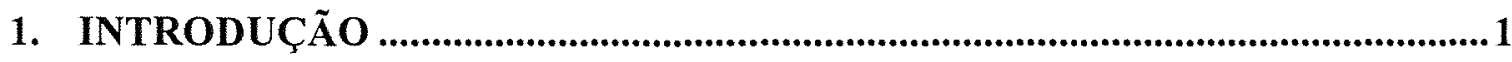

2. INSTRUMENTOS PARA GERENCIAMENTO DO RISCO DE PREÇO........ 4

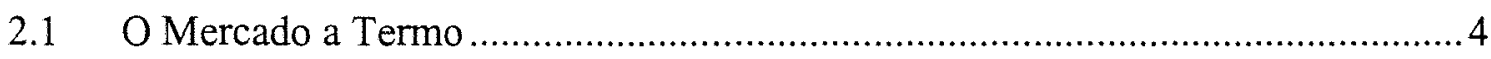

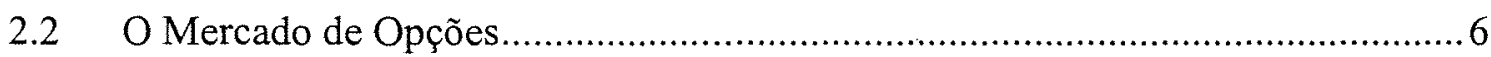

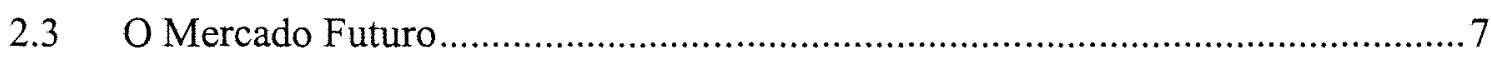

3. ASPECTOS TEÓRICOS DAS OPERAÇÕES DE HEDGE EM MERCADOS FUTUROS...................................................................................................... 10

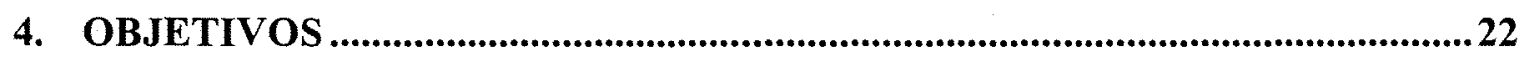

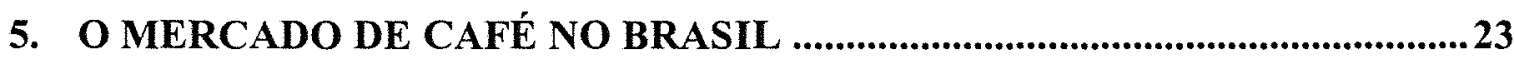

5.1 Importância Econômica e Evolução Recente .............................................23

5.2 A Evolução dos Preços de Café no Brasil: 1950 a 1996...................................28

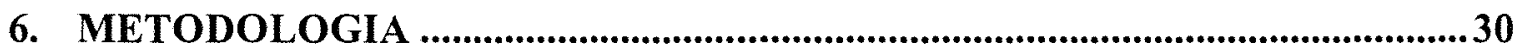

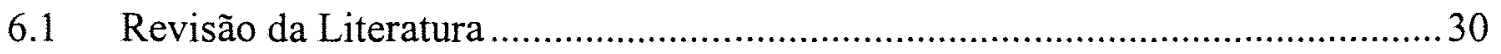

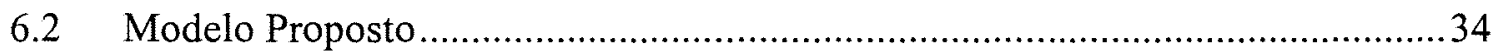

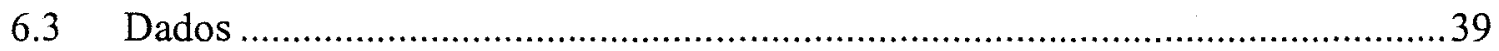

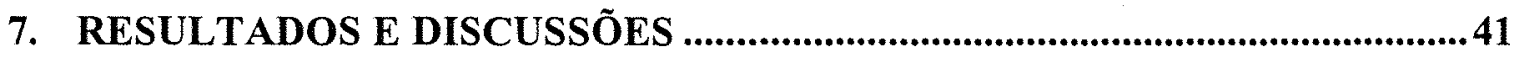

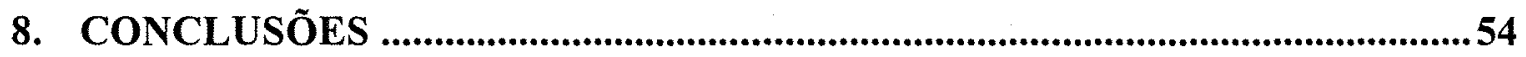

9. REFERÊNCIA BIBLIOGRÁFICA .............................................................77 


\section{ÍNDICE DE TABELAS}

Página

Tabela 1. Produção mundial total de café verde, em grãos, total e por principais países produtores, em 1.000 sacas de $60 \mathrm{~kg}$, safras 1991/92 1995/96.......24

Tabela 2. Área, população e produção de café no Brasil, safras 1960/61 1998/99..25

Tabela 3. Produção brasileira de café por estados produtores - milhões scs. $60 \mathrm{~kg} 26$

Tabela 4. Produção de café arábica classificada por bebida (scs $60 \mathrm{~kg})$..................29

Tabela 5. Médias e desvios-padrão (DP) das séries diferenciadas em relação ao Café Santos 4 (CFD), em US\$/saca................................................................4 43

Tabela 6. Média da razão de hedge para as diferentes qualidades de café, no mercado futuro da BM\&F e para 4 meses de duração.............................. 48

Tabela 7. Média da razão de hedge para as diferentes qualidades de café, no mercado futuro da CSCE e para 4 meses de duração.

Tabela 8. Média da razão de hedge para as diferentes qualidades de café, no mercado futuro da $\mathrm{BM} \& \mathrm{~F}$ e para 6 meses de duração.

Tabela 9. Média da razão de hedge para as diferentes qualidades de café, no mercado futuro da CSCE e para 6 meses de duração. 50

Tabela 10. Média da redução do risco $\left(R^{2}\right)$ para as diferentes qualidades de café, no mercado futuro da BM\&F e para 4 meses de duração............................51

Tabela 11. Média da redução do risco $\left(R^{2}\right)$ para as diferentes qualidades de café, no mercado futuro da CSCE e para 4 meses de duração. .................................51

Tabela 12. Média da redução do risco $\left(R^{2}\right)$ para as diferentes qualidades de café, no mercado futuro da BM\&F e para 6 meses de duração.

Tabela 13. Média da redução do risco $\left(\mathbf{R}^{2}\right)$ para as diferentes qualidades de café, no mercado futuro da CSCE e para 6 meses de duração. 52

Tabela 14 - Resultados das regressões utilizadas neste estudo. .63 


\section{ÍNDICE DE FIGURAS}

Página

Figura 1. Oferta e demanda para armazenamento em função da base (Leuthold, 1989). .15

Figura 2. Participação \% dos principais países produtores de café, safra $96 / 97 \ldots 23$

Figura 3. Evolução da participação dos estados na produção brasileira de café.....27

Figura 4. Média anual de janeiro de 1950 a outubro de 1996 dos preços recebidos pelos produtores de São Paulo, pela saca de $60 \mathrm{~kg}$ de café beneficiado. (em R\$ de outubro de 1996)..............................................................................28

Figura 5. Evolução dos preços das diferentes qualidades de café utilizadas neste estudo (US\$/saca).

Figura 6. Diferenciais de preços, em US\$/saca, em relação ao Café Santos 4 (CFD).42

Figura 7 - Razão de hedge para o café CFA, vencimento de setembro e com duração de hedge de 6 meses.........................................................................45

Figura 8 - Razão de hedge para o café CFB, vencimento de setembro e com duração de hedge de 6 meses.................................................................................46

Figura 9 - Razão de hedge para o café CFC, vencimento de setembro e com duração de hedge de 6 meses..........................................................................4 47

Figura 10 - Razão de hedge para o café CFD, vencimento de setembro e com duração de hedge de 6 meses.

Figura 11 - Razão de hedge para o café CFE, vencimento de setembro e com duração de hedge de 6 meses. 


\title{
ANÁLISE DAS OPERAÇÕES DE HEDGING EM MERCADOS FUTUROS: O CASO DO CAFÉ ARÁBICA NO BRASIL
}

\author{
Autor: Felipe Bertinatto Pelizari Pacheco
}

Orientador: Ricardo Shirota

\section{RESUMO}

No que diz respeito aos mercados futuros agrícolas, a coisa mais importante para os agentes envolvidos nesse mercados é conhecer o comportamento entre os preços no mercado disponível e os preços futuros.

Afim de minimizar o risco de preço, o agente pode utilizar vários instrumentos para administrá-lo. As alternativas mais importantes para minimizar esse tipo de risco são: o mercado de opções, o mercado a termo e o mercado futuro, o qual é objeto deste estudo.

O café é uma mercadoria muito importante no cenário mundial e seus preços são bastante voláteis. Desse modo, é relevante estudar o mercado futuro para esse produto e tentar entender o comportamento entre preços futuro e disponível do café afim de fornecer alguns parâmetros que possam auxiliar os "hedgers" a administrar suas posições no mercado futuro de café.

Para implementar este estudo, 3 séries temporais de preços são estruturados para gerar inúmeras situações hipotéticas de hedge utilizando duas bolsas que negociam futuros de café no mundo. O mercado de café disponível no Brasil é utilizado como referência para comparar essas duas bolsas no que diz respeito à eficiência de hedge. 
Para medir a eficiência de hedge, é utilizado a regressão simples entre os preços em nível dos mercados disponível e futuro para cinco diferentes tipos de café do Brasil, os quais cobrem a maior parte da produção brasileira de café.

Os resultados mostraram que existe uma estreita relação entre os preços futuro e disponível, mas, para o autor, alguns fatores afetaram a formação de preços do café no Brasil, possivelmente causada pelos altos níveis de inflação observados no período em estudo.

Mesmo assim, alguns resultado importantes mostram que a Bolsa de Mercadorias \& Futuros (BM\&F) é mais eficiente para o hedge de produtores brasileiros do que a Bolsa de Nova Iorque (CSCE). É importante ressaltar que as duas bolsas negociam diferentes padrões de café. Sendo assim, a BM\&F possui um padrão de café para a entrega mais adequado aos produtores brasileiros de café.

Além do mais, muito do risco de preço pode ser reduzido com a utilização do mercado futuro para a realização do hedge. No caso da BM\&F, a eficiência de hedge pode variar de 87 a $95 \%$ na maior parte dos casos, onde a média é de $90 \%$ quando é utilizado a razão de hedge determinada nesse estudo.

Os resultados também mostraram que a razão de hedge média para a BM\&F é cerca de $30 \%$ maior quando comparada a Bolsa de Nova Iorque (CSCE). Em alguns casos, essa diferença pode chegar a $50 \%$. 


\title{
HEDGING ANALYSIS ON FUTURES MARKETS: THE ARABICA COFFEE CASE IN BRAZIL
}

\author{
Author: Felipe Bertinatto Pelizari Pacheco
}

Adviser: Ricardo Shirota

\section{SUMMARY}

Concerning the agricultural futures markets, the most important thing for the agents involved in these markets is to know the behavior between the spot prices and the futures prices.

In order to minimize the price risk, the agent can use many tools to manage it. The most important alternatives to minimize this kind of risk are the options market, the forward market and the future market, which is the object of this study.

The coffee is a very important commodity in the world scenario and its prices are also very volatile. This way, it's relevant to study the future market for this commodity and try to understand the behavior between spot and future coffee prices in order to furnish some parameters that can help hedgers to manage their positions in the coffee future market.

In order to implement this study, three time series are structured to generate many hypothetical hedge situations using two coffe exchanges around the world. The brazilian spot market is the one chose to compare the two exchanges regarding the hedge efficiency. 
To measure the hedge efficiency, it's used a simple regression between spot and future prices levels for five kind of brazilian coffees which cover the most part of brazilian coffee production.

The results shown that there is a close relation between spot and futures prices, but for the author some factors have affected the spot coffee price formation in Brazil mainly caused by the high levels of inflation.

Nevertheless, some important results show that the Brazilian Coffee Exchange (BM\&F) is more effective concernig the hedge for the brazilian producers than the New York Coffee Exchange (CSCE). It's important to know that the two exchanges call two different types of coffee for delivery. This way, the brazilian exchange has a more specific kind of coffee to assist the brazilian producers.

Furthermore, much of price risk can be reduced when the future market is used to hedge. For the BM\&F, the hedge efficiency can vary from 87 to $95 \%$ in most cases, where the average is about $90 \%$ when is used the recommended hedge ratio.

The results also shown that the average hedge ratio for the BM\&F Exchange is about $30 \%$ higher when compared to CSCE Exchange. In some cases, this difference can be almost $50 \%$. 


\section{INTRODUÇ̃̃O}

Este trabalho tem o objetivo de estudar a eficiència do mercado futuro de produtos agrícolas como instrumento de "hedge" de preços. O trabalho justifica-se pela existência de produtos com elevada volatilidade de preços, a qual causa uma série de problemas tanto para produtores quanto para intermediários, processadores e também para consumidores.

É verdade que o mercado dispõe hoje de vários instrumentos para proteção contra variações indesejáveis de preços, tais como mercado a termo, mercado futuro, mercado de opções e outros instrumentos mais informais, como, por exemplo, a troca de insumo por produto. A finalidade desses instrumentos é possibilitar às partes interessadas a oportunidade de negociar antecipadamente seus produtos, garantindo assim um preço pré-fixado na data da negociação.

Porém, o presente trabalho analisa o mercado futuro como instrumento potencial para o "hedge", ou seja, para a proteção contra o risco de preço.

A maioria dos processos produtivos ao longo de todo o agribusiness está sujeita a uma série de riscos e incertezas ${ }^{1}$. Entre eles, a variabilidade dos preços têm uma grande importância como fonte desses riscos.

Muitos dos processos de tomada de decisões exigem que se tenha um certo conhecimento dos eventos futuros. Embora muitas previsões sejam feitas com base em

\footnotetext{
${ }^{1}$ Frank Knight foi o economista que, no início do século XX, preocupou-se em diferenciar risco de incerteza. Para este famoso economista, risco está associado à uma probabilidade matemática, enquanto incerteza não pode ser auferido por esses métodos. Nas palavras de Frank Knight: “ “. Descobrir-se-á que uma incerteza mensurável, ou risco propriamente... é tão diferente de uma imensurável que, na verdade, não chega a ser uma incerteza." (Bernstein, 1997).
} 
dados passados, isso não é garantia de que elas ocorrerão como previstas. Ou seja, muitos acontecimentos futuros são incertos e acabam interferindo diretamente nos resultados econômicos da decisão tomada inicialmente.

O segmento da produção é afetado pela interação entre as variáveis climáticas, pragas, doenças etc. e sofre também o problema do risco de preço. Esse último é particularmente grave na agricultura pela natureza competitiva desse segmento. $O$ resultado é que, o qual devido ao elevado número de produtores agrícolas, são incapazes de determinar o preço de seus produtos, sendo considerados "tomadores" de preço. Isto é, os produtores individualmente representam uma parcela muito pequena da oferta total, os seus produtos são relativamente homogêneos e, consequentemente, nenhum produtor pode afetar de maneira significativa o preço de seu produto.

É notório que a questão do risco deve estar associada diretamente a receita gerada pelo negócio, que, por sua vez, é resultado da multiplicação do preço e a quantidade produzida. Embora essas duas variáveis estejam relacionadas, neste trabalho será dado ênfase à variável preço.

Para muitos produtos agrícolas, existe o que é conhecido como épocas de safra e entressafra. A safra, por ser um periodo de maior oferta do produto, é caracterizada por preços geralmente mais baixos. Na época da entressafra, a oferta de produto é menor e, com isso, o preço tende a ser mais elevado. Esse comportamento de preços, característico dos produtos agrícolas, é conhecido como estacionalidade de preços.

Considerando que a demanda apresenta um comportamento mais estável ao longo do tempo, o ajuste de preço nos mercados agrícolas sofre uma grande influência da oferta. Como a oferta de produtos agrícolas é estacional ao longo do tempo, o preço também o será. Cabe ressaltar que, como essa estacionalidade está diretamente relacionada ao comportamento do processo produtivo agrícola, as variações de preços a 
ela atribuídas já são esperadas pelos agentes envolvidos nesse mercado, embora seja difícil quantificá-las de forma precisa.

Além dessas variações estacionais de preços, existem as oscilações de preços causadas por mudanças repentinas na oferta ou demanda, causadas principalmente por fatores climáticos capazes de gerar grandes variações nos preços dos produtos agrícolas. Outros fatores que podem causar essas variações repentinas de preços são problemas fitossanitários, variação de estoques do governo, diminuição ou extinção de tarifas de importação de produtos agrícolas, mudanças cambiais etc.

Os principais agentes envolvidos nesse mercado são os vendedores (agregando, principalmente, os produtores e suas cooperativas) e os compradores (exportadores, intermediários, varejistas etc.) e todos defrontam-se com esse risco de preço.

No caso dos produtores, a decisão do que, quanto e quando plantar, depende em grande parte da expectativa de preço que o produtor receberá por seu produto na hora da venda. O produtor pode obter um preço maior do que a expectativa de preço que tinha na época do plantio, mas também pode obter um preço menor e, com isso, reduzir o retorno econômico de sua atividade.

Do outro lado estão os compradores, representados pelos atacadistas, varejistas, exportadores e empresas de transformação. Assim como os produtores, eles também enfrentam o problema do risco de preço ${ }^{2}$.

Por outro lado, se os preços pudessem ser determinados ex-ante, via estabelecimento de um contrato por exemplo, os vendedores e compradores de produtos agrícolas poderiam eliminar, ou ao menos minimizar, o risco do preço.

\footnotetext{
${ }^{2}$ Este é um caso de um exportador de produtos agricolas que tenha fechado um contrato de exportação para entrega futura e com preço fixado. Se o preço subir na época que o exportador for adquirir o produto haverá uma diminuição na sua margem de lucro, ou mesmo um prejuizo nessa operaçào.
} 


\section{INSTRUMENTOS PARA GERENCIAMENTO DO RISCO DE PRECO}

Entre os mecanismos mais utilizados para gerenciamento dos riscos de preço pode-se destacar o mercado a termo, o mercado de opções e o mercado futuro. No Brasil, a utilização desses instrumentos ainda é incipiente, mas vem crescendo nos últimos anos, principalmente o mercado de futuros agropecuários. O potencial para crescimento do mercado de futuros é bastante grande, dado o potencial agrícola do país e a crescente diminuição da intervenção governamental na comercialização desses produtos.

\subsection{O Mercado a Termo}

Contratos a termo são acordos para comprar e vender um determinado ativo numa certa data futura por um certo preço. Uma das partes no contrato a termo assume uma posição comprada e concorda em comprar o ativo numa certa data especificada, por um certo preço. A outra parte assume uma posição vendida e concorda em vender o ativo na mesma data e pelo mesmo preço.

Contratos a termo não precisam se adequar aos padrões de uma determinada bolsa. A data de entrega especificada no contrato pode ser determinada pela conveniência mútua de compradores e vendedores. O maior risco desse tipo de contrato é que uma das partes não venha a cumprir o compromisso na data do vencimento. (Bessada, 1995) 
O Certificado de Mercadoria com Emissão Garantida (CM-G) e a Cédula de Produto Rural (CPR) são exemplos de contratos a termo. Enquanto o primeiro teve suas emissões interrompidas, o segundo vem ganhando espaço, principalmente nos casos do café, soja e boi gordo.

A Cédula de Produto Rural (CPR) é um contrato cambial estabelecido entre um vendedor (emitente) e um comprador, onde o primeiro compromete-se a entregar determinado produto ao comprador, no local e data estipulados no título, sendo um título endossável, e que pode ser negociado em bolsas de mercadorias e de futuros. (Rochelle, 1995)

A CPR oferece muitas vantagens ao produtor. Em primeiro lugar, ela fornece capital de giro para a produção, já que o pagamento é feito à vista, e assegura o risco da queda de preço. Com isso, pode haver redução nos custos de buscar financiamento e na incerteza quanto à preços.

O comprador da CPR, que receberá futuramente a mercadoria, pode utilizar o mercado futuro do mesmo como garantia de preço. Ou seja, ele pode fazer uma oferta de preço para o produtor a partir da cotação no mercado futuro, descontando os custos incorridos no pagamento antecipado do produto.

Uma das desvantagens do mercado a termo é o risco do produtor não entregar a mercadoria na data especificada, seja por uma frustração de safra, seja por ter entregue seu produto para outro comprador. Além disso, a mercadoria entregue pode estar fora dos padrões estabelecidos no contrato. Embora haja exigências contratuais que penalizam essa falta, existe a possibilidade que isso venha a ocorrer, prejudicando a parte compradora. Outra desvantagem é a provável falta de compradores interessados ou a dificuldade de se acordar um preço futuro entre as partes. 


\subsection{O Mercado de Opções}

Um contrato de opção dá direito ao seu comprador a opção de comprar ou vender (opção de compra ou venda) um determinado ativo, em uma data futura, por um preço estabelecido (preço de exercício). O comprador da opção paga uma certa quantia para ter esse direito, o que é conhecido como "prêmio". Se a variação de preço do ativo envolvido for desfavorável ao detentor da opção, ele simplesmente não a exerce, e seu prejuízo fica limitado ao "prêmio" pago pela opção

O vendedor da opção recebe o prêmio, mas fica na obrigação de assumir seu compromisso caso o comprador deseje exercer sua opção. A opção pode envolver tanto um ativo específico, como um contrato futuro de um ativo. Nesse último caso, ao execer sua opção, o comprador assume uma posição comprada ou vendida no mercado futuro, dependendo do tipo da opção.

Uma das vantagens do mercado de opções é a desobrigação por parte do comprador da opção de disponibilizar garantias. Além disso, o comprador pode aproveitar-se de mudanças favoráveis nos preços, deixando de exercer sua opção.

O pagamento do prêmio da opção pode ser visto como uma desvantagem para o comprador, já que esse é um custo não recuperável. Particularmente no mercado brasileiro de opções, a falta de liquidez também é uma desvantagem para os compradores. Considerando a experiência de outros países nesse mercado, pode-se dizer que o mercado de opções tende a evoluir rapidamente aqui no Brasil, mas ainda não atingimos um bom nível de liquidez. 


\subsection{O Mercado Futuro}

Um contrato futuro é um acordo para comprar ou vender um determinado ativo por um certo preço, numa certa época no futuro, com padronização de qualidade, quantidade, locais de entrega e datas específicas para a liquidação dos negócios. Esses contratos são negociados no pregão de uma bolsa de futuros (Hull, 1995).

Um contrato futuro é muito semelhante ao contrato a termo, mas com uma diferença importante. Ao realizar um negócio no mercado futuro, as partes envolvidas (comprador e vendedor) não mais se relacionam entre si. Ambas as partes assumem compromisso com a câmara de compensação da bolsa ("clearing house"), que torna-se a compradora de todos os vendedores e a vendedora de todos os compradores.

A bolsa exige dos agentes que entram no mercado futuro um depósito referente à margem de garantia, como forma de assegurar a liquidação dos negócios. Diariamente é realizado o que é conhecido como ajuste diário, que consiste em débitos na conta corrente dos indivíduos que tiveram prejuízos e créditos na conta dos que tiveram ganhos com a variação na cotação de ajuste de cada dia.

A imensa maioria dos contratos futuros negociados não é liquidada com a entrega do ativo, sendo as posições encerradas antes da data limite de entrega especificada no contrato, assumindo-se uma posição contrária àquela assumida no início do contrato. Isso favorece àqueles agentes que não possuem mercadoria dentro dos padrões especificados pela bolsa e pretendem participar do mercado futuro. Fazer a entrega ou receber o produto nos termos de um contrato futuro pode tornar-se inconveniente e, em alguns casos, muito caro. 
No início dos mercados futuros, possivelmente anterior ao século XVII, a liquidação era necessariamente realizada com a entrega física da mercadoria. Com o desenvolvimento e aperfeiçoamento desses mercados, percebeu-se que a liquidação poderia ser realizada financeiramente, sem a necessidade de entrega do produto especificado em alguns casos. A experiência com a utilização desse instrumento de liquidação é recente no mundo e data do final da década de 70 .

No Brasil, essa experiência é ainda mais recente. O primeiro contrato futuro agrícola a ser liquidado por um indicador financeiro foi o de boi gordo na Bolsa de Mercadorias \& Futuros (BM\&F) em 1994, gerando um aumento exponencial no volume de contratos negociados. Com o sucesso alcançado por essa experiência pioneira no Brasil, essa mesma bolsa resolveu estender esse instrumento para os demais contratos agrícolas, com exceção do café. Com isso, são quatro os contratos futuros agrícolas que são liquidados financeiramente nessa bolsa: boi gordo, soja, milho e açúcar. Esses indicadores de preços são calculados diariamente pela Escola Superior de Agricultura "Luiz de Queiroz" (ESALQ), no caso do boi gordo, soja e açúcar, e pela Fundação Getúlio Vargas (FGV), no caso do milho.

Os principais agentes que operam com futuros são os especuladores e os "hedgers". Enquanto os primeiros estão interessados em lucrar com a compra e venda de contratos futuros, os "hedgers" (produtores, atacadistas, exportadores, empresas de transformação etc.) utilizam este mercado para diminuir seus riscos de preço, que são assumidos pelos especuladores.

O mercado futuro apresenta como vantagem a credibilidade do sistema que, através do sistema de garantia e ajuste diário, faz com que compradores e vendedores não sejam prejudicados pela inadimplência de uma das partes. Além disso, o processo de formação de preços é transparente, feito através de leilão "viva-voz" entre compradores e vendedores localizados no pregão da bolsa ou através de um sistema eletrônico. 
A Chicago Mercantile Exchange (CME), juntamente com a Bolsa de Mercadorias da França (MATIF), criou, em 1993, um sistema eletrônico que opera 24 horas por dia, conhecido como GLOBEX. E, no ano de 1999, lançou uma versão mais aprimorada desse sistema e chamada de GLOBEX 2.

Na Chicago Board of Trade (CBOT), em Chicago, existe uma experiência com a negociação eletrônica de futuros e opções de contratos agrícolas, conhecida como "Project A". Durante o dia, existe o pregão "viva-voz" de contratos futuros de soja, óleo de soja, farelo de soja, aveia, arroz integral, milho e trigo, enquanto o pregão eletrônico é realizado durante a noite.

No Brasil, uma experiência já concretizada com negociação eletrônica é conduzida na Bolsa de Valores de São Paulo (BOVESPA), onde parte das ações de empresas negociadas nessa bolsa é feita totalmente via pregão eletrônico. Esse sistema é chamado de "Megabolsa".

Essa questão de sistema eletrônico versus pregão viva-voz tem gerado bastante polêmica nos últimos anos em várias bolsas do mundo, que tratam de discutir as vantagens e desvantagens do sistema eletrônico em relação ao sistema de pregão vivavoz. O sistema eletrônico pode se tornar mais competitivo no que se refere ao custo operacional, já que elimina a necessidade de haver uma instalação física para a realização dos negócios, além de dipensar o serviço do operador de pregão.

A utilização combinada dos mercados disponivel, a termo, futuro e de opções pode gerar várias estratégias para os mais diferentes agentes e para as mais diversas finalidades. Neste trabalho será dado ênfase às operações de proteção ("hedge") contra os riscos de preço, utilizando o mercado futuro de produtos agropecuários. 


\section{ASPECTOS TEÓRICOS DAS OPERAÇÕES DE HEDGE EM MERCADOS FUTUROS}

O conceito de hedge está associado com a idéia de proteção contra as variações (risco) de preço, assumindo no mercado futuro uma posição que proteja contra as variações prejudiciais de preço. Se a intenção é se proteger contra possíveis quedas nos preços, a posição a ser tomada no mercado futuro é de venda. Caso a preocupação seja a de proteção contra as altas de preços, a posição recomendada é a de compra.

Para melhor esclarecer esse conceito, suponha o seguinte exemplo de operação de "hedge" de venda no mercado de café. Um cafeicultor estima sua safra em 2.000 sacas e pretende vender uma parte de seu café em julho. No mercado futuro, no dia 9 de fevereiro de 1998, o café para entrega em julho do mesmo ano estava cotado a US\$ $143,20 /$ saca. Fevereiro é mês de entressafra do café e ele ainda não possui o produto, mas julho já é mês de safra. O preço do café no disponivel, em 9 de fevereiro, era de US\$ 158,50/saca. Para não correr o risco de preço, o cafeicultor vê que essa cotação para o mês de julho lhe garante um bom retomo e vende 10 contratos, ou seja, o equivalente à 1.000 sacas àquele preço.

Em 16 de julho de 1998, o café no mercado disponível estava cotado em US\$ 98,50/saca e, no mercado futuro, no vencimento do contrato, a saca de café estava sendo negociada a US\$ 107,00 . O resultado do hedge na bolsa, está descrito no quadro abaixo.

\footnotetext{
${ }^{3}$ Exemplo extraido de material didático da Bolsa de Mercadorias \& Futuros (BM\&F).
} 


\begin{tabular}{|l|c|c|}
\hline Data & Futuro (julho/98) & Disponível* $^{*}$ \\
\hline 09/Fev/1998 & US\$ 143,20 & US\$ 158,50 \\
\hline $16 / J u l / 1998$ & US\$ 107,00 & US\$ 98,50 \\
\hline Resultado & + US\$ 36,20 & - US\$ 60,00 \\
\hline
\end{tabular}

* Dados hipotéticos

Esse produtor obteve um ganho no mercado futuro de US\$ $36,200.00$ (US\$ 36.20 x 1000 sacas). Com a receita obtida pela venda do café no disponivel em 16 de julho, o produtor obteve uma receita de US\$ $98,500.00$. Somando-se a este valor o ganho obtido no mercado futuro, ele chega a um preço de US\$134.70/saca.

Valor Final $=$ US\$ $98.50+$ US\$ $36.20=$ US\$ 134.70

Ve-se pelo quadro acima, que a variação de preço no mercado futuro não foi igual a variação de preço no mercado disponivel no período considerado. Enquanto o preço da saca de café caiu US\$ 36.20 no mercado futuro, o mesmo produto caiu US\$ 60.00 no mercado disponível.

O conhecimento do comportamento entre os preços nos mercados disponivel e futuro é de essencial importância para que o agente econômico possa balizar suas operações de hedge no mercado futuro.

Quando a operação de hedge elimina completamente o risco de preço (variações idênticas entre os preços futuro e disponivel), é denominada hedge perfeito (Hull, 1995). No entanto, esse tipo de operação é muito dificil de ocorrer na prática, devido às oscilações assimétricas das cotações de mercado disponível vis-a-vis o mercado futuro. 
Mas, mesmo não sendo perfeita, a operação de hedge no mercado futuro pode ser uma boa alternativa para a proteção contra as oscilações de preço.

Pelo exemplo acima, se o mesmo produtor não tivesse realizado o hedge no mercado futuro, o preço final obtido seria de US\$ $98.50 / \mathrm{saca}$, visto que esse era o preço o vigente no mercado disponivel daquela data, contra os US\$ 134.70 que obteve na operação de hedge. Mais importante do que isso, é que esse produtor pôde negociar antecipadamente um preço para o seu produto antes mesmo de tê-lo em mãos, diminuido o risco da queda no preço de seu produto.

Deve-se enfatizar que o hedge de venda não é necessariamente garantia de preço maior do que os custos de produção. Ex-post, essa operação pode nem mesmo representar um resultado econômico melhor do que a simples venda ou compra no mercado disponível. A operação de hedge deve ser utilizada tão somente com a intenção de reduzir o risco de uma mudança desfavorável de preço, ou seja, de queda de preços para o vendedor, e aumento para o comprador.

Por outro lado, é claro que, de modo geral, o hedge só deve ser efetuado quando garantir um preço que seja capaz de gerar uma receita maior do que os custos de produção. Numa situação extrema, onde os preços futuros não proporcionam uma receita maior que os custos, o hedge ainda pode ser efetuado, caso a previsão seja de preços ainda mais desfavoráveis.

A decisão de fazer hedge (ou não) no mercado futuro, deve seguir os mesmos princípios de uma decisão comercial de compra ou venda do produto no mercado disponível. A vantagem é que há inúmeras oportunidades para a realização da operação durante o período que antecede a comercialização da mercadoria no mercado disponível. A existência de tais possibilidades de negócio no mercado futuro serve para orientar o processo decisório do agente econômico. Sem a existência dos mercados 
futuros, os vendedores e compradores ficariam a mercê das condições de mercado que ocorrem no momento da disponibilização da mercadoria.

No caso do produtor agrícola, pode-se separar as operações de hedge em dois grupos principais: o hedge efetuado antes da colheita do produto e o hedge efetuado após a colheita do produto. Nesse último caso, trata-se de hedge para armazenagem do produto.

Nessas operações, uma variável que pode determinar a rentabilidade da operação é a evolução da base, ou seja, a diferença entre o preço cotado no mercado futuro para um determinado mês de vencimento e o preço disponível ("spot") num determinado mercado (Leuthold, 1989), como se segue:

$$
B_{t, T}=F_{t, T}-S_{t}
$$

Onde:

$$
\begin{aligned}
& \boldsymbol{B}_{t, T} \text { é o valor da base no período t, para o mês de vencimento T; } \\
& \boldsymbol{F}_{t, T} \text { é o preço futuro em t, para o mês de vencimento T; e, } \\
& S_{t} \text { é o preço no mercado disponível ("spot"), no período } \mathrm{t} \text {. }
\end{aligned}
$$

A base, descrita acima, apresenta 3 dimensões: tempo, espaço e qualidade. A dimensão tempo é a que se refere ao armazenamento do produto até o mês de vencimento. Os custos de transportar a mercadoria até o local de entrega representam a dimensão espacial da base. E, ainda, pode existir uma diferença de qualidade entre a mercadoria em questão e o produto especificado no contrato futuro, que pode influenciar o valor da base, representando a dimensão qualidade da base (Leuthold, 1989). 
Além disso, a análise das relações de preço (base) deve ser separada em dois grupos: o grupo das commodities não-estocáveis (como é o caso do boi gordo) e outro das estocáveis (como é o caso do café).

Para as commodities estocáveis, a possibilidade de carregamento da mercadoria, entre dois períodos no tempo, estabelece uma relação temporal entre o preço "spot" e o preço futuro. O custo desse carregamento ("cost of carrying") depende, em grande parte, do tempo que separa as datas que estão sendo utilizadas no cálculo deste custo.

Ceteris paribus, uma firma irá armazenar na medida em que o custo marginal de armazenamento for igual ou inferior às expectativas de variação de preço de seu produto no período considerado. O custo de armazenamento é composto, basicamente, pelos gastos com aluguel do armazém, carga e descarga, juros e seguro, que aumentam com o aumento do nível de estoques. E o custo marginal de armazenamento é razoavelmente constante, ou seja, não aumenta com o aumento do nível de estoques. 
Figura 1. Oferta e demanda hipotética para armazenamento em função da base (Leuthold, 1989).

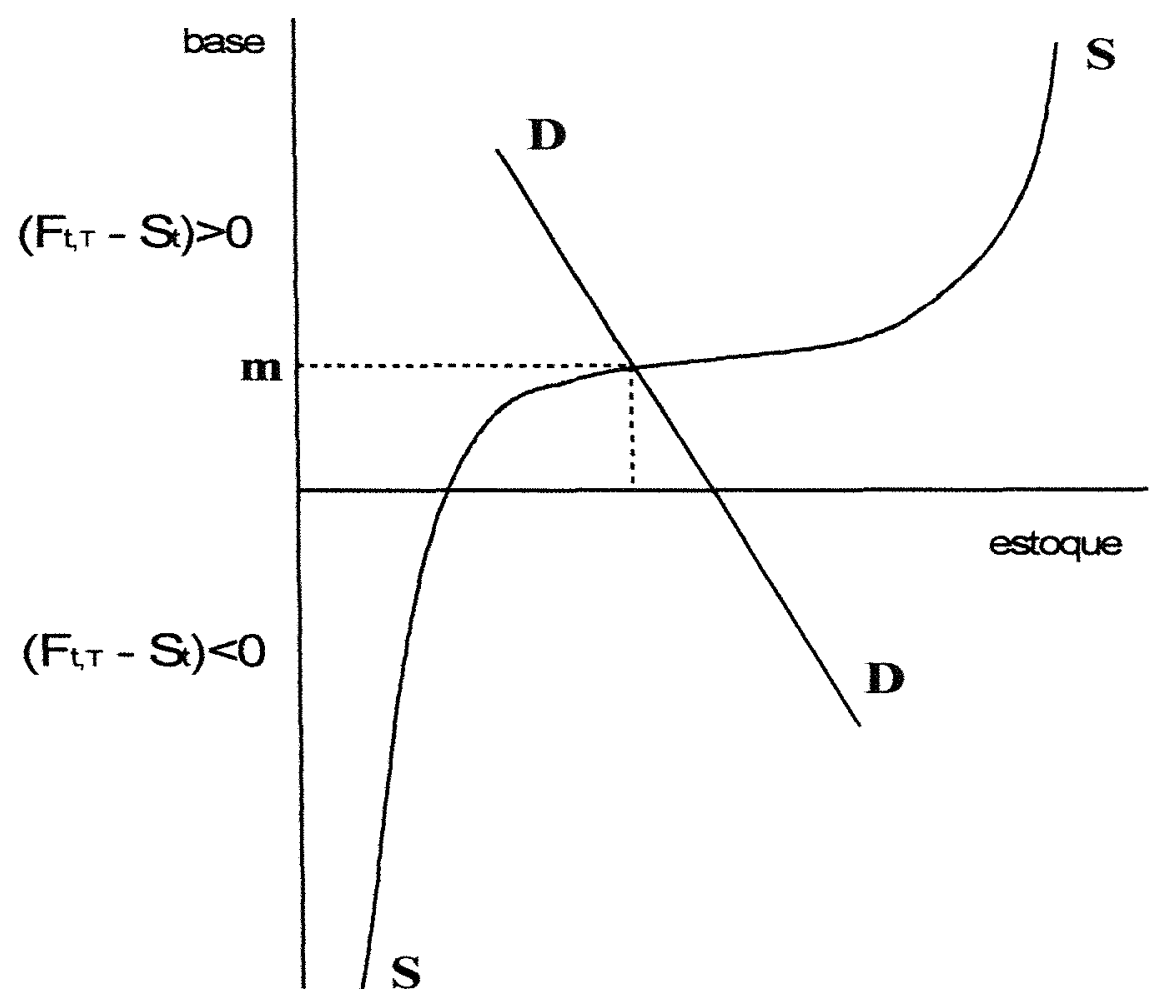

Na Figura 1, a curva (SS) mede a oferta de estoques em função da base. O nível de estoques aumenta com o aumento da base, quando a expectativa de preços futuros justificam o armazenamento num período $t$ para a posterior liberação em $\mathrm{t}+1$. Em níves elevados de estoque, a curva se torna inelástica, caracterizada pela limitação de espaço disponível para armazenamento.

Para valores negativos da base, quando, a priori, não haveria oferta de estoques, ainda assim o nível de estoques é maior que zero. Isso se justifica porque os detentores de estoques podem reter parte dos mesmos, já que o armazenamento, embora com preço negativo, torna-se conveniente do ponto de vista de seu negócio como um todo. 
A curva (DD) representa a demanda por estoques, que está associada diretamente à demanda do consumidor. Quanto maior a base, menor a demanda por estoques, o que caracteriza a inclinação dessa curva.

No equilibrio entre oferta (SS) e demanda (DD), a base $\left(\mathrm{F}_{\mathrm{t}, \mathrm{T}}-\mathrm{S}_{\mathrm{t}}\right)$ torna-se igual ao custo marginal de armazenamento (m). Com isso, pode-se dizer que a base, no caso de commodities estocáveis, é o preço de mercado para o armazenamento. E, dada a existência de estoques, todos os preços futuros relacionam-se entre si, refletindo o custo esperado de armazenamento entre os períodos (Leuthold, 1989).

A formação de preço nos mercados futuro e disponivel ocorre pela interação entre oferta e demanda nos respectivos mercados. Mas ambos os preços estão relacionados pela possibilidade de armazenamento da mercadoria, em função de expectativas de preços mais ou menos lucrativas no futuro em relação ao mercado "spot".

Por outro lado, no caso de valores negativos para a base, não existe um limite para a diferença entre o preço "spot" e o preço futuro, já que não há a possibilidade de armazenamento futuro visando consumo presente. Nesse caso, segundo Barros (1987), poderia haver um adiamento do consumo, dado as expectativas de preços futuros menores, ou seja, ocorrer uma transferência de demanda e não de oferta.

Geralmente, as expectativas que afetam o preço futuro também afetam o preço "spot". Assim, embora possam ocorrer variações drásticas na base em alguns dias, sua variabilidade tende a ser muito menor do que a variabilidade do nível de preços.

A base varia, de ano para ano, de acordo com o tamanho da safra, o nível de estoques e a demanda para armazenamento. Grandes valores para a base e "spreads" representam, geralmente, alto nivel de estoques. Valores pequenos ou negativos podem

\footnotetext{
${ }^{4}$ Spread representa a diferença entre os preços futuros, para uma mesma mercadoria, de diferentes meses de vencimento.
} 
significar escassez de produto, onde o mercado estaria sinalizando a liberação de estoques.

No vencimento do contrato, teoricamente a base deve ser zero para o produto com as mesmas especificações do contrato futuro, já que haveria intercambialidade do produto nos dois mercados. Caso o valor da base seja diferente de zero, geram-se oportunidades de arbitragem, forçando a base para zero.

Se o produto possuir diferenças de especificações em relação ao contrato futuro, a base não tenderá necessariamente a zero e sim ao valor do diferencial na data de liquidação. A eficiência do hedge será medida pelo comportamento desse diferencial na data da liquidação e o diferencial previsto no início da operação.

Para os produtos estocáveis, a base está associada aos niveis de estoque e o custo de carregamento, o que faz com que preços futuro e disponivel desses produtos mantenham-se correlacionados mesmo fora do mês de vencimento.

Dependendo do comportamento da base, vender/comprar uma quantidade de contratos futuros igual a quantidade de mercadoria a ser negociada no mercado disponivel (hedge de 100\%), não minimizará necessariamente o risco dessa operação, ou seja, a probabilidade do preço variar no sentido desfavorável ao desejado. A proporção entre o volume de contratos futuros negociados e o volume de mercadoria no disponível, que minimiza o risco da operação, é conhecida como "razão de hedge" e é determinada pela correlação entre os preços futuro e disponivel.

Se a variabilidade das cotações no futuro for maior do que no mercado disponivel, a razão de hedge tende a ser menor que a unidade, caso contrário, ela tende a ser maior que um. Este assunto será melhor abordado no capítulo referente à metodologia, onde será discutido um modelo para a estimativa dessa "razão de hedge". 
A idéia de "razão de hedge" pode ser melhor explicada por meio de um exemplo de uma operação hipotética envolvendo os parâmetros que serão obtidos neste estudo.

A explicação detalhada do modelo para a obtenção desse parâmetro está colocada no capitulo 6, mas para esse exemplo deve-se admitir que a "razão de hegde" pode ser obtida através da regressão dos preços no mercado disponível contra os preços no mercado futuro.

Suponha o caso onde a razão de hedge é igual a 0,7 ou $70 \%$, ou seja:

$$
S_{t}=0,70 . F_{t}+e_{t}
$$

Onde:

$\mathbf{S}_{\mathfrak{t}}$ é o preço no mercado disponivel; e

$F_{t}$ é o preço no mercado futuro, ambos no periodo $t$.

Se, no momento t, o preço no mercado futuro for igual a 100, então, o preço no mercado disponivel é igual a 70 . O quadro abaixo mostra o resultado líquido da operação para dois casos distintos. O primeiro é para uma variação positiva no preço do mercado futuro e para o caso de um hedge de venda:

\begin{tabular}{lccc}
\hline Mercado & Futuro & Disponível & Base \\
\hline Proporção & $\mathbf{7 0 \%}$ & $\mathbf{1 0 0 \%}$ & \\
\hline Início & $\mathrm{F}_{\mathrm{t}}=100$ & $\mathrm{~S}_{\mathrm{t}}=70$ & -30 \\
& $\downarrow$ & $\downarrow$ & \\
Fim & $\mathrm{F}_{\mathrm{t}}=50$ & $\mathrm{~S}_{\mathrm{t}}=35$ & -15 \\
\hline Resultado & $\Delta=(100-50) \times 0,7=35$ & $\Delta=(35-70)=-35$ & \\
\hline
\end{tabular}

Fonte: Elaborado pelo autor a partir de dados hipotéticos 
No exemplo acima, a queda de 50 unidades no preço do mercado futuro equivale a apenas 35 , já que a proporção de utilização (razão de hedge) é de $70 \%$. Isso representa um ganho de 35 unidades no mercado futuro. Ao mesmo tempo, a queda no mercado disponivel resultou num prejuízo de 35 unidades. O resultado líquido da operação nos dois mercados é nulo.

A seguir, é apresentado um exemplo de alta de preços para os mesmos parâmetros.

\begin{tabular}{lccc}
\hline Mercado & Futuro & Disponível & Base \\
\hline Proporção & $\mathbf{7 0 \%}$ & $\mathbf{1 0 0 \%}$ & \\
\hline Início & $\mathrm{F}_{\mathrm{t}}=100$ & $\mathrm{~S}_{\mathrm{t}}=70$ & -30 \\
& $\downarrow$ & $\downarrow$ & \\
Fim & $\mathrm{F}_{\mathrm{t}}=150$ & $\mathrm{~S}_{\mathrm{t}}=105$ & -45 \\
\hline Resultado & $\Delta=(100-150) \times 0,7=-35$ & $\Delta=(105-70)=35$ & \\
\hline
\end{tabular}

Fonte: Elaborado pelo autor a partir de dados hipotéticos

Pelo quadro acima, ve-se que o resultado líquido da operação nos dois mercados também é nulo. A diferença é que o prejuízo é obtido no mercado futuro e o lucro no mercado disponivel. Outro fato a ser notado é a variação da base nos dois casos. Enquanto no primeiro ela passou de -30 para -15 (fortalecimento da base), no segundo, ela passou de -30 para -45 (enfraquecimento da base).

Para contrapor os exemplos acima, será mostrado dois casos de operação no mercado futuro onde trabalha-se com valores da razão de hedge diferentes do valor obtido através da regressão. O primeiro caso supõe a utilização de uma razão hedge de $50 \%$, quando o valor indicado pela regressão é de $70 \%$. O caso abaixo é de queda nos preços e para um hedge de venda. 


\begin{tabular}{lccc}
\hline Mercado & Futuro & Disponível & Base \\
\hline Proporção & $\mathbf{5 0 \%}$ & $\mathbf{1 0 0 \%}$ & \\
\hline Início & $\mathrm{F}_{\mathrm{t}}=100$ & $\mathrm{~S}_{\mathrm{t}}=70$ & -30 \\
& $\downarrow$ & $\downarrow$ & \\
Fim & $\mathrm{F}_{\mathrm{t}}=50$ & $\mathrm{~S}_{\mathrm{t}}=35$ & -15 \\
\hline Resultado & $\Delta=(100-50) \times 0,5=25$ & $\Delta=70-35=-35$ & \\
\hline
\end{tabular}

Fonte: Elaborado pelo autor a partir de dados hipotéticos

No caso acima, o hedge de $50 \%$ fez com que o ganho obtido no mercado futuro fosse menor que a perda no mercado disponivel, ou seja, o resultado líquido da operação foi um prejuízo de 10 unidades. Por analogia, se os preços tivessem subido no período, o ganho no mercado disponível seria maior do que a perda do mercado futuro.

O outro exemplo será o caso onde o hedge de venda é feito para $100 \%$ da produção.

\begin{tabular}{lccc}
\hline Mercado & Futuro & Disponível & Base \\
\hline Proporção & $\mathbf{1 0 0 \%}$ & $\mathbf{1 0 0 \%}$ & \\
\hline Início & $\mathrm{F}_{\mathrm{t}}=100$ & $\mathrm{~S}_{\mathrm{t}}=70$ & -30 \\
& $\downarrow$ & $\downarrow$ & \\
Fim & $\mathrm{F}_{\mathrm{t}}=50$ & $\mathrm{~S}_{\mathrm{t}}=35$ & -15 \\
\hline Resultado & $\Delta=(100-50) \times 1,0=50$ & $\Delta=70-35=-35$ & \\
\hline
\end{tabular}

Fonte: Elaborado pelo autor a partir de dados hipotéticos 
O resultado líquido da operação mostrada no quadro acima é de 15 unidades, já que o ganho obtido no mercado futuro foi de 50 unidades contra um prejuízo de 35 unidades no mercado disponível. Para esse mesmo caso, se os preços tivessem subido, o resultado seria negativo, já que a perda no mercado futuro seria maior que o ganho no mercado disponível.

É importante ressaltar que o hedge é realizado para diminuir risco, independente da direção que os preços tomem após a realização desse tipo de operação. Portanto, é imprescindível que se conheça o comportamento conjunto dos preços futuro e disponível, já que o resultado do hedge depende diretamente desse comportamento. 


\section{OBJETIVOS}

O objetivo principal deste trabalho será tentar responder às seguintes questões:

$\Rightarrow$ Os mercados futuros de café arábica são uma boa alternativa de proteção contra risco de preço para os agentes envolvidos com esta mercadoria?

$\Rightarrow$ Qual a eficiência de hedge para os agentes que negociam qualidades de café arábica diferentes do padrão exigido pelas bolsas?

$\Rightarrow$ Como se comparam as Bolsas de Nova Iorque (CSCE) e a Bolsa de Mercadorias \& Futuros (BM\&F), no que diz respeito às razões de hedge e aos níveis de redução de risco de preço?

Através de uma análise estatística dos dados disponiveis, determinar-se-á:

(a) as razões de hedge que deveriam ser implementadas pelos agentes, visando minimizar o risco de preço;

(b) a eficiência da operação no mercado futuro no que diz respeito à redução desse tipo de risco.

Para finalidade de análise empírica, será utilizado o mercado de café arábica no Brasil e os mercados futuros de café na Bolsa de Nova Iorque (CSCE) e na Bolsa de Mercadorias \& Futuros (BM\&F). 


\section{O MERCADO DE CAFÉ NO BRASIL}

\subsection{Importância Econômica e Evolução Recente}

O café é um produto consumido em diversos países do mundo. Os principais consumidores estão localizados no hemisfério norte, sendo os Estados Unidos o maior consumidor. Além deste, vários países da Europa e o Japão são consumidores de uma grande parte da produção mundial.

Figura 2. Participação percentual dos principais países na produção mundial de café, safra 96/97.

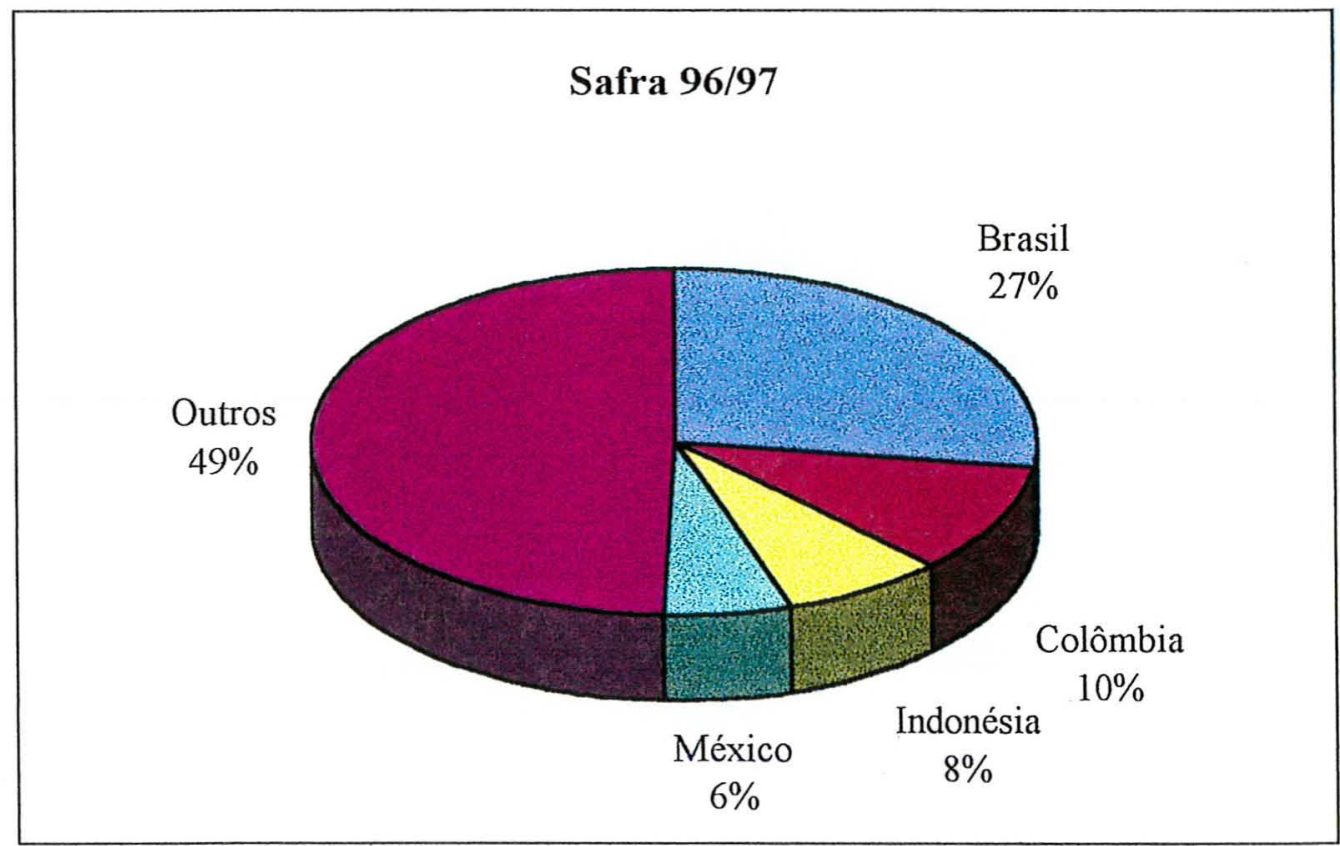

Fonte: Elaborado com base nos dados publicados no Anuário Estatístico Coffee Business. 
Essa produção é de aproximadamente 100 milhões de sacas ao ano. Considerando um preço médio de US\$150,00 por saca, o valor global da produção de café é de cerca de US\$ 15 bilhões/ano, sem considerar as outras etapas da cadeia como insumos, distribuição, exportação, torrefação etc.

O Brasil, além de maior produtor, é o segundo maior consumidor mundial de café. Em seguida, aparecem a Colômbia, a Indonésia e o México (Figura 2 e Tabela 1).

Existem, basicamente, duas espécies de café: o café arábica e o robusta. Aproximadamente $70 \%$ da produção mundial é composta por café arábica, e o restante por café robusta. No Brasil, segundo estimativas do $\mathrm{USDA}^{5}$, de um total de 27,5 milhões de sacas produzidas na safra $96 / 97$, a produção de café robusta foi de 4,8 milhões de sacas $(17,5 \%$ do total $)$.

Tabela 1. Produção mundial total de café verde, em grãos, total e por principais países produtores, em 1.000 sacas de $60 \mathrm{~kg}$, safras 1991/92 1995/96.

\begin{tabular}{llrrrrrrrrrr}
\hline Países & $\mathbf{9 1 / 9 2}$ & $\%$ & $\mathbf{9 2 / 9 3}$ & $\%$ & $\mathbf{9 3 / 9 4}$ & $\%$ & $\mathbf{9 4 / 9 5}$ & $\%$ & $\mathbf{9 5 / 9 6}$ & $\%$ \\
\hline 1 & Brasil & 28.500 & 27,4 & 24.000 & 25,8 & 28.500 & 30,6 & 26.000 & 27,1 & 16.800 & 19,0 \\
2 & Colômbia & 17.980 & 17,3 & 14.950 & 16,1 & 11.400 & 12,2 & 13.800 & 14,4 & 13.500 & 15,3 \\
3 & Indonésia & 7.100 & 6,8 & 7.350 & 7,9 & 7.400 & 7,9 & 6.000 & 6,3 & 5.800 & 6,6 \\
4 & México & 4.620 & 4,4 & 4.180 & 4,5 & 4.200 & 4,5 & 4.030 & 4,2 & 4.600 & 5,2 \\
5 & Etiópia & 3.000 & 2,9 & 2.800 & 3,0 & 3.000 & 3,2 & 3.500 & 3,6 & 3.700 & 4,2 \\
6 & India & 3.200 & 3,1 & 2.700 & 2,9 & 2.485 & 2,7 & 3.185 & 3,3 & 3.700 & 4,2 \\
7 & Guatemala & 3.549 & 3,4 & 3.584 & 3,9 & 3.078 & 3,3 & 3.500 & 3,6 & 3.622 & 4,1 \\
8 & Vietnã & 1.980 & 1,9 & 2.250 & 2,4 & 2.500 & 2,7 & 3.500 & 3,6 & 3.500 & 4,0 \\
9 & Costa do Marfim & 3.967 & 3,8 & 2.500 & 2,7 & 2.700 & 2,9 & 3.733 & 3,9 & 3.000 & 3,4 \\
10 & Uganda & 2.900 & 2,8 & 2.800 & 3,0 & 2.700 & 2,9 & 3.000 & 3,1 & 3.000 & 3,4 \\
11 & Costa Rica & 2.530 & 2,4 & 2.620 & 2,8 & 2.475 & 2,7 & 2.492 & 2,6 & 2.500 & 2,8 \\
12 & El Salvador & 2.357 & 2,3 & 2.894 & 3,1 & 2.361 & 2,5 & 2.314 & 2,4 & 2.425 & 2,7 \\
13 & Honduras & 2.255 & 2,2 & 1.981 & 2,1 & 2.060 & 2,2 & 2.295 & 2,4 & 2.400 & 2,7 \\
14 & Equador & 1.700 & 1,6 & 1.560 & 1,7 & 2.150 & 2,3 & 2.400 & 2,5 & 2.150 & 2,4 \\
15 & Quênia & 1.505 & 1,4 & 1.217 & 1,3 & 1.230 & 1,3 & 1.572 & 1,6 & 1.600 & 1,8 \\
16 & Outros & 16.906 & 16,2 & 15.539 & 16,7 & 14.998 & 16,1 & 14.672 & 15,3 & 15.929 & 18,1 \\
\hline & Total & 104.049 & 100,0 & 92.925 & 100,0 & 93.237 & 100,0 & 95.993 & 100,0 & 88.226 & 100,0 \\
\hline
\end{tabular}

Fonte: Departamento de Agricultura dos Estados Unidos (USDA).

${ }^{5}$ O Departamento de Agricultura dos Estados Unidos (USDA) tem mostrado uma certa tendência altista na suas previsões de safra, visto que esse pais é o maior consumidor mundial de café. 
O setor cafeeiro no Brasil sempre ocupou posição de destaque entre as atividades econômicas do País. Embora a cafeicultura tenha perdido espaço para outras atividades, ela detém ainda grande importância no cenário econômico do país. De fato, a sua contribuição na geração de renda, de emprego e na exportação é das mais significativas na agricultura, como pode-se comprovar com os dados do parágrafo abaixo.

Esse segmento conta com cerca de 210 mil propriedades agrícolas que se dedicam a sua produção. Elas estão espalhadas por 1.850 municípios de 10 unidades da Federação e conta com 3,3 bilhões de covas cultivadas. Além disso, existem 1.700 torrefações, com aproximadamente 2.000 marcas, 11 indústrias de solúvel e 144 exportadores, que geram 4 milhões de empregos diretos e indiretos. A receita total do setor é estimada em US\$ 5 bilhões (ASSIS, 1997).

Tabela 2. Área, população e produção de café no Brasil, safras 1960/61 1998/99.

\begin{tabular}{lrrrrrrrr}
\hline & \multicolumn{2}{c}{ Área (1000 ha) } & \multicolumn{2}{c}{ Árvores (milhões) } & \multicolumn{3}{c}{ Produção $(1000 \mathrm{scs} 60 \mathrm{~kg})$} & Rend. \\
\hline Safra & Plantada & Colhida & Produtivas & Total & Arábica & Robusta & Total & sc/ha \\
\hline $1960 / 61$ & 4.893 & 4.550 & 4.022 & 4.022 & 29.800 & 0 & 29.800 & 6,55 \\
$1965 / 66$ & 3.612 & 3.359 & 2.975 & 2.975 & 37.700 & 0 & 37.700 & 11,22 \\
$1970 / 71$ & 2.565 & 2.379 & 2.058 & 2.058 & 11.000 & 0 & 11.000 & 4,62 \\
$1975 / 76$ & 2.700 & 2.251 & 2.060 & 2.060 & 22.800 & 200 & 23.000 & 10,22 \\
$1980 / 81$ & 3.020 & 2.700 & 2.800 & 2.800 & 20.250 & 1.250 & 21.500 & 7,96 \\
$1985 / 86$ & 3.300 & 3.045 & 3.500 & 3.500 & 30.600 & 2.400 & 33.000 & 10,84 \\
$1990 / 91$ & 3.480 & 3.370 & 3.970 & 3.970 & 26.500 & 4.500 & 31.000 & 9,20 \\
$1991 / 92$ & 3.500 & 3.400 & 3.970 & 3.970 & 24.000 & 4.500 & 28.500 & 8,38 \\
$1992 / 93$ & 2.450 & 2.200 & 3.320 & 3.320 & 19.200 & 4.800 & 24.000 & 10,91 \\
$1993 / 94$ & 2.310 & 2.250 & 3.000 & 3.000 & 24.000 & 4.500 & 28.500 & 12,67 \\
$1994 / 95$ & 2.330 & 2.200 & 3.050 & 3.050 & 22.500 & 3.500 & 26.000 & 11,82 \\
$1995 / 96$ & 2.265 & 1.850 & 2.144 & 2.144 & 14.000 & 2.800 & 16.800 & 9,08 \\
$1996 / 97$ & 2.340 & 2.300 & 3.285 & 3.400 & 23.200 & 4.800 & 28.000 & 12,17 \\
$1997 / 98$ & 2.410 & 2.360 & 3.440 & 3.550 & 19.540 & 3.960 & 23.500 & 9,96 \\
$1998 / 99$ & 1.788 & - & 3.260 & - & 29.410 & 4.540 & 33.950 & 18,98 \\
\hline
\end{tabular}

Fonte: Anuario Estatistico Coffee Business

Segundo dados da EMBRAPA (Empresa Brasileira de Pesquisa Agropecuária), a safra 98/99 brasileira de café é estimada em 33,95 milhões de sacas (ver Tabela 2). Uma grande parcela dessa produção destina-se à exportação na forma de café verde beneficiado. Estima-se que no ano safra 98/99, o volume de exportação deve ser de 
cerca de 15 milhões de sacas. Outra parte da produção brasileira é destinada ao mercado interno (café torrado e moído, principalmente), que consome cerca de 12 milhões de sacas. Outras 3 milhões de sacas destinam-se à indústria de café solúvel, voltada principalmente à exportação. Quando necessário, a diferença entre oferta e demanda pode ser atendida, parcialmente, pelos estoques de café do Governo Federal ${ }^{6}$.

No ano de 1996, a receita da exportação de café cru e solúvel chegou a US\$2,1 bilhões, o que fez do produto o oitavo na pauta de exportações gerais do País.

Nos anos 60, a produção de café concentrava-se, principalmente, nos Estados do Paraná e São Paulo. Esses dois estados respondiam por 80 a $90 \%$ da produção total brasileira. Com o passar do tempo, a produção cafeeira deslocou-se, parcialmente, para o Estado de Minas Gerais. Atualmente, este Estado responde por quase $60 \%$ da produção nacional (Tabela 3 ).

Tabela 3. Produção brasileira de café por estados produtores - milhões scs. $60 \mathrm{~kg}$

\begin{tabular}{lrrrrrrrrrrrr}
\hline & \multicolumn{1}{c}{ São } & \multicolumn{1}{c}{ Minas } & \multicolumn{3}{c}{ Espírito } & & & & & \\
Safra & Paraná & (\%) & Paulo & (\%) & Gerais & (\%) & Santo & (\%) & Outros & $(\%)$ & Brasil & $(\%)$ \\
\hline $1961 / 62$ & 21,4 & 54,0 & 11,3 & 28,5 & 4,0 & 10,1 & 1,9 & 4,8 & 1,0 & 2,5 & 39,6 & 100,0 \\
$1965 / 66$ & 20,4 & 55,1 & 11,2 & 30,3 & 2,9 & 7,8 & 1,9 & 5,1 & 0,6 & 1,6 & 37,0 & 100,0 \\
$1970 / 71$ & 1,6 & 14,5 & 4,4 & 40,0 & 3,0 & 27,3 & 1,6 & 14,5 & 0,4 & 3,6 & 11,0 & 100,0 \\
$1975 / 76$ & 11,7 & 52,7 & 7,0 & 31,5 & 2,0 & 9,0 & 1,0 & 4,5 & 0,5 & 2,3 & 22,2 & 100,0 \\
$1980 / 81$ & 3,0 & 17,2 & 7,0 & 40,2 & 3,4 & 19,5 & 3,1 & 17,8 & 0,9 & 5,2 & 17,4 & 100,0 \\
$1985 / 86$ & 5,4 & 16,6 & 8,9 & 27,3 & 10,7 & 32,8 & 5,1 & 15,6 & 2,5 & 7,7 & 32,6 & 100,0 \\
$1990 / 91$ & 4,0 & 12,9 & 9,5 & 30,6 & 9,1 & 29,4 & 5,2 & 16,8 & 3,2 & 10,3 & 31,0 & 100,0 \\
$1991 / 92$ & 2,5 & 8,8 & 4,0 & 14,0 & 13,5 & 47,4 & 5,5 & 19,3 & 3,0 & 10,5 & 28,5 & 100,0 \\
$1992 / 93$ & 1,8 & 7,5 & 5,2 & 21,7 & 9,5 & 39,6 & 5,0 & 20,8 & 2,5 & 10,4 & 24,0 & 100,0 \\
$1993 / 94$ & 3,0 & 10,5 & 5,5 & 19,2 & 13,0 & 45,7 & 4,5 & 15,8 & 2,5 & 8,8 & 28,5 & 100,0 \\
$1994 / 95$ & 2,0 & 7,7 & 4,0 & 15,4 & 13,0 & 50,0 & 4,0 & 15,4 & 3,0 & 11,5 & 26,0 & 100,0 \\
$1995 / 96$ & 0,2 & 1,2 & 1,8 & 10,7 & 9,2 & 54,8 & 3,1 & 18,5 & 2,5 & 14,9 & 16,8 & 100,0 \\
$1996 / 97$ & 0,8 & 2,9 & 3,0 & 10,9 & 15,0 & 54,5 & 5,4 & 19,6 & 3,3 & 12,0 & 27,5 & 100,0 \\
$1997 / 98$ & 1,8 & 9,6 & 2,3 & 12,2 & 8,8 & 46,8 & 3,8 & 20,2 & 2,1 & 11,2 & 18,8 & 100,0 \\
$1998 / 99$ & 2,1 & 6,2 & 4,4 & 12,9 & 19,6 & 58,0 & 5,0 & 14,7 & 2,8 & 8,2 & 33,9 & 100,0 \\
\hline
\end{tabular}

Fonte: 1961/92 a 1989/90: IBC; 1990/91 a 1996/97: USDA; 1997/98 e 1998/99: Embrapa (Coffee Business)

\footnotetext{
${ }^{6}$ Em 1998, esse estoque era de aproximadamente 11 milhões de sacas.
} 
Essa alteração na localização geográfica do parque cafeeiro tem contribuído, em parte, para a melhor qualidade da bebida, principalmente no que se refere ao café produzido na região do Cerrado de Minas Gerais. Essa região possui condições climáticas favoráveis para a produção de café.

Um outro estado que vem crescendo na produção nacional de café é o Espírito Santo, que produziu 5,4 milhões de sacas na safra 96/97. Com esta produção, na maior parte constituída por café robusta, o Espírito Santo alcança a segunda posição na produção nacional de café, com $19,6 \%$ do total.

O Paraná, que atualmente responde por apenas $4 \%$ da produção nacional, vem aumentando seu parque cafeeiro. Os produtores daquele estado estão utilizando os sistemas de plantio adensado e superadensado, que apresentam alta produtividade.

Figura 3. Evolução da participação dos estados na produção brasileira de café.

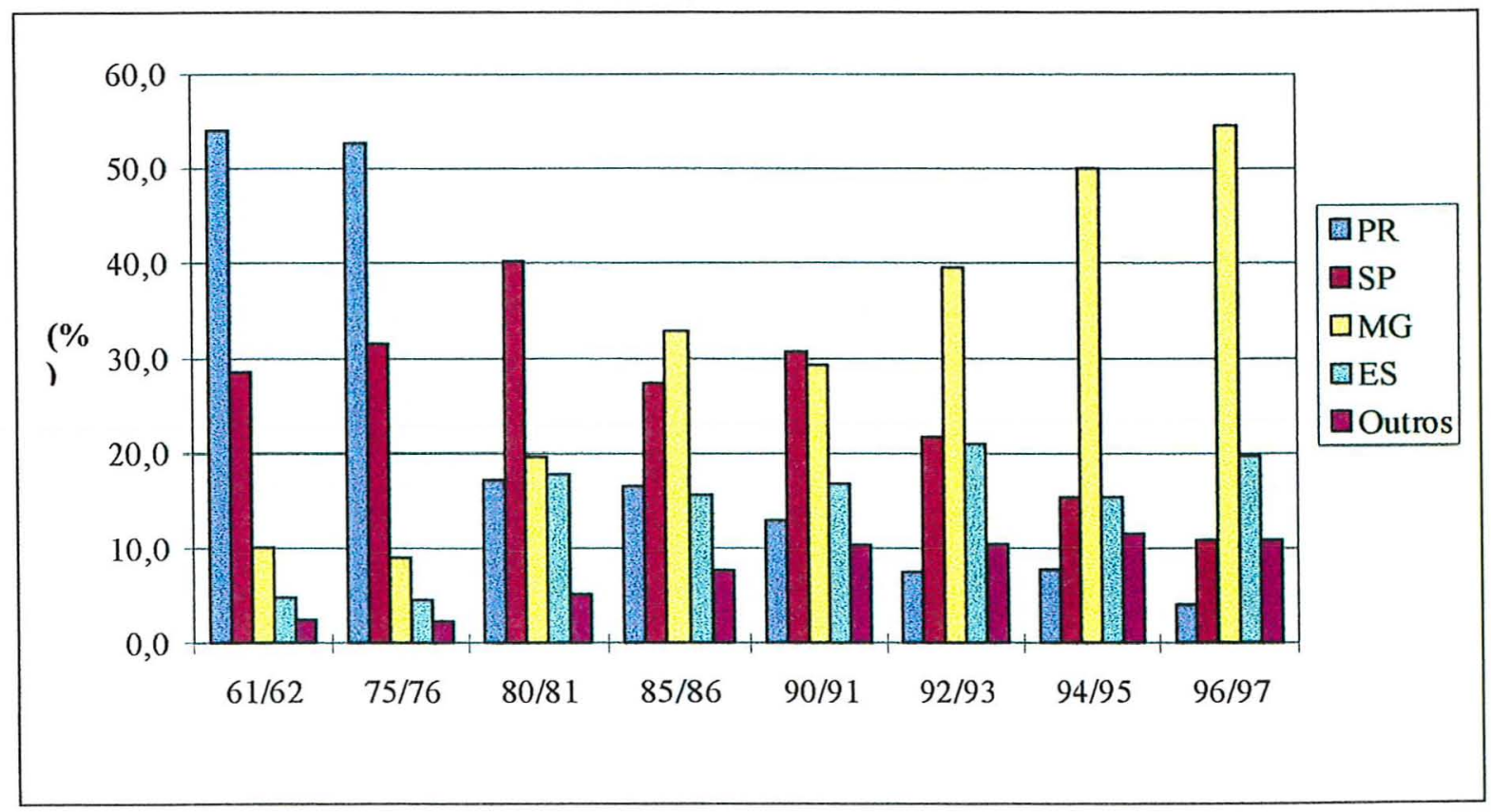

Fonte: Anuário Estatístico Coffee Business 1998. 
5.2 A Evolução dos Preços de Café no Brasil: 1950 a 1996.

O preço do café no mercado internacional sempre apresentou grande volatilidade, influenciado pelas geadas (principalmente no Brasil), controle da oferta pelos países produtores, política de estoques mínimos dos países consumidores, sazonalidade da oferta e demanda e acordos internacionais, entre outros.

A Figura 4 mostra o preço médio anual recebido pelo produtor de São Paulo pela saca de café beneficiado, juntamente com o coeficiente de variação dos preços médios. Pode-se observar que o coeficiente de variação é bastante elevado em alguns anos, chegando a atingir até $40 \%$. A média histórica dos preços, no período considerado, é de $\mathrm{R} \$ 170,00$, enquanto a o coeficiente de variação dessa média é de $55,5 \%$.

Figura 4. Média anual de janeiro de 1950 a outubro de 1996 dos preços recebidos pelos produtores de São Paulo, pela saca de $60 \mathrm{~kg}$ de café beneficiado. (em R\$ de outubro de 1996).

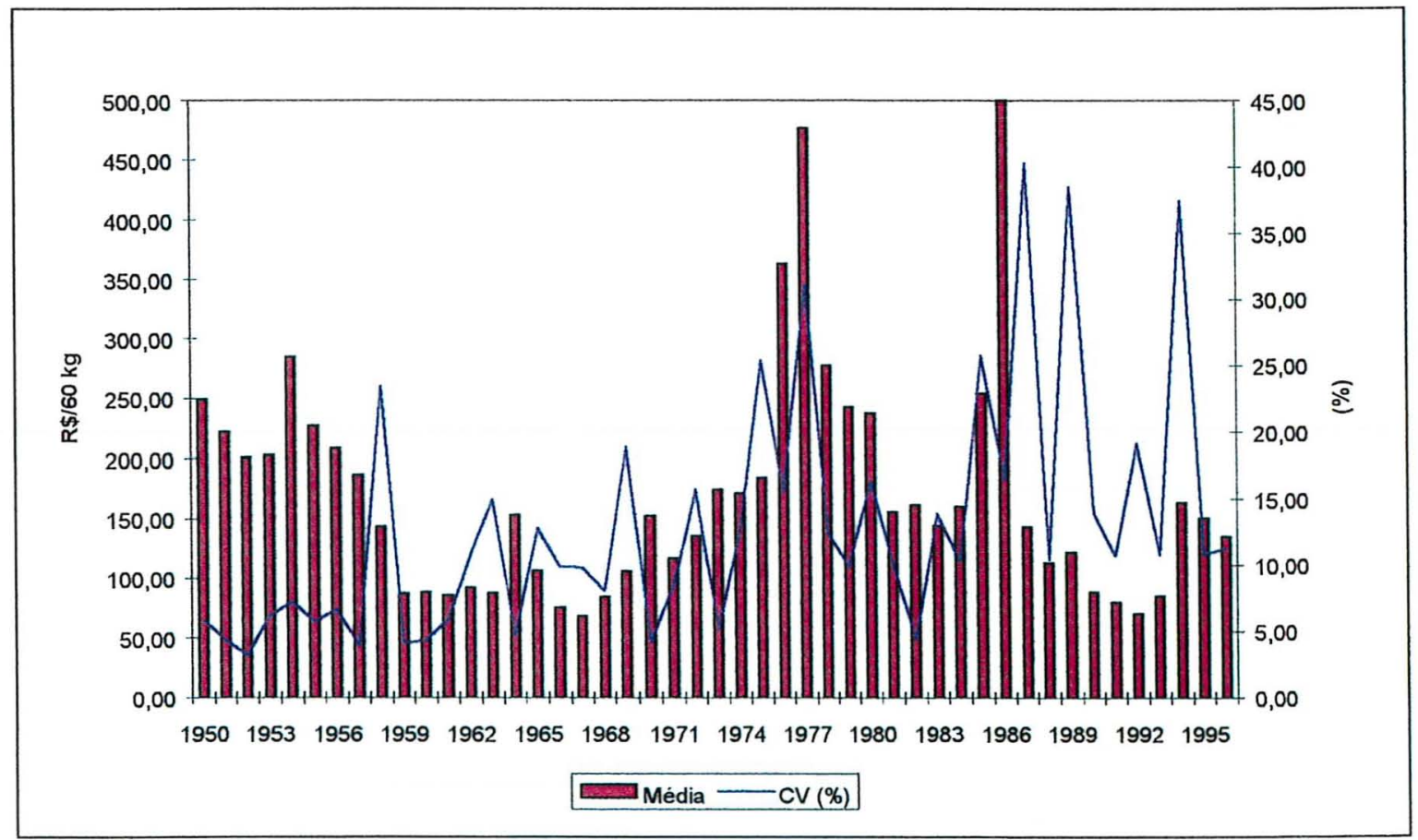

Fonte: Elaborado pelo autor a partir dos dados do Instituto de Economia Agrícola (IEA). 
Por esses dados, pode-se ter idéia da variabilidade dos preços de café ao longo dos anos. Com isso, é muito importante que os agentes participantes desse mercado se utilizem de instrumentos de gerenciamento de riscos, a fim de assegurar o retorno desejado com o menor risco possível.

No mundo, as principais bolsas que negociam contratos futuros de café arábica são a Coffee, Sugar \& Cocoa Exchange (CSCE), localizada em Nova Iorque, e a Bolsa de Mercadorias e Futuros (BM\&F), localizada em São Paulo.

A BM\&F negociou, em 1995, 76.206 contratos de café arábica, enquanto a CSCE negociou cerca de 2 milhões de contratos. ${ }^{7}$ Em 1996, de um total de 315.885 contratos negociados de todos os produtos agropecuários negociados no pregão da BM\&F, foram negociados 116.071 contratos futuros de café arábica, ou seja, 36,7\% desse total.

Com relação ao tipo de bebida, pela Tabela 4, pode-se dizer que, considerando apenas o tipo da bebida, cerca de $20 \%$ do total de café arábica produzido pelo Brasil, em 1995, seria passível de entrega na BM\&F. Mas deve-se lembrar que existem outras especificações no contrato futuro de café da BM\&F, e o percentual de café com características dentro do padrão da BM\&F seria bastante reduzido.

Tabela 4. Produção de café arábica classificada por bebida (scs $60 \mathrm{~kg}$ )

\begin{tabular}{lrrrr}
\hline Bebida & $\mathbf{1 9 9 4}$ & $\mathbf{\%}$ & $\mathbf{1 9 9 5}$ & $\mathbf{\%}$ \\
\hline Dura p/melhor & 3.250 .089 & 26,16 & 2.047 .560 & 19,29 \\
Dura p/ riada & 2.415 .582 & 19,44 & 1.581 .052 & 14,89 \\
Riada & 2.531 .146 & 20,37 & 2.252 .525 & 21,22 \\
Rio & 2.023 .474 & 16,28 & 2.258 .586 & 21,27 \\
Rio-zona & 2.133 .211 & 17,17 & 2.422 .090 & 22,81 \\
S/ descr. & 70.547 & 0,57 & 52.920 & 0,50 \\
\hline Total & 12.426 .043 & 100,00 & 10.616 .728 & 100,00 \\
\hline
\end{tabular}

Fonte: Febec - Depto. Técnico

${ }^{7} \mathrm{O}$ tamanho do contrato de café arábica da BM\&F é de 100 sacas de $60 \mathrm{~kg}$, enquanto na CSCE o contrato é de aproximadamente 283 sacas. 


\section{METODOLOGIA}

\subsection{Revisão da Literatura}

Apesar dos mercados futuros estarem em rápido crescimento no Brasil, a literatura acadêmica sobre esse assunto é muito escassa, principalmente por ser um mercado ainda incipiente. Em outros países, onde os mercados futuros de commodities agrícolas são mais desenvolvidos, a quantidade de trabalhos é muito maior. Porém, são poucos os trabalhos que tratam especificamente da questão do mercado futuro de café.

No que diz respeito à utilização dos mercados futuros na redução de risco de preço do café, Ouattara et al. (1990), estudando o uso potencial dos mercados futuros para o comércio internacional do café da Costa do Marfim, concluiu que a sua utilização poderia ter reduzido o desvio padrão das receitas em aproximadamente $29 \%$. Os resultados sugerem que os ganhos com exportação de café desse país poderiam ser estabilizados com a utilização de estratégias de comercialização envolvendo mercados futuros

Segundo Ederington (1979), existem três teorias principais que abordam a questão de hedge em mercados futuros. São elas: a teoria tradicional, a teoria de Holbrook Working e a teoria do portfolio.

A teoria tradicional propõe que a redução do risco de preço pode ser obtida com a venda (compra) no mercado futuro de igual montante à quantidade a ser negociada no 
mercado disponivel. A teoria de Holbrook Working (1953) prega o uso do hedge "discreto", baseado em mudanças previsíveis na base, ou seja, de acordo com uma mudança favorável ou desfavorável da base, o agente faz $100 \%$ de hedge ou $0 \%$, respectivamente. E, a teoria do portfolio pode ser entendida como uma teoria que integra as duas teorias anteriores. Ela permite determinar o percentual da quantidade de mercadoria no mercado disponível que deve ser "hedgeada" no mercado futuro.

A teoria do portfolio pode ser usada para medir a eficiência de hedge, comparando o risco da posição hedgeada em relação à posição não hedgeada. Uma grande parte dos trabalhos nessa área enfoca a questão referente aos modelos para a determinação da razão de hedge baseados na teoria do portfolio. Na formulação desses modelos de razão de hedge, o preço no mercado disponível é sempre utilizado como variável dependente, e os preços no mercado futuro como variável independente. Essa relação de causalidade entre preços do mercado disponível e preços futuros é abordada por Purcell (1991).

Para esse autor, ambos os mercados reagem ao mesmo tipo de informação. O tempo de reação às informações para cada mercado vai depender da capacidade de cada mercado. Geralmente, o mercado futuro é mais eficiente e mais rápido na assimilação das informações, possivelmente porque este é mais concentrado, onde existem pessoas mais preparadas para analisar o mercado, já que a frequência de operações no mercado futuro é maior. Por isso, tem-se a impressão de que o mercado futuro "causa" o mercado disponível.

Alguns autores utilizaram os modelos de hedge ótimo baseados na questão da maximização da utilidade, e nem sempre a minimização do risco é a que traz maior utilidade ao agente. Vários trabalhos tentam formular um modelo para estimativa da razão ótima de hedge.

Para Lence e Hayes (1994), as estimativas da razão de hedge de variância mínima, no que se refere a economia agrícola, são feitas assumindo que a função de densidade e 
seus parâmetros são conhecidos com certeza. Além de não ser o que geralmente acontece, esse método não é consistente com a maximização da utilidade. Para resolver esta questão, eles sugerem a utilização do critério de Bayes.

A estimativa da razão de hedge pode ser feita através de um modelo de regressão simples, utilizando os níveis de preços, suas variações ou seus retornos. Mas, segundo Myers e Thompson (1989), nenhuma dessas especificações é apropriada para a estimativa do hedge ótimo. Essas regressões simples dão a razão da covariância incondicional entre variável dependente e explicativa e a variância incondicional da variável explicativa. Entretanto, a variância e covariância na razão ótima de hedge são claramente condicionais, que dependem da informação disponível no momento da tomada de decisão em que o hedge é feito. A estimativa apropriada da razão ótima de hedge é dada através de um modelo generalizado, onde essa estimativa baseia-se nas informações disponíves no momento da tomada de decisão. Esse conjunto de informações pode incluir preços defasados do mercados futuro e disponível, produção, nível de estoques, exportações e renda do consumidor, além de uma variável que leve em consideração o grau de aversão ao risco do agente em questão.

Ainda para esses autores, a utilização do modelo de regressão simples pode ser compatível com o modelo generalizado de hedge ótimo. A utilização dos níveis de preço ou de suas variações, nesse modelo de regressão simples, dependerá do processo de formação de preços em ambos os mercados.

A estimativa da razão de hedge usando os niveis de preços do mercado futuro e disponível é útil na previsão do preço líquido resultante da operação de hedge (Shafer, 1993). Quando essa estimativa utiliza as variações de preço, os resultados indicam o comportamento da base durante o hedge, e também permite a previsão do preço líquido esperado na operação. 
Ainda existem aqueles autores que estudam melhores alternativas para estimar o hedge de variância mínima, visando adequar o modelo às características de determinado produto agrícola ou devido aos problemas econométricos com os dados utilizados.

No caso de commodities estocáveis, Lence et al. (1996) afirmam que existe uma assimetria intrinseca ao comportamento dos preços dessas commodities. As oportunidades de arbitragem podem impedir que os preços no mercado disponível fiquem muito abaixo dos preços futuros, mas não existe um mecanismo de arbitragem que impeça que os preços no mercado disponivel permaneçam muito acima dos preços futuros. Por isso as estimativas da razão de hedge devem ser influenciadas pela expectativa de armazenamento lucrativo da commoditie analisada.

Para Lien (1996), é importante verificar a possibilidade de existência de cointegração entre preço futuro e disponível. A performance do hedge pode variar bruscamente quando a variável de cointegração é omitida do modelo estatístico. A omissão dessa variável tende a subestimar a razão de hedge, caso os preços futuro e disponível sejam cointegrados.

Em contrapartida ao ponto levantado por Lien (1996), Leuthold e Lu (1994) argumentam que, mesmo com a existência de cointegração, essa informação representa uma pequena contribuição no que diz respeito a eficiência de hedge. Caberia, nesse momento, uma análise mais ampla do problema da cointegração no estudo da razão de hedge, mas este assunto não será aprofundado nesse trabalho.

Emmet (1991) faz a regressão no nível de preço, só que fazendo o ajuste para a autocorrelação nos resíduos. Sua análise mostrou que a redução no risco do hedge, com esse ajuste, é função do grau de autocorrelação e do tempo pelo qual o hedge é mantido. 


\subsection{Modelo Proposto}

A intenção principal do presente estudo é o de encontrar evidências do potencial de utilização do mercado futuro de café como instrumento de redução de risco de preço.

O modelo proposto será utilizado para detectar o nível de redução de risco proporcionado pela utilização das operações com futuros, bem como a correlação entre os preços no mercado disponível e os preços do mercados futuro de café. A correlação entre esses preços está diretamente relacionada à razão de hedge, que é o foco principal deste trabalho.

A eficiência da utilização da operação de hedge como instrumento de redução de risco pode ser medida, aproximadamente, pelo coeficiente de determinação da regressão do modelo utilizado. Segundo Ederington (1979), o nível de redução de risco, medido através do coeficiente de determinação da regressão $\left(r^{2}\right)$, pode ser demonstrado através das equações (2) a (5), que está baseado na teoria do portfolio:

$$
\begin{aligned}
& E(U)=X_{s} E\left(S^{2}-S^{1}\right) \\
& \operatorname{Var}(U)=X_{s}^{2} \sigma_{s}^{2} \\
& E(R)=X_{s} E\left(S^{2}-S^{1}\right)+X_{f} E\left(F^{2}-F^{1}\right)
\end{aligned}
$$


$\operatorname{Var}(R)=X_{s}^{2} \sigma_{s}^{2}+X_{f}^{2} \sigma_{f}^{2}+2 X_{s} X_{f} \sigma_{s f}$

onde:

$E(U)$ é o retorno esperado na operação não-hedgeada ("unhedged");

$\operatorname{Var}(U)$ é a variância do retorno obtido numa posição não hedgeada;

$X_{s}$ e $X_{f}$ são as quantidades negociadas no mercado disponível e futuro respectivamente;

$S^{t}$ é o preço no mercado disponível no período t;

$F^{t}$ é o preço no mercado futuro no período t;

$E(R)$ é o retorno esperado na operação hedgeada;

$\operatorname{Var}(R)$ é a variância do retorno esperado na operação de hedging;

$\sigma_{s}^{2}, \sigma_{t}^{2}$ e $\sigma_{s f}$ representam as variâncias e covariância das variações de preço entre os períodos 1 e 2 , referentes aos dados da amostra.

O retorno mencionado acima é o resultado líquido da operação nos dois mercados (disponível e futuro), que considera a quantidade aplicada em cada mercado e as respectivas variações de preços.

Fazendo $\boldsymbol{b}=-\boldsymbol{X}_{f} / \boldsymbol{X}_{s}$, temos:

$\operatorname{Var}(R)=X_{s}^{2} \sigma_{s}^{2}+b^{2} X_{s}^{2} \sigma_{f}^{2}-2 b X_{s}^{2} \sigma_{s f}$

Simplificando a equação (6), temos: 


$$
\operatorname{Var}(R)=X_{s}^{2}\left\{\sigma_{s}^{2}+b^{2} \sigma_{f}^{2}-2 b \sigma_{s f}\right\}
$$

Mantendo $X_{s}$ constante e considerando o efeito de uma variação em b na variância do retorno, tem-se:

$$
\frac{\partial \operatorname{Var}(R)}{\partial b}=X_{s}^{2}\left\{2 b \sigma_{f}{ }^{2}-2 \sigma_{s f}\right\}
$$

Então, a estimativa de b (razão de hedge) que minimiza o risco, $\boldsymbol{b}^{*}$, é:

$$
b^{*}=\frac{\sigma_{s f}}{\sigma_{f}^{2}}
$$

A condição de segunda ordem para o mínimo é satisfeita, já que $\frac{\partial^{2} \operatorname{Var}(R)}{\partial b^{2}}=X_{s}^{2} 2 \sigma_{f}^{2}>0$.

A eficiência de hedge pode ser medida pela expressão (10), que representa a fração da variância da posição que utiliza o mercado futuro na proporção indicada pela razão de hedge em relação à posição não-hedgeada (Ederington, 1979):

$$
e=1-\frac{\operatorname{Var}\left(R^{*}\right)}{\operatorname{Var}(U)}
$$

onde:

$\operatorname{Var}\left(\boldsymbol{R}^{*}\right)$ é a variância mínima obtida no modelo do portfolio; e $\operatorname{Var}(U)$ é a variância do retorno obtido numa posição não-hedgeada. 
A estimativa de $\boldsymbol{e}$ pode ser obtida através do coeficiente de determinação $\left(\mathbf{r}^{2}\right)$ da regressão entre os preços futuro e disponível durante o período analisado. Como se segue, substituindo a equação (9) em (7), temos:

$$
\begin{aligned}
& \operatorname{Var}\left(R^{*}\right)=X_{s}{ }^{2}\left\{\sigma_{s}{ }^{2}-\frac{\sigma_{s f}{ }^{2}}{\sigma_{f}^{2}}\right\} \\
& \frac{\operatorname{Var}\left(R^{*}\right)}{\operatorname{Var}(U)}=\frac{X_{s}{ }^{2}\left\{\sigma_{s}{ }^{2}-\frac{\sigma_{s f}{ }^{2}}{\sigma_{f}^{2}}\right\}}{X_{s}{ }^{2} \sigma_{s}{ }^{2}} \\
& \frac{\operatorname{Var}\left(R^{*}\right)}{\operatorname{Var}(U)}=1-\frac{\sigma_{s f}{ }^{2}}{\sigma_{s}{ }^{2} \sigma_{f}{ }^{2}}
\end{aligned}
$$

Substituindo a equação (13) em (10), temos:

$$
e=1-\frac{\operatorname{Var}\left(R^{*}\right)}{\operatorname{Var}(U)}=\frac{\sigma_{s f}{ }^{2}}{\sigma_{s}{ }^{2} \sigma_{f}^{2}}=\rho^{2}
$$

Considerando que $b^{*}=\frac{\sigma_{s f}}{\sigma_{f}^{2}}$ (Equação 9), a razão de hedge $\mathbf{b}^{*}$ é então obtida a partir da estimativa de mínimos quadrados ordinários do seguinte modelo utilizando os preços em nivel:

$$
S_{t}=a+b F_{t}+e_{t}
$$

Onde:

$S_{\mathbf{t}}$ é o preço no mercado disponível; e 
$\mathbf{F}_{\mathrm{t}}$ é o preço no mercado futuro, ambos no período $\mathrm{t}$.

Para minimizar o problema de autocorrelação nos resíduos, o modelo é estimado utilizando uma filtragem baseada no método de Hildreth-Lu e descrita em Gujarati (1995). É feita a pressuposição de que os resíduos da série apresentam correlação com a primeira defasagem.

A filtragem de Hildreth-Lu consiste numa estimativa iterativa do coeficiente de regressão $(\rho)$ entre o resíduo e o resíduo defasado da equação (16).

$$
e_{t}=\rho e_{t-1}+u_{t}
$$

Partindo do modelo original, descrito em (15), utiliza-se o seguinte modelo para tentar minimizar o problema de autocorrelação do resíduo.

$$
\left(S_{t}-\rho \cdot S_{t-1}\right)=(a-\rho \cdot a)+b \cdot\left(F_{t}-\rho \cdot F_{t-1}\right)+\left(e_{t}-e_{t-1}\right)
$$

Fazendo as devidas simplificações e substituições, chega-se a:

$$
\left(S_{t}-\rho \cdot S_{t-1}\right)=a^{*}+b\left(F_{t}-\rho \cdot F_{t-1}\right)+u_{t}
$$

Onde:

$$
a^{*}=a \cdot(1-\rho)
$$

Então, a filtragem de Hildreth-Lu consiste em estimar a soma de quadrados do resíduo da equação (18) para diversos valores de $\rho$, sendo escolhido aquele que apresentar o menor valor para a soma de quadrados do resíduo. 


\subsection{Dados}

Os dados do mercado disponível foram obtidos junto à Associação Comercial de Santos (ACS). São utilizados cinco diferentes tipos de café, descritos e denominados pelas respectivas siglas.

- CFA: Tipo 6 p/ melhor, livre de Rio Zona (Grupo I);

- CFB: Tipo $7 \mathrm{p} /$ melhor (Grupo II);

- CFC: Conillon (Grupo III);

- CFD: Santos 4, duro para melhor, qualidade Folger B; e

- CFE: Tipo 8 COB

Os dados sobre o mercado futuro de café arábica foram obtidos da Bolsa de Mercadorias \& Futuros (BM\&F), localizada em São Paulo, e da Bolsa de Café, Açúcar e Cacau (CSCE), localizada em Nova Iorque. São utilizadas as cotações diárias de fechamento (ajuste) para cada mês de vencimento em questão. Os contratos futuros de café, tanto em São Paulo quanto em Nova Iorque, possuem os mesmos meses de vencimento. Esses meses são: março, maio, julho, setembro e dezembro.

Os dados diários, em dólar corrente por saca de $60 \mathrm{~kg}$, referentes às qualidades de café acima descritas e os dados dos contratos futuros de Nova Iorque formam uma série que se inicia em janeiro de 1990 e vai até julho de 1997. A série de dados da BM\&F, também em dólar, inicia em agosto de 1991 e encerra em julho de 1997. Os dados futuros são originalmente em dólares americanos e os dados de preços do mercado disponível foram convertidos pela cotação média do dia do dólar comercial de venda.

A partir dos dados acima, são montadas séries de preços para cada mês de vencimento futuro, com duas diferentes extensões: 4 e 6 meses. No caso da série de 4 meses, foi considerado o período dos 4 meses que antecedem cada vencimento em 
cada ano, excluindo o mês de vencimento. Para o caso de 6 meses, são utilizados os 6 meses anteriores a cada mês de vencimento, também excluindo o mês de vencimento.

A escolha de não trabalhar com a série de preços dentro do mês de vencimento é devido ao enfoque do trabalho, já que este está baseado em tipos e qualidades de café que são diferentes do café padronizado pelas bolsas de futuros. Nesse caso, os tipos de café em estudo não são passíveis de entrega nas bolsas. 


\section{RESULTADOS E DISCUSSÕES}

Para melhor visualizar os resultados obtidos, primeiramente é apresentado o gráfico com os preços diários das cinco qualidades de café utilizadas neste trabalho.

Figura 5. Evolução dos preços das diferentes qualidades de café utilizadas neste estudo (US\$/saca).

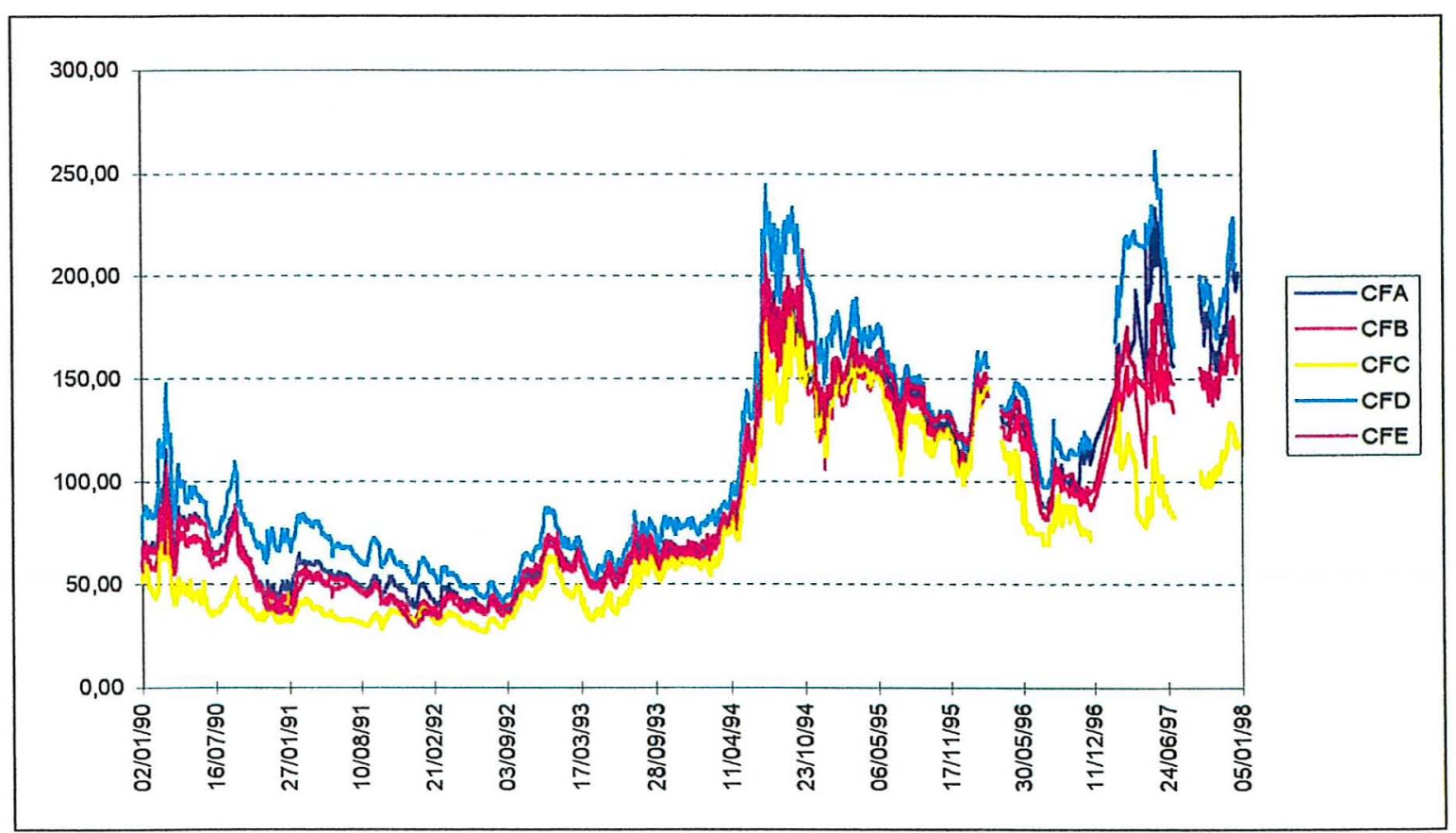

Fonte: Elaborado a partir dos dados da Associação Comercial de Santos (ACS)

Nota: CFA: Café Tipo 6; CFB: Café Tipo 7; CFC: Café Conillon; CFD: Café Santos 4; CFE: Café Tipo 8 COB 
Para complementar a análise visual dos dados do mercado disponível de café e tornar mais clara a diferença de preços entre as séries, foi feito um gráfico com todas as séries de preços diferenciadas em relação a série CFD (Café Santos 4, Folger B), já que este é o tipo que mais se aproxima do padrão exigido pela Bolsa de Mercadorias \& Futuros. O resultado está na figura abaixo.

Figura 6. Diferenciais de preços, em US\$/saca, em relação ao Café Santos 4 (CFD).

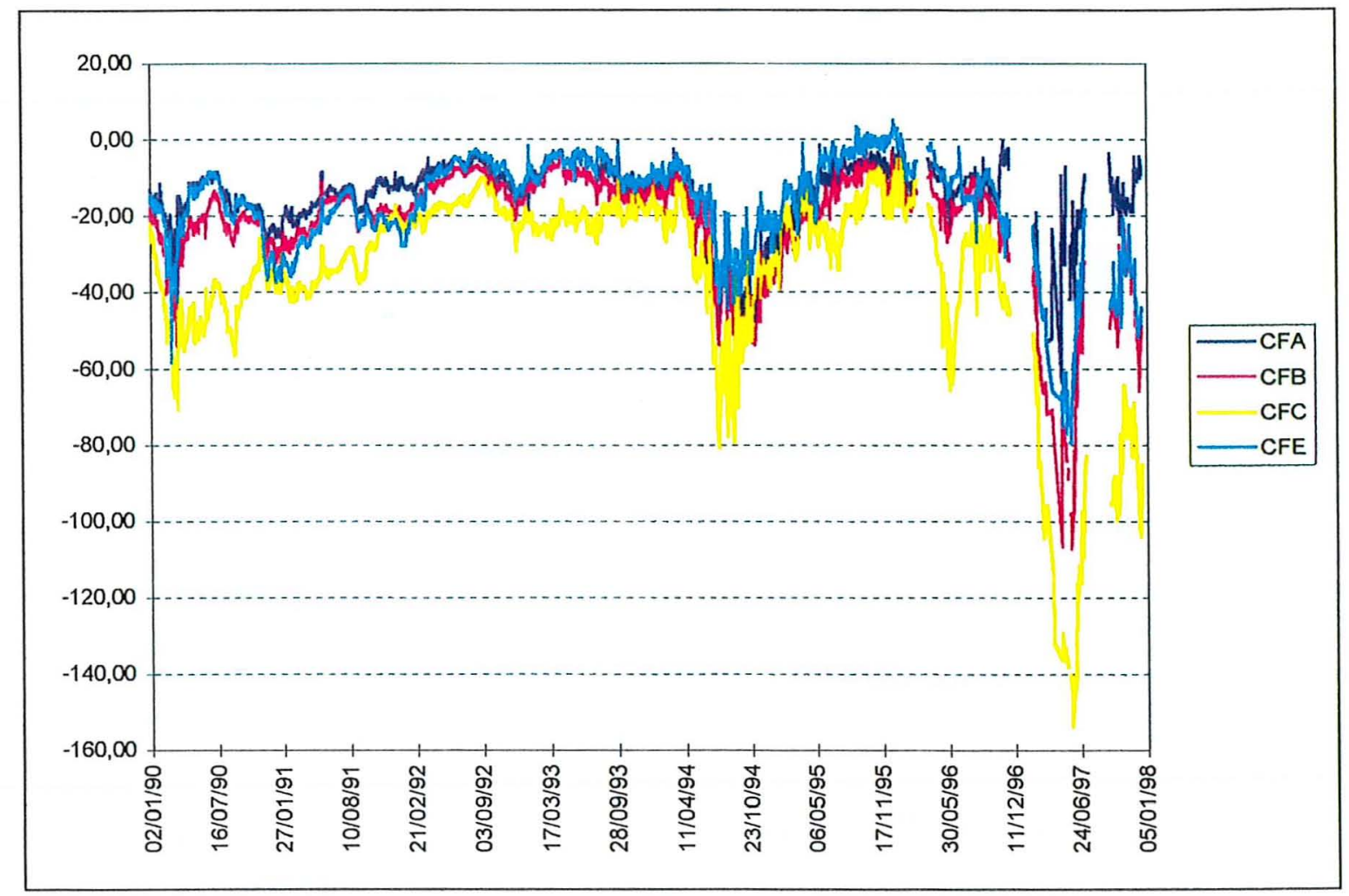

Fonte: Elaborado a partir dos dados da Associação Comercial de Santos (ACS)

Nota: CFA: Café Tipo 6; CFB: Café Tipo 7; CFC: Café Conillon; CFE: Café Tipo 8 COB

Pela Figura 6, pode-se notar que os preços do café Conillon (CFC) são os que mais se distanciam dos preços do café Santos 4. Guardadas as devidas proporções, o café arábica e o café robusta apresentam características de substitutibilidade e 
complementariedade. O produto final mais importante da cadeia do café é o café torrado e moído. Esse produto é composto por uma mistura ("blend") de diferentes qualidades de café, visando atender as preferências do consumidor. A necessidade de se compor as misturas adequadas aos padrões dos consumidores cria a complementariedade entre diferentes qualidades de café. Mas, ao mesmo tempo, por questões de preços, pode existir uma certa substitutibilidade entre cafés arábicas e robustas, afim de diminuir os custos de industrialização.

A figura 6 mostra que, em alguns periodos, o preço do café conillon (CFE) afastase demasiadamente do café Santos 4 (CFD), podendo inviabilizar a operação de hedge com o mercado futuro.

A tabela abaixo mostra as médias anuais destes diferenciais, assim como os respectivos desvios-padrão.

Tabela 5. Médias e desvios-padrão (DP) das séries diferenciadas em relação ao Café Santos 4 (CFD), em US\$/saca.

\begin{tabular}{lrrrrrrrr}
\hline & \multicolumn{2}{c}{ CFA } & \multicolumn{2}{c}{ CFB } & \multicolumn{2}{c}{ CFC } & \multicolumn{2}{c}{ CFE } \\
\cline { 2 - 8 } Ano & Média & \multicolumn{1}{c}{ DP } & Média & \multicolumn{1}{c}{ DP } & Média & \multicolumn{1}{c}{ DP } & \multicolumn{1}{c}{ Média } & \multicolumn{1}{c}{ DP } \\
\hline $\mathbf{1 9 9 0}$ & $-16,96$ & 5,37 & $-24,26$ & 6,92 & $-43,00$ & 8,74 & $-19,19$ & 7,84 \\
$\mathbf{1 9 9 1}$ & $-16,19$ & 4,10 & $-20,84$ & 4,70 & $-33,07$ & 6,25 & $-23,34$ & $\mathbf{6}, 26$ \\
$\mathbf{1 9 9 2}$ & $-9,04$ & 3,19 & $-12,68$ & 4,08 & $-18,27$ & 3,85 & $-10,63$ & 6,60 \\
$\mathbf{1 9 9 3}$ & $-8,24$ & 3,28 & $-11,42$ & 3,02 & $-20,64$ & 2,79 & $-7,47$ & 3,14 \\
$\mathbf{1 9 9 4}$ & $-24,33$ & 13,67 & $-29,03$ & 14,76 & $-36,89$ & 17,95 & $-19,69$ & 10,81 \\
$\mathbf{1 9 9 5}$ & $-11,08$ & 6,50 & $-15,70$ & 7,84 & $-19,97$ & 6,85 & $-7,07$ & 7,41 \\
$\mathbf{1 9 9 6}$ & $-10,97$ & 4,60 & $-16,84$ & 5,67 & $-30,48$ & 13,83 & $-11,09$ & 6,57 \\
$\mathbf{1 9 9 7}$ & $-21,37$ & 11,78 & $\mathbf{- 5 2 , 7 0}$ & 19,31 & $-95,28$ & 24,18 & $-43,63$ & 13,26 \\
\hline Geral & $\mathbf{- 1 4 , 3 9}$ & $\mathbf{8 , 9 8}$ & $\mathbf{- 2 1 , 0 5}$ & $\mathbf{1 3 , 6 8}$ & $\mathbf{- 3 3 , 4 1}$ & $\mathbf{2 2 , 0 5}$ & $\mathbf{- 1 6 , 2 8}$ & $\mathbf{1 2 , 3 1}$ \\
\hline
\end{tabular}

Nota: CFA: Café Tipo 6; CFB: Café Tipo 7; CFC: Café Conillon; CFE: Café Tipo 8 COB

Observa-se na tabela acima que, analisando as médias dos diferenciais, a série CFA (Tipo 6) é a que apresenta o menor desvio absoluto em relação à série CFD, com um diferencial médio de $-14,39$ e um devio-padrão de 8,98 . Por outro lado, a série CFC 
(Café Conillon) apresenta um diferencial médio de -33,41 e um desvio-padrão de 22,05 dólares por saca.

Feita essa análise inicial dos diferenciais de preço, parte-se agora para as análises de regressão, apresentada na equação (15). O principal parâmetro obtido desse tipo de regressão é a razão de hedge, que indica a proporção que deverá ser "hedgeada" no mercado futuro afim de minimizar o risco de preço.

As combinações entre as qualidades de café, preços futuros, meses de vencimento e duração do hedge, resultaram em 615 regressões. Além dos parâmetros da regressão, constante e coeficiente, foi calculado o teste $Q$ para medir o nível de significância da estimativa de correlação dos resíduos. Valores altos para o teste $Q$ indicam maior probabilidade de que a correlação dos resíduos seja nula. Também foi utilizado coeficiente de correlação da regressão ( $R$ quadrado) para medir quanto a utilização do mercado futuro, na proporção indicada pela razão de hedge, reduz o risco de preço. Os parâmetros de todas essas regressões se encontram tabulados no anexo.

Para mostrar a evolução temporal da razão de hedge para todos os tipos de café e para todos os períodos de duração do hegde, seriam necessários 50 gráficos para todas as combinações possíveis. Para simplificar, serão escolhidos 5 casos visando dar um idéia do todo. Serão apresentados 5 gráficos das diferentes qualidades de café para o vencimento de setembro e com período de hedge de 6 meses. Posteriormente, será feita uma análise com os dados resumidos, com as médias para todos os anos.

O primeiro caso é para o café CFA. Na Figura 7 abaixo, observa-se que a razão de hedge para a BM\&F é maior, em todos os casos, do que para o caso da CSCE. Também fica evidente a variabilidade desses valores ao longo do tempo (desde quase nulos até cerca de 0,70 ). 
O café CFC (Figura 9) apresenta valores muito baixos para a razão de hedge. O café CFC é do tipo conillon e suas características são bem diferentes das especificações dos contratos de café das duas bolsas, o que explica a baixa correlação entre os preços.

\section{Figura 7 - Razão de hedge para o café CFA, vencimento de setembro e com duração de hedge de 6 meses.}

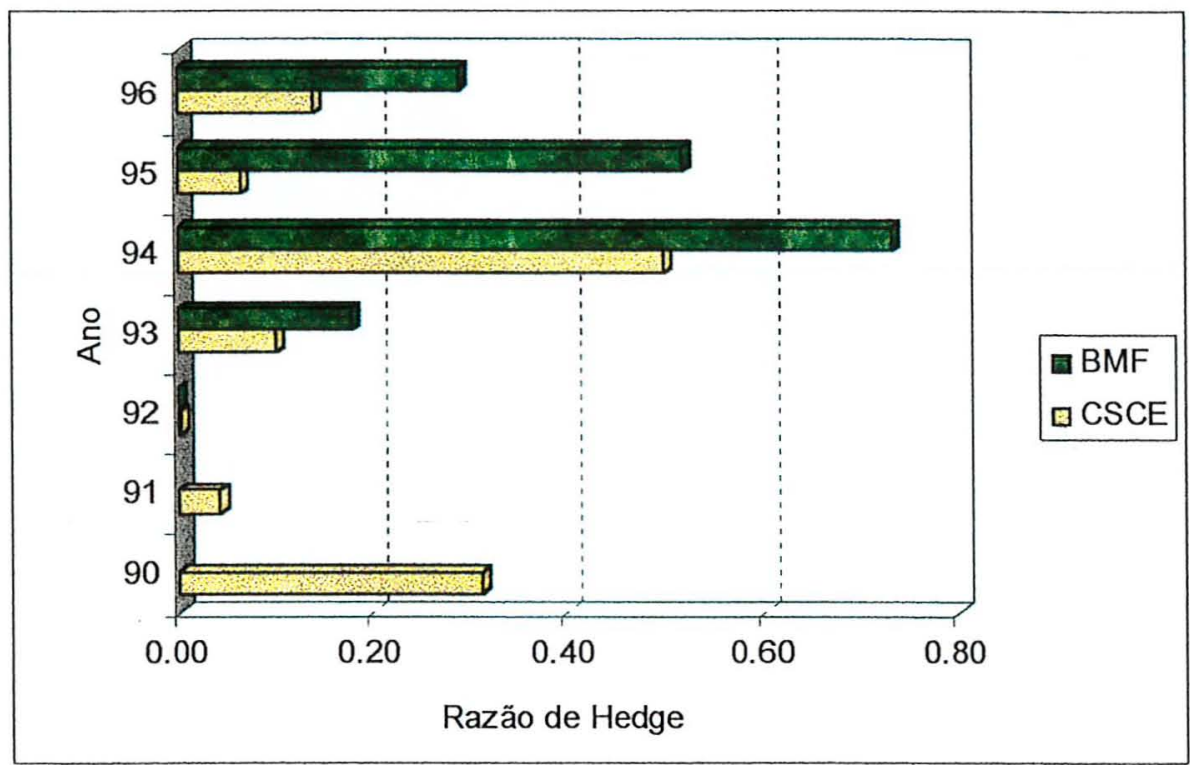

É importante ressaltar a grande variabilidade dos resultados obtidos ao longo do tempo. Nesse tipo de análise, seria extremamente desejável que os resultados apresentassem um comportamento mais homogêneo ao longo do tempo, pois poderia definir-se um padão capaz de orientar as estratégias dos agentes da cadeia com base nos resultados passados (ex-ante).

A inexistência de uma bolsa de futuros forte aqui no Brasil nos primeiros quatro anos analisados neste estudo (90 a 94) deve ser olhada como um fator bastante importante que influenciou negativamente os resultados obtidos. Aliado a isso, o Brasil passava, nesse período, por uma cenário econômico marcado por um elevado nível de inflação, que dificultava a visualização de preços no mercado interno. 
Somente após o advindo do Plano Real, em julho de 1994, é que o Brasil passou a apresentar baixos níveis de inflação. Com a estabilização da economia, os mercados futuros agrícolas começaram a surgir como um instrumento atrativo para os agentes econômicos interessados em se proteger contra o risco das oscilações prejudiciais de preço.

Como consequência desses fatores, os resultados obtidos a partir do ano de 1994 apresentaram maior consistência. Paralelamente, é de extrema importância observar que os resultados obtidos mostram a superioridade nos casos onde o hedge foi realizado na $\mathrm{BM} \& \mathrm{~F}$, quando comparado à $\mathrm{CSCE}$.

Figura 8 - Razão de hedge para o café CFB, vencimento de setembro e com duração de hedge de 6 meses.

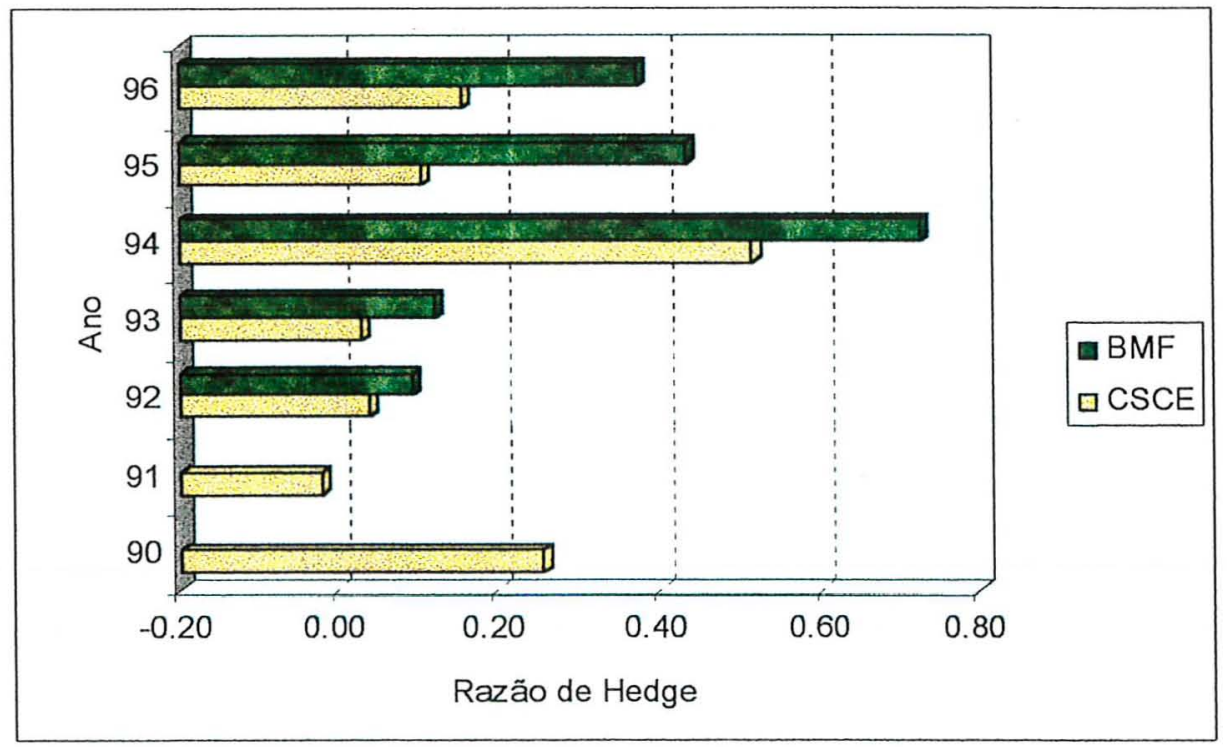

Com o fortalecimento dos mercados futuros agrícolas aqui no Brasil, espera-se que grande parte dos agentes que se utilizavam da Bolsa de Nova Iorque (CSCE) para realizarem hedge contra as variações dos preços do café no mercado interno, passem a utilizar a Bolsa de Mercadorias \& Futuros (BM\&F). 
Figura 9 - Razão de hedge para o café CFC, vencimento de setembro e com duração de hedge de 6 meses.

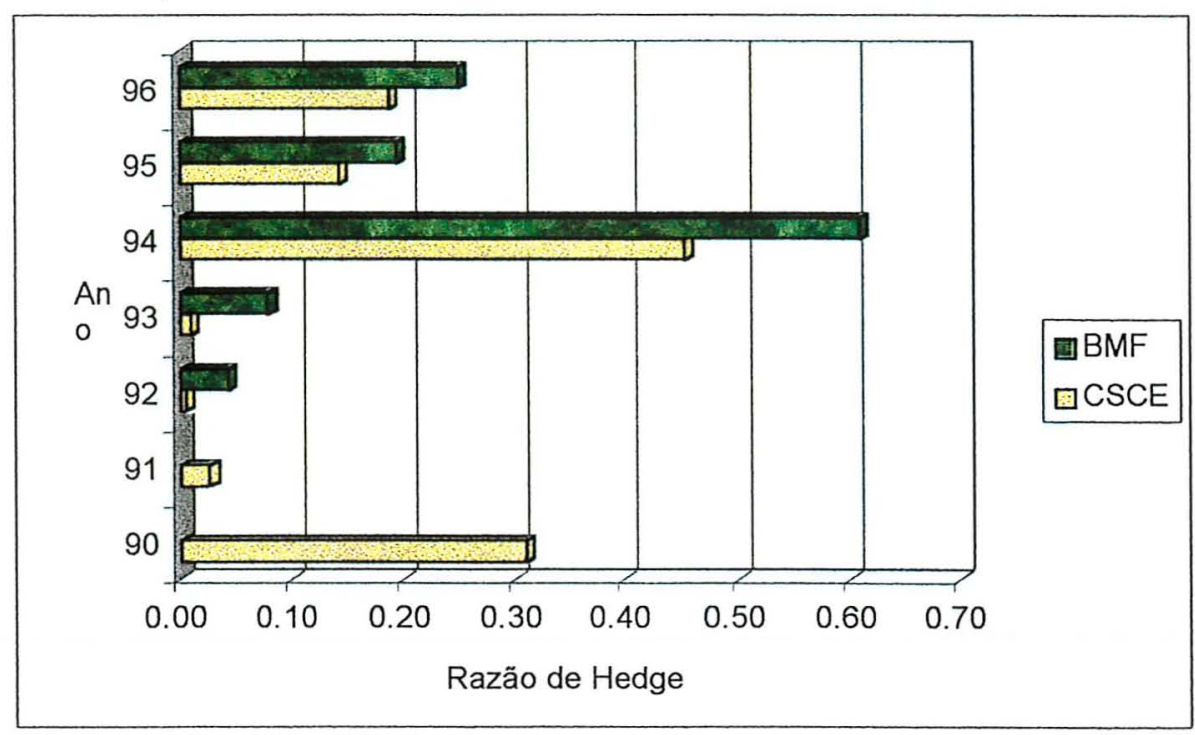

Figura 10 - Razão de hedge para o café CFD, vencimento de setembro e com duração de hedge de 6 meses.

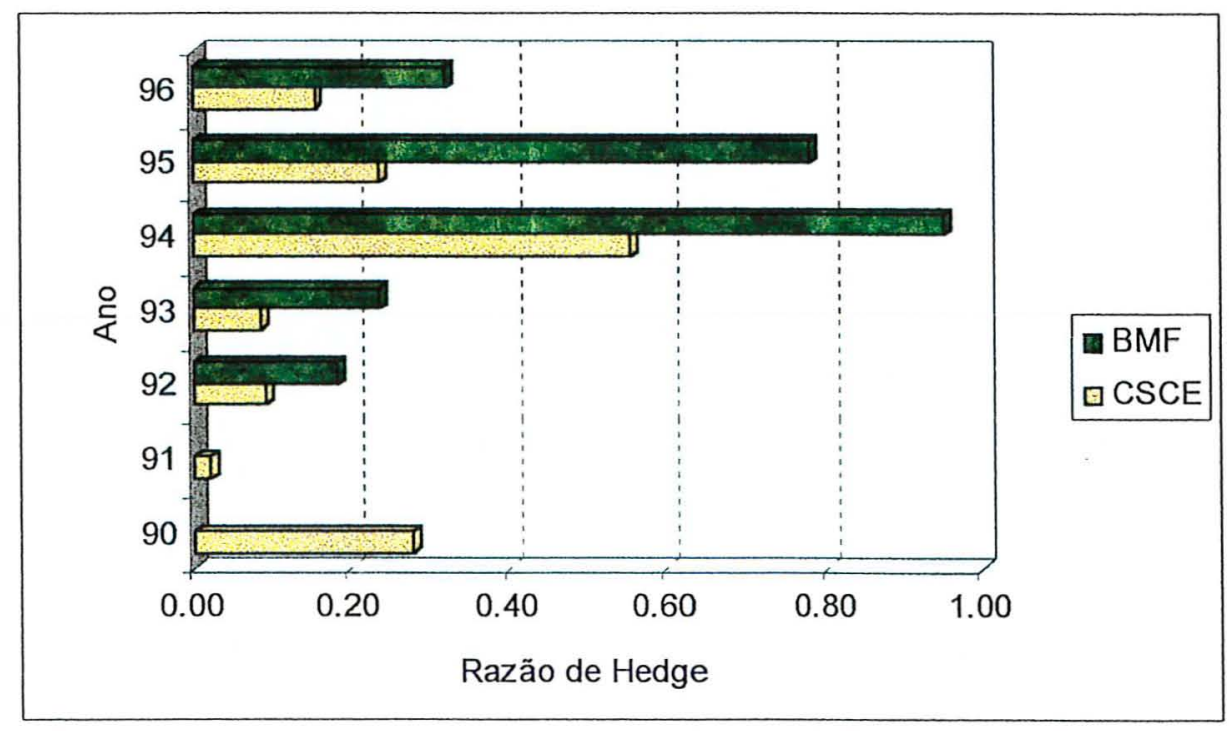


Figura 11 - Razão de hedge para o café CFE, vencimento de setembro e com duração de hedge de 6 meses.

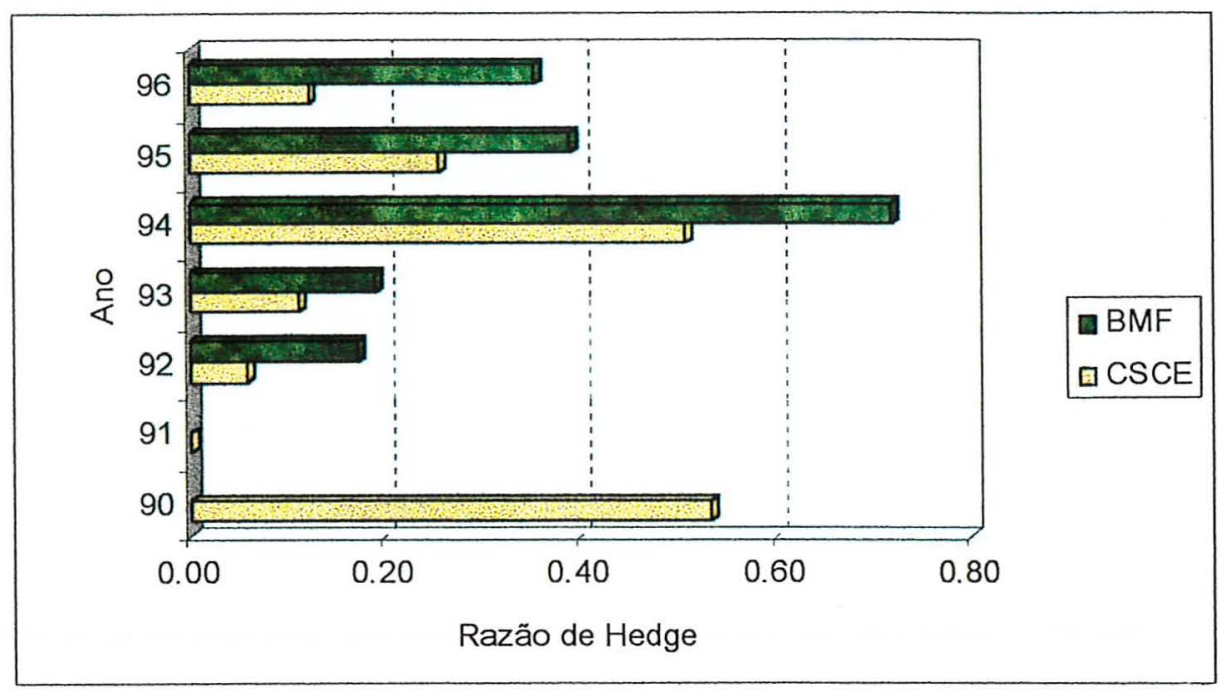

A seguir, é apresentado um resumo dos resultados obtidos. Inicia-se com a análise para o mercado futuro de café na Bolsa de Mercadorias \& Futuros (BM\&F) e para operações com duração de 4 meses.

É importante lembrar que, nas tabelas mostradas a seguir, foram calculadas as médias somente para os valores do coeficiente da regressão (razão de hedge) cujos testes são significativos a $5 \%$ de probabilidade.

Os dados apresentados representam a média de todos os anos analisados.

Tabela 6. Média da razão de hedge para as diferentes qualidades de café, no mercado futuro da BM\&F e para 4 meses de duração.

\begin{tabular}{lcccccc}
\hline Tipo & Março & Maio & Julho & Setembro & Dezembro & Média \\
\hline CFA & 0,49 & 0,30 & 0,50 & 0,67 & 0,40 & 0,47 \\
CFB & 0,51 & 0,30 & 0,35 & 0,58 & 0,41 & 0,43 \\
CFC & 0,42 & 0,16 & 0,31 & 0,38 & 0,36 & 0,33 \\
CFD & 0,60 & 0,38 & 0,60 & 0,47 & 0,65 & 0,54 \\
CFE & 0,42 & 0,62 & 0,40 & 0,39 & 0,31 & 0,33 \\
\hline
\end{tabular}

Nota: CFA: Café Tipo 6; CFB: Café Tipo 7; CFC: Café Conillon; CFD: Café Santos 4; CFE: Café Tipo 8 COB 
Pela Tabela 6, pode-se observar que o café CFD é o que apresenta maior valor para a razão de hedge em três dos cinco vencimentos, com uma média de 0,54 para todos os meses de vencimento, o que vai ao encontro das características desse café. Os menores valore são para os tipos CFC e CFE.

Tabela 7. Média da razão de hedge para as diferentes qualidades de café, no mercado futuro da CSCE e para 4 meses de duração.

\begin{tabular}{lcccccc}
\hline Tipo & Março & Maio & Julho & Setembro & Dezembro & Média \\
\hline CFA & 0,35 & 0,26 & 0,31 & 0,49 & 0,28 & 0,34 \\
CFB & 0,31 & 0,22 & 0,27 & 0,49 & 0,27 & 0,31 \\
CFC & 0,35 & 0,24 & 0,25 & 0,27 & 0,24 & 0,27 \\
CFD & 0,39 & 0,30 & 0,38 & 0,35 & 0,38 & 0,36 \\
CFE & 0,32 & 0,52 & 0,32 & 0,30 & 0,21 & 0,33 \\
\hline
\end{tabular}

Nota: CFA: Café Tipo 6; CFB: Café Tipo 7; CFC: Café Conillon; CFD: Café Santos 4; CFE: Café Tipo 8 COB

Comparando os valores das Tabelas 6 e 7, observa-se que as regressões baseadas nos preços futuros da BM\&F apresentam, na quase totalidade, valores superiores aos obtidos nas regressões baseadas nos preços futuros da CSCE, indicando uma maior correlação entre os preços do mercado disponivel dos diferentes tipos de café com os preços da BM\&F. No caso do café tipo CFD, a média da razão de hedge para a BM\&F é de 0,54 contra 0,36 na CSCE, ou seja, cerca de $50 \%$ maior. Considerando todas as qualidades de café, essa diferença é de $35,4 \%$.

Tabela 8. Média da razão de hedge para as diferentes qualidades de café, no mercado futuro da BM\&F e para 6 meses de duração.

\begin{tabular}{lcccccc}
\hline Tipo & Março & Maio & Julho & Setembro & Dezembro & Média \\
\hline CFA & 0,39 & 0,37 & 0,43 & 0,48 & 0,47 & 0,43 \\
CFB & 0,39 & 0,34 & 0,26 & 0,41 & 0,31 & 0,34 \\
CFC & 0,32 & 0,30 & 0,34 & 0,40 & 0,28 & 0,33 \\
CFD & 0,46 & 0,36 & 0,52 & 0,54 & 0,45 & 0,46 \\
CFE & 0,34 & 0,37 & 0,52 & 0,37 & 0,29 & 0,38 \\
\hline
\end{tabular}

Nota: CFA: Café Tipo 6; CFB: Café Tipo 7; CFC: Café Conillon; CFD: Café Santos 4; CFE: Café Tipo 8 COB 
A mesma conclusão aplica-se para o período de 6 meses de hedge. A análise das Tabelas 8 e 9 mostra que os valores obtidos para as razões de hedge na BM\&F são maiores que os valores obtidos para a CSCE. Na média, os valores da razão de hedge na BM\&F são $30 \%$ maiores que os valores da CSCE. No caso específico do café CFD, a diferença média entre os dois valores é de $52 \%$ a favor da BM\&F, chegando a um máximo de $85,7 \%$.

Tabela 9. Média da razão de hedge para as diferentes qualidades de café, no mercado futuro da CSCE e para 6 meses de duração.

\begin{tabular}{lcccccc}
\hline Tipo & Março & Maio & Julho & Setembro & Dezembro & Média \\
\hline CFA & 0,28 & 0,24 & 0,28 & 0,41 & 0,27 & 0,29 \\
CFB & 0,29 & 0,24 & 0,22 & 0,39 & 0,23 & 0,27 \\
CFC & 0,25 & 0,29 & 0,24 & 0,30 & 0,26 & 0,27 \\
CFD & 0,31 & 0,27 & 0,34 & 0,29 & 0,31 & 0,31 \\
CFE & 0,26 & 0,51 & 0,39 & 0,43 & 0,19 & 0,36 \\
\hline
\end{tabular}

Nota: CFA: Café Tipo 6; CFB: Café Tipo 7; CFC: Café Conillon; CFD: Café Santos 4; CFE: Café Tipo 8 COB

A partir destas tabelas, pode-se comparar a diferença entre as razões de hedge para os diferentes períodos de hedge. No caso da BM\&F, as razões de hedge obtidas no período de 6 meses são cerca de $11 \%$ menores que no período de 4 meses, o que mostra uma maior correlação de preços no período mais curto. Para os dados obtidos com relação a CSCE, a razão de hedge para 6 meses é, na média, cerca de $6,6 \%$ menor quando comparada com o período de 4 meses.

A próxima análise é feita em cima da redução do risco de preço nas operações simuladas neste estudo. O risco de preço é medido através do coeficiente de correlação da regressão $\left(\mathrm{R}^{2}\right)$. 
Tabela 10. Média da redução do risco $\left(R^{2}\right)$ para as diferentes qualidades de café, no mercado futuro da BM\&F e para 4 meses de duração.

\begin{tabular}{lcccccc}
\hline Tipo & Março & Maio & Julho & Setembro & Dezembro & Média \\
\hline CFA & 0,90 & 0,86 & 0,84 & 0,97 & 0,84 & 0,88 \\
CFB & 0,90 & 0,86 & 0,74 & 0,97 & 0,90 & 0,87 \\
CFC & 0,91 & 0,90 & 0,86 & 0,95 & 0,82 & 0,89 \\
CFD & 0,96 & 0,90 & 0,92 & 0,97 & 0,91 & 0,93 \\
CFE & 0,94 & 0,73 & 0,83 & 0,96 & 0,90 & 0,87 \\
\hline
\end{tabular}

Nota: CFA: Café Tipo 6; CFB: Café Tipo 7; CFC: Café Conillon; CFD: Café Santos 4; CFE: Café Tipo 8 COB

Ve-se, pela Tabela 10, que a redução do risco de preço para o caso da BM\&F e para 4 meses de hedge é de $89 \%$ na média. A maior redução fica para o caso da qualidade CFD, que apresentou uma redução média de $93 \%$, chegando a $97 \%$ em alguns casos.

Analisando os mesmos dados para a Bolsa de Nova Iorque (CSCE), observa-se que esses valores se situam num intervalo bastante semelhante aos obtidos para a BM\&F. Novamente, os maiores valores percentuais de redução de risco estão associados ao café tipo CFD.

Tabela 11. Média da redução do risco $\left(R^{2}\right)$ para as diferentes qualidades de café, no mercado futuro da CSCE e para 4 meses de duração.

\begin{tabular}{lcccccc}
\hline Tipo & Março & Maio & Julho & Setembro & Dezembro & Média \\
\hline CFA & 0,91 & 0,87 & 0,86 & 0,98 & 0,90 & 0,90 \\
CFB & 0,92 & 0,81 & 0,91 & 0,97 & 0,90 & 0,90 \\
CFC & 0,69 & 0,84 & 0,93 & 0,95 & 0,82 & 0,85 \\
CFD & 0,96 & 0,89 & 0,91 & 0,97 & 0,90 & 0,93 \\
CFE & 0,94 & 0,72 & 0,79 & 0,96 & 0,91 & 0,86 \\
\hline
\end{tabular}

Nota: CFA: Café Tipo 6; CFB: Café Tipo 7; CFC: Café Conillon; CFD: Café Santos 4; CFE: Café Tipo 8 COB 
Mesmo quando se analisa os dados para seis meses de hedge, os valores obtidos não apresentam grandes diferenças em relação aos obtidos nas análises de 4 meses de hedge.

Tabela 12. Média da redução do risco $\left(R^{2}\right)$ para as diferentes qualidades de café, no mercado futuro da BM\&F e para 6 meses de duração.

\begin{tabular}{lcccccc}
\hline Tipo & Março & Maio & Julho & Setembro & Dezembro & Média \\
\hline CFA & 0,94 & 0,93 & 0,87 & 0,95 & 0,90 & 0,92 \\
CFB & 0,95 & 0,93 & 0,71 & 0,95 & 0,94 & 0,89 \\
CFC & 0,88 & 0,91 & 0,90 & 0,97 & 0,89 & 0,91 \\
CFD & 0,97 & 0,94 & 0,95 & 0,97 & 0,94 & 0,95 \\
CFE & 0,95 & 0,93 & 0,82 & 0,95 & 0,94 & 0,92 \\
\hline
\end{tabular}

Nota: CFA: Café Tipo 6; CFB: Café Tipo 7; CFC: Café Conillon; CFD: Café Santos 4; CFE: Café Tipo 8 COB

Para ambos os períodos de hedge e para ambas as bolsas, os valores percentuais de redução de risco se situam num intervalo entre 70 e $100 \%$. Na média, os valores obtidos para a BM\&F são ligeiramente superiores aos obtidos para a CSCE.

Tabela 13. Média da redução do risco $\left(\mathbf{R}^{2}\right)$ para as diferentes qualidades de café, no mercado futuro da CSCE e para 6 meses de duração.

\begin{tabular}{lcccccc}
\hline Tipo & Março & Maio & Julho & Setembro & Dezembro & Média \\
\hline CFA & 0,95 & 0,92 & 0,89 & 0,97 & 0,91 & 0,93 \\
CFB & 0,96 & 0,93 & 0,75 & 0,93 & 0,94 & 0,90 \\
CFC & 0,85 & 0,79 & 0,87 & 0,95 & 0,85 & 0,86 \\
CFD & 0,98 & 0,93 & 0,93 & 0,97 & 0,94 & 0,95 \\
CFE & 0,95 & 0,87 & 0,79 & 0,90 & 0,95 & 0,89 \\
\hline
\end{tabular}

Nota: CFA: Café Tipo 6; CFB: Café Tipo 7; CFC: Café Conillon; CFD: Café Santos 4; CFE: Café Tipo 8 COB

Um fato curioso a ser observado é que o vencimento de setembro é aquele que apresenta o maior valor para a redução de risco para quase todos os casos. Para o caso 
da BM\&F, esse fato ocorre em 9 das 10 médias obtidas (Tabelas 10 e 11). Nas médias obtidas para a CSCE, a ocorrência é de 7 em 10. (Tabelas 12 e 13).

Aplicando-se a mesma análise para a razão de hedge, vê-se que o vencimento de setembro também se destaca por apresentar maiores valores, embora com menor frequência. Esse vencimento é importante por representar um período de safra da produção de café do Brasil.

No caso da redução percentual de risco, os vencimentos de maio e julho aparecem como os que apresentam os menores valores para as médias obtidas. 


\section{CONCLUSÕES}

A utilização dos mercados futuros agrícolas é uma ferramenta muito importante e eficiente para que os agentes que comercializam esses produtos possam se proteger contra as variações de preços tão comuns nos mercados agropecuários.

Como um contrato futuro envolve a padronização do produto, é muito dificil de se esperar que essa padronização envolva todo o universo de diferentes tipos e qualidades de um mesmo produto agrícola. No caso específico do café, isso não é diferente. O padrão exigido pela Bolsa de Mercadorias \& Futuros (BM\&F) envolve apenas uma pequena parcela do universo de tipos e qualidades existentes no mercado brasileiro de café.

Visto que esse é um instrumento disponível para o gerenciamento de risco de preço para todos os agentes envolvidos com esta mercadoria, é necessário que se conheçam alguns parâmetros do comportamento entre os preços para que se possa garantir um bom nível de eficiência, mesmo quando o produto em questão não apresenta as mesmas características do café padronizado pela BM\&F.

Neste trabalho tem-se alguns parâmetros que mostram o comportamento de 5 diferentes tipos de café comercializados no mercado brasileiro. Valores médios para os diferenciais de preço em diferentes períodos, bem como seus respectivos desviospadrão e a razão de hedge servem como referência para que os agentes possam melhor orientar suas estratégias operacionais quando forem utilizar o mercado futuro de café da BM\&F para se protegerem contra as variações de preços. 
Os resultados deste estudo mostram que as correlações entre os preços das diferentes qualidades de café no mercado disponível e os preços futuros variam para cada caso. Por exemplo, o café tipo 6 (CFA) apresenta um diferencial médio de aproximadamente US\$ -14,39/saca, com um desvio-padrão de US\$ 8,98/saca. A razão de hedge média, em relação à $B M \& F$, é de aproximadamante $45 \%$, ou seja, a quantidade que deve ser hedgeada no mercado futuro para minimizar o risco, é de $45 \%$ da quantidade a ser negociada no mercado disponível. Utilizando essa proporção, o risco de preço nessa operação estaria sendo reduzido em cerca de $90 \%$.

O café Santos 4 (CFD), que foi utilizado como referência neste trabalho, apresentou uma razão de hedge média de 50\%, proporcionando uma redução de $94 \%$ no risco de preço.

Pelos resultados obtidos, ve-se que o comportamento dos preços do café tipo 6 (CFA) em relação ao café Santos 4 (CFD) apresenta uma boa correlação, sugerindo que o mercado futuro de café na $B M \& F$ poderia ser utilizado por produtores e compradores que negociam este tipo de café. E, por se tratar de um padrão de café bastante comum no mercado interno brasileiro, o potencial de utilização do mercado futuro de café poderia sofrer um razoável incremento.

O café conillon (CFC) é o que apresentou menor razão de hedge (correlação) com os preços futuros. A surpresa fica com o café tipo $8 \mathrm{COB}$ (CFE), que apresentou valores acima dos esperados, por se tratar de um café com características um tanto diferentes do padrão exigido pelas bolsas. Para este tipo de café, a razão de hedge média no período foi de $35,5 \%$. Este valor pode ser considerado um tanto baixo, mas o nível de redução de risco (média de $89 \%$ ) pode ser visto com otimismo, pois denota uma correlação bastante elevada em relação aos preços no mercado futuro da BM\&F.

Comparando-se as duas bolsas, as operações que envolvem o mercado futuro da BM\&F são aquelas que apresentam maior razão de hedge e, portanto, maior capacidade de reduzir o risco de preço da operação. $\mathrm{Na} \mathrm{CSCE}$, os valores encontrados 
para a razão de hedge ficaram quase sempre abaixo dos valores obtidos para a BM\&F.

A razão de hedge também varia de periodo para período, com o mês de vencimento e, com menor intensidade, com o período de duração do hedge.

A análise empírica dos dados mostrou que a razão de hedge e a redução de risco variam de ano para ano. Os maiores valores foram observados para o anos de 1994, quando os preços se elevaram muito.

Quanto ao mês de vencimento, cabe ressaltar que o vencimento de setembro, tanto na CSCE quanto na BM\&F, apresentou, na média, valores maiores para a razão de hedge e redução de risco quando comparados aos outros meses de vencimento.

O período de duração do hedge também influenciou os resultados obtidos. Os valores da razão de hedge e redução de risco foram maiores para o caso de 4 meses.

Os resultados deste trabalho sugerem que o universo de tipos de café que podem ser hedgeados no mercado futuro vai além do padrão contratual. A Bolsa de Mercadorias \& Futuros (BM\&F) pode, a partir destes dados, iniciar um acompanhamento mais detalhado dos preços de diferentes tipos de café existentes no mercado brasileiro e, com isso, gerar valores mais atualizados de diferenciais e razões de hedge, para que os agentes interessados possam planejar melhor suas estratégias de utilização do mercado futuro.

Com a ampliação da utilização desse mercado pelos agentes envolvidos na cadeia agroindustrial do café, haverá uma possível redução do custo dos créditos de custeio e investimento, já que o risco de preço foi minimizado com a utilização das operações no mercado futuro. 
Finalizando, cabe ressaltar que outros estudos desse tipo podem vir a ser realizados num futuro próximo, quando se espera uma maior consolidação dos mercados futuros no Brasil. Além disso, é importante que haja um levantamento sistemático e confiável de dados de preços de café no mercado disponível, sem os quais não seria possível a realização desse tipo de estudo. 


\section{ANEXO}

\section{Algumas das especificações do Contrato Futuro Cambial de Café Arábica da Bolsa de Mercadorias \& Futuros}

\section{Objeto de negociação}

Café cru, em grão, de produção brasileira, coffea arábica, tipo seis ou melhor, bebida dura ou melhor, ensacado em sacas novas de juta, não viajadas, tipo oficial adotado, bem identificável, em perfeito estado de conservação, que não tenha sofrido avarias, danos, adulteração nem deterioração, não seja resultante de salvados de incêndio nem contenha corpos estranhos, além dos que lhe sejam próprios. O café deve ser classificado pela $B M \& F$, de acordo com seus regulamentos e sob os padrões descritos no Decreto Federal 27173, de 14 de setembro de 1949, depositado em armazém credenciado pela BM\&F e formado em lotes, que comporão um contrato.

\section{Cotação}

Pontos por saca de 60 quilos líquidos, com duas casas decimais, sendo cada ponto equivalente à taxa de câmbio média de reais por dólar dos Estados Unidos, para entrega pronta, contratada nos termos da Resolução 1690/90, do Conselho Monetário NacionalCMN, e divulgada pelo Banco Central do Brasil-Bacen.

\section{Variação mínima de apregoação}

0,01 ponto (equivalente a US\$0,01) por saca de 60 quilos líquidos.

\section{Oscilação máxima diária}

O limite de oscilação será fixado pela BM\&F.

A BM\&F poderá, a qualquer momento, alterar os limites de oscilação, bem como sua aplicação aos diversos vencimentos. 
Unidade de negociação

100 sacas de 60 quilos líquidos.

\section{Meses de vencimento}

Março, maio, julho, setembro e dezembro.

\section{Número de vencimentos em aberto}

No máximo sete.

\section{Data de vencimento e último dia de negociação}

Sexto dia útil anterior ao último dia do mês de vencimento. Nesse dia, não se admitirá day trade nem a abertura de novas posições vendidas para esse vencimento.

\section{Ponto de entrega}

Município de São Paulo (SP).

\section{Locais de formação dos lotes}

Armazéns credenciados pela BM\&F, localizados nos municípios de São Paulo (SP), Santos (SP), Catanduva (SP), Espírito Santo do Pinhal (SP), Franca (SP), Batatais (SP), Leme (SP), Londrina (PR), Rolândia (PR), Elói Mendes (MG), Araguari (MG), Patrocínio (MG), Machado (MG), Monte Santo de Minas (MG), Varginha (MG), Guaxupé (MG), Poços de Caldas (MG), Piumhi (MG), Ouro Fino (MG), São Sebastião do Paraíso (MG), Três Corações (MG) e Andradas (MG).

Formação do(s) lote(s) e do(s) contrato(s)

- Os tipos serão seis ou melhor, não se admitindo lotes inferiores a esse tipo;

- não podem ser entregues cafés chuvados, úmidos, mal secos, barrentos, infestados ou de gostos estranhos aos característicos do café arábica;

- serão admitidos até o máximo de $8 \%$ de grãos brocados ou carunchados; 
- serão admitidas entregas de lotes de peneiras 15 acima. Admite-se vazamento da peneira 15 de $30 \%$, sendo na peneira 13 o máximo de $10 \%$. Os lotes compostos por grãos chatos poderão conter o máximo de $10 \%$ de grãos moca e os lotes compostos por grãos moca poderão conter o máximo de $10 \%$ de grãos chatos;

- para os lotes de moca, não serão consideradas as peneiras;

- para formação do lote a cor do café será verde ou esverdeada, uniforme, compreendendo-se, por cor esverdeada, a cor característica da safra em curso ou da imediatamente anterior. Não serão admitidos cafés claros ou manchados;

- na entrega do contrato, mantida a uniformidade, será admitida variação de cor, em função do espaço de tempo decorrido entre a data de emissão do Certificado de Classificação e a data de entrega;

- não poderão ser entregues lotes alterados por más condições de armazenagem;

- o lote terá no máximo 100 sacas de $60 \mathrm{~kg}$ líquidos, com tolerância de até $1 \%$ de peso, para mais ou para menos, e será formado em um só armazém, onde a mercadoria estiver depositada; 
Especificações do contrato futuro de café da Bolsa de Nova Iorque (CSCE)

\section{Objeto de Negociação}

Especifica a entrega de café arábica lavado produzido em vários países da América do Sul e Central, Ásia e África.

\section{Unidade de Negociação}

37.500 libras-peso (aproximadamente 283 sacos de $60 \mathrm{~kg}$ )

\section{Horário de Negociação}

9:15 AM to 1:32 PM New York Time.

\section{Cotação}

Centavos de dólar por libra-peso.

\section{Meses de Entrega}

Março, Maio, Julho, Setembro, Dezembro.

\section{Oscilação Mínima de Preço}

$5 / 100$ centavos/libra-peso, equivalente a US\$ 18,75 por contrato.

\section{Limites de Oscilação Diária}

Nenhum

\section{Padrões}

Um Aviso de Entrega é emitido baseado numa classificação sobre o tamanho dos grãos e sobre a qualidade da bebida de acordo com o teste de degustação. A Bolsa utiliza determinados cafés para estabelecer a "base". Cafés classificados como melhores do que a 
"base" levam um prêmio, enquanto aqueles classificados como inferiores a "base" levam um disconto.

\begin{tabular}{|l|c|}
\hline País & Diferencial \\
\hline $\begin{array}{l}\text { Mexico, Salvador, Guatemala, Costa Rica, Nicaragua, } \\
\text { Kenya, New Guinea, Tanzania, Uganda }\end{array}$ & Base \\
\hline Colombia & Mais 200 pts \\
\hline Honduras, Venezuela & Menos 100 pts \\
\hline Burundi, India, Rwanda & Menos 300 pts \\
\hline Dominican Republic, Ecuador, Peru & Menos 400 pts \\
\hline
\end{tabular}

*Iniciando com o vencimento de dezembro de 1999, Panamá será incluído como país de origem e com diferencial zero ("base").

\section{Pontos de Entrega}

A Bolsa autorizou armazéns de entrega no Porto de New York (sem desconto), Porto de New Orleans e Porto de Miami (com um desconto de 1,25 centavos/libra-peso) e no Porto de São Francisco (com desconto de 0,75 centavos/libra-peso).

\section{Último Dia de Negociação}

Um dia útil anterior ao último dia para o aviso de entrega.

\section{Primeiro Dia de Aviso de Entrega}

Sete dias úteis anteriores ao primeiro dia útil do mês de entrega.

\section{Último Dia de Aviso de Entrega}

Sete dias úteis anteriores ao último dia útil do mês de entrega. 
Tabela 14 - Resultados das regressões utilizadas neste estudo.

\begin{tabular}{|c|c|c|c|c|c|c|c|c|c|c|c|}
\hline Ano & Mês & Periodo & $Y$ & $x$ & $\mathrm{R} 2$ & $a$ & ta & $b$ & tb & $N$ & Teste Q \\
\hline 90 & 5 & 4 & CFA & CSCE & 0,93 & 36,11 & 0,07 & 0,38 & 0,02 & 78 & 0,01 \\
\hline 90 & 5 & 4 & CFB & CSCE & 0,88 & 33,24 & 0,13 & 0,31 & 0,08 & 78 & 0,40 \\
\hline 90 & 5 & 4 & CFC & CSCE & 0,88 & 7,41 & 0,72 & 0,37 & 0,02 & 78 & 0,01 \\
\hline 90 & 5 & 4 & CFD & CSCE & 0,93 & 66,39 & 0,01 & 0,30 & 0,15 & 78 & 0,02 \\
\hline 90 & 5 & 4 & CFE & CSCE & 0,77 & $-1,10$ & 0,96 & 0,65 & 0,00 & 78 & 0,77 \\
\hline 90 & 7 & 4 & CFA & CSCE & 0,91 & 36,57 & 0,04 & 0,33 & 0,02 & 81 & 0,12 \\
\hline 90 & 7 & 4 & CFB & CSCE & 0,85 & 35,04 & 0,09 & 0,28 & 0,09 & 81 & 0,39 \\
\hline 90 & 7 & 4 & CFC & CSCE & 0,89 & 0,88 & 0,96 & 0,36 & 0,02 & 81 & 0,35 \\
\hline 90 & 7 & 4 & CFD & CSCE & 0,93 & 50,77 & 0,04 & 0,31 & 0,09 & 81 & 0,00 \\
\hline 90 & 7 & 4 & CFE & CSCE & 0,68 & 12,09 & 0,65 & 0,53 & 0,01 & 81 & 0,88 \\
\hline 90 & 7 & 6 & CFA & CSCE & 0,93 & 38,39 & 0,01 & 0,35 & 0,00 & 119 & 0,00 \\
\hline 90 & 7 & 6 & $\mathrm{CFB}$ & CSCE & 0,87 & 35,87 & 0,03 & 0,28 & 0,04 & 119 & 0,70 \\
\hline 90 & 7 & 6 & CFC & CSCE & 0,89 & 10,81 & 0,53 & 0,31 & 0,02 & 119 & 0,42 \\
\hline 90 & 7 & 6 & CFD & CSCE & 0,94 & 55,97 & 0,01 & 0,34 & 0,03 & 119 & 0,02 \\
\hline 90 & 7 & 6 & CFE & CSCE & 0,77 & 8,52 & 0,66 & 0,56 & 0,00 & 119 & 0,75 \\
\hline 90 & 9 & 4 & CFA & CSCE & 0,98 & 66,11 & 0,00 & 0,14 & 0,07 & 84 & 0,04 \\
\hline 90 & 9 & 4 & CFB & CSCE & 0,93 & 55,39 & 0,00 & 0,12 & 0,22 & 84 & 0,03 \\
\hline 90 & 9 & 4 & CFC & CSCE & 0,81 & 22,23 & 0,12 & 0,16 & 0,16 & 84 & 0,34 \\
\hline 90 & 9 & 4 & CFD & CSCE & 0,98 & 1489,87 & 0,30 & 0,21 & 0,02 & 84 & 0,00 \\
\hline 90 & 9 & 4 & CFE & CSCE & 0,98 & 59,47 & 0,00 & 0,18 & 0,01 & 84 & 0,09 \\
\hline 90 & 9 & 6 & CFA & CSCE & 0,94 & 36,96 & 0,01 & 0,31 & 0,00 & 125 & 0,06 \\
\hline 90 & 9 & 6 & CFB & CSCE & 0,88 & 36,42 & 0,02 & 0,26 & 0,04 & 125 & 0,49 \\
\hline 90 & 9 & 6 & CFC & CSCE & 0,91 & 5,28 & 0,72 & 0,31 & 0,01 & 125 & 0,26 \\
\hline 90 & 9 & 6 & CFD & CSCE & 0,95 & 56,30 & 0,00 & 0,28 & 0,04 & 125 & 0,00 \\
\hline 90 & 9 & 6 & CFE & CSCE & 0,79 & 8,80 & 0,66 & 0,53 & 0,00 & 125 & 0,85 \\
\hline 90 & 12 & 4 & CFA & CSCE & 0,99 & $-2940,00$ & 0,05 & 0,07 & 0,42 & 79 & 0,03 \\
\hline 90 & 12 & 4 & CFB & CSCE & 0,98 & $-2411,00$ & 0,11 & 0,10 & 0,27 & 79 & 0,02 \\
\hline 90 & 12 & 4 & CFC & CSCE & 0,96 & 27,86 & 0,00 & 0,08 & 0,20 & 79 & 0,44 \\
\hline 90 & 12 & 4 & CFD & CSCE & 0,98 & $-2313,00$ & 0,26 & 0,04 & 0,73 & 79 & 0,14 \\
\hline 90 & 12 & 4 & CFE & CSCE & 0,99 & $-3126,00$ & 0,05 & 0,09 & 0,32 & 79 & 0,06 \\
\hline 90 & 12 & 6 & CFA & CSCE & 0,99 & $-2969,00$ & 0,01 & 0,07 & 0,27 & 120 & 0,00 \\
\hline 90 & 12 & 6 & CFB & CSCE & 0,97 & $-2323,00$ & 0,07 & 0,10 & 0,18 & 120 & 0,87 \\
\hline 90 & 12 & 6 & CFC & CSCE & 0,91 & 27,86 & 0,00 & 0,09 & 0,21 & 120 & 0,98 \\
\hline 90 & 12 & 6 & CFD & CSCE & 0,98 & $-167,00$ & 0,25 & 0,11 & 0,22 & 120 & 0,13 \\
\hline 90 & 12 & 6 & CFE & CSCE & 0,99 & $-3071,00$ & 0,01 & 0,12 & 0,07 & 120 & 0,16 \\
\hline 91 & 3 & 4 & CFA & CSCE & 0,81 & 72,25 & 0,00 & $-0,18$ & 0,29 & 74 & 0,65 \\
\hline 91 & 3 & 4 & CFB & CSCE & 0,79 & 58,04 & 0,00 & $-0,10$ & 0,44 & 74 & 0,97 \\
\hline 91 & 3 & 4 & CFC & CSCE & 0,48 & 0,66 & 0,96 & 0,30 & 0,02 & 74 & 0,88 \\
\hline 91 & 3 & 4 & CFD & CSCE & 0,73 & 58,64 & 0,01 & 0,11 & 0,56 & 74 & 0,98 \\
\hline 91 & 3 & 4 & CFE & CSCE & 0,87 & 45,69 & 0,00 & $-0,04$ & 0,70 & 74 & 0,84 \\
\hline 91 & 3 & 6 & CFA & CSCE & 0,96 & 62,55 & 0,00 & $-0,09$ & 0,43 & 113 & 0,74 \\
\hline 91 & 3 & 6 & CFB & CSCE & 0,96 & 51,42 & 0,00 & $-0,04$ & 0,69 & 113 & 0,99 \\
\hline 91 & 3 & 6 & CFC & CSCE & 0,77 & 4,72 & 0,63 & 0,27 & 0,00 & 113 & 0,92 \\
\hline 91 & 3 & 6 & CFD & CSCE & 0,92 & 58,07 & 0,00 & 0,13 & 0,39 & 113 & 0,99 \\
\hline
\end{tabular}


Tabela 14 - Resultados das regressões utilizadas neste estudo (cont.)

\begin{tabular}{|c|c|c|c|c|c|c|c|c|c|c|c|}
\hline Ano & Mês & Periodo & $\bar{Y}$ & $x$ & $\mathrm{R2}$ & $a$ & ta & $\mathbf{b}$ & tb & $\mathbf{N}$ & Teste $Q$ \\
\hline 91 & 3 & 6 & CFE & CSCE & 0,99 & 39,50 & 0,00 & 0,02 & 0,86 & 113 & 0,98 \\
\hline 91 & 5 & 4 & CFA & CSCE & 0,95 & 42,73 & 0,00 & 0,13 & 0,13 & 79 & 0,00 \\
\hline 91 & 5 & 4 & CFB & CSCE & 0,97 & 59,53 & 0,00 & $-0,04$ & 0,57 & 79 & 0,66 \\
\hline 91 & 5 & 4 & CFC & CSCE & 0,76 & 10,99 & 0,41 & 0,23 & 0,05 & 79 & 0,94 \\
\hline 91 & 5 & 4 & CFD & CSCE & 0,92 & 50,40 & 0,00 & 0,23 & 0,02 & 79 & 0,00 \\
\hline 91 & 5 & 4 & CFE & CSCE & 0,99 & 45,28 & 0,00 & 0,09 & 0,06 & 79 & 0,00 \\
\hline 91 & 5 & 6 & CFA & CSCE & 0,91 & 66,65 & 0,00 & $-0,10$ & 0,35 & 115 & 0,46 \\
\hline 91 & 5 & 6 & CFB & CSCE & 0,93 & 62,15 & 0,00 & $-0,11$ & 0,24 & 115 & 0,99 \\
\hline 91 & 5 & 6 & CFC & CSCE & 0,68 & 10,37 & 0,41 & 0,22 & 0,03 & 115 & 0,76 \\
\hline 91 & 5 & 6 & CFD & CSCE & 0,85 & 60,66 & 0,00 & 0,12 & 0,39 & 115 & 0,97 \\
\hline 91 & 5 & 6 & CFE & CSCE & 0,95 & 45,18 & 0,00 & $-0,01$ & 0,90 & 115 & 0,57 \\
\hline 91 & 7 & 4 & CFA & CSCE & 0,96 & 52,93 & 0,00 & 0,00 & 0,90 & 80 & 0,24 \\
\hline 91 & 7 & 4 & CFB & CSCE & 0,91 & 61,71 & 0,00 & $-0,07$ & 0,09 & 80 & 0,82 \\
\hline 91 & 7 & 4 & CFC & CSCE & 0,98 & 24,03 & 0,00 & 0,03 & 0,37 & 80 & 0,00 \\
\hline 91 & 7 & 4 & CFD & CSCE & 0,95 & 68,08 & 0,00 & 0,01 & 0,96 & 80 & 0,39 \\
\hline 91 & 7 & 4 & CFE & CSCE & 0,87 & 47,67 & 0,00 & 0,02 & 0,72 & 80 & 0,80 \\
\hline 91 & 7 & 6 & CFA & CSCE & 0,95 & 43,94 & 0,00 & 0,11 & 0,08 & 119 & 0,00 \\
\hline 91 & 7 & 6 & CFB & CSCE & 0,96 & 57,41 & 0,00 & $-0,03$ & 0,57 & 119 & 0,67 \\
\hline 91 & 7 & 6 & CFC & CSCE & 0,83 & 9,50 & 0,30 & 0,23 & 0,00 & 119 & 0,97 \\
\hline 91 & 7 & 6 & CFD & CSCE & 0,93 & 53,70 & 0,00 & 0,18 & 0,05 & 119 & 0,11 \\
\hline 91 & 7 & 6 & CFE & CSCE & 0,98 & 44,35 & 0,00 & 0,06 & 0,26 & 119 & 0,97 \\
\hline 91 & 9 & 4 & CFA & CSCE & 0,99 & 11,87 & 0,31 & 0,05 & 0,11 & 82 & 0,34 \\
\hline 91 & 9 & 4 & CFB & CSCE & 0,98 & $-559,63$ & 0,23 & 0,05 & 0,19 & 82 & 0,12 \\
\hline 91 & 9 & 4 & CFC & CSCE & 0,98 & 27,54 & 0,00 & 0,02 & 0,39 & 82 & 0,52 \\
\hline 91 & $\theta$ & 4 & CFD & CSCE & 0,93 & 62,56 & 0,00 & 0,01 & 0,89 & 82 & 0,48 \\
\hline 91 & 9 & 4 & CFE & CSCE & 0,78 & 50,30 & 0,00 & $-0,02$ & 0,72 & 82 & 0,69 \\
\hline 91 & 9 & 6 & CFA & CSCE & 0,99 & $-873,00$ & 0,02 & 0,04 & 0,14 & 123 & 0,52 \\
\hline 91 & 9 & 6 & CFB & CSCE & 0,98 & $-16,42$ & 0,70 & $-0,02$ & 0,44 & 123 & 0,83 \\
\hline 91 & 9 & 6 & CFC & CSCE & 0,99 & 23,65 & 0,00 & 0,03 & 0,26 & 123 & 0,00 \\
\hline 91 & 9 & 6 & CFD & CSCE & 0,98 & 60,66 & 0,00 & 0,02 & 0,77 & 123 & 0,27 \\
\hline 91 & 9 & 6 & CFE & CSCE & 0,92 & 48,56 & 0,00 & 0,00 & 0,97 & 123 & 0,85 \\
\hline 91 & 12 & 4 & CFA & CSCE & 0,83 & 24,68 & 0,00 & 0,22 & 0,00 & 82 & 0,01 \\
\hline 91 & 12 & 4 & CFB & CSCE & 0,90 & 23,46 & 0,00 & 0,18 & 0,00 & 82 & 0,13 \\
\hline 91 & 12 & 4 & CFC & CSCE & 0,92 & 24,77 & 0,00 & 0,09 & 0,07 & 82 & 0,05 \\
\hline 91 & 12 & 4 & CFD & CSCE & 0,91 & 27,68 & 0,01 & 0,32 & 0,00 & 82 & 0,16 \\
\hline 91 & 12 & 4 & CFE & CSCE & 0,96 & 21,01 & 0,01 & 0,14 & 0,01 & 82 & 0,05 \\
\hline 91 & 12 & 6 & CFA & CSCE & 0,91 & 29,09 & 0,00 & 0,19 & 0,00 & 123 & 0,00 \\
\hline 91 & 12 & 6 & CFB & CSCE & 0,96 & 30,15 & 0,00 & 0,12 & 0,01 & 123 & 0,08 \\
\hline 91 & 12 & 6 & CFC & CSCE & 0,92 & 26,37 & 0,00 & 0,07 & 0,08 & 123 & 0,02 \\
\hline 91 & 12 & 6 & CFD & CSCE & 0,93 & 37,46 & 0,00 & 0,23 & 0,00 & 123 & 0,10 \\
\hline 91 & 12 & 6 & CFE & CSCE & 0,97 & $-611,00$ & 0,28 & 0,11 & 0,01 & 123 & 0,04 \\
\hline 92 & 3 & 4 & CFA & CSCE & 0,92 & 29,82 & 0,00 & 0,13 & 0,12 & 78 & 0,06 \\
\hline 92 & 3 & 4 & CFA & BMF & 0,93 & 32,09 & 0,00 & 0,14 & 0,08 & 78 & 0,01 \\
\hline 92 & 3 & 4 & CFB & CSCE & 0,94 & 36,39 & 0,00 & 0,00 & 0,97 & 78 & 0,00 \\
\hline 92 & 3 & 4 & CFB & BMF & 0,94 & 34,06 & 0,00 & 0,03 & 0,62 & 78 & 0,00 \\
\hline 92 & 3 & 4 & CFC & CSCE & 0,92 & 30,24 & 0,00 & 0,01 & 0,79 & 78 & 0,07 \\
\hline
\end{tabular}


Tabela 14 - Resultados das regressões utilizadas neste estudo (cont.)

\begin{tabular}{|c|c|c|c|c|c|c|c|c|c|c|c|}
\hline Ano & Mês & Periodo & $\bar{Y}$ & $x$ & R2 & $a$ & $\mathrm{ta}$ & $b$ & tb & $N$ & Teste Q \\
\hline 92 & 3 & 4 & CFC & BMF & 0,93 & 26,69 & 0,00 & 0,09 & 0,06 & 78 & 0,18 \\
\hline 92 & 3 & 4 & CFD & CSCE & 0,94 & 43,53 & 0,00 & 0,10 & 0,11 & 78 & 0,00 \\
\hline 92 & 3 & 4 & CFD & BMF & 0,94 & 48,52 & 0,00 & 0,07 & 0,29 & 78 & 0,00 \\
\hline 92 & 3 & 4 & CFE & CSCE & 0,94 & 31,62 & 0,00 & 0,01 & 0,81 & 78 & 0,28 \\
\hline 92 & 3 & 4 & CFE & BMF & 0,94 & 27,59 & 0,00 & 0,08 & 0,24 & 78 & 0,39 \\
\hline 92 & 3 & 6 & CFA & CSCE & 0,92 & 23,92 & 0,00 & 0,21 & 0,00 & 121 & 0,05 \\
\hline 92 & 3 & 6 & CFA & BMF & 0,93 & 28,93 & 0,00 & 0,21 & 0,00 & 121 & 0,00 \\
\hline 92 & 3 & 6 & CFB & CSCE & 0,96 & 28,39 & 0,00 & 0,10 & 0,07 & 121 & 0,08 \\
\hline 92 & 3 & 6 & CFB & BMF & 0,96 & 28,89 & 0,00 & 0,13 & 0,01 & 121 & 0,05 \\
\hline 92 & 3 & 6 & CFC & CSCE & 0,89 & 25,33 & 0,00 & 0,09 & 0,03 & 121 & 0,04 \\
\hline 92 & 3 & 6 & CFC & BMF & 0,90 & 24,46 & 0,00 & 0,13 & 0,00 & 121 & 0,03 \\
\hline 92 & 3 & 6 & CFD & CSCE & 0,96 & 32,55 & 0,00 & 0,24 & 0,00 & 121 & 0,68 \\
\hline 92 & 3 & 6 & CFD & BMF & 0,96 & 37,78 & 0,00 & 0,25 & 0,00 & 121 & 0,59 \\
\hline 92 & 3 & 6 & CFE & CSCE & 0,97 & 22,90 & 0,00 & 0,11 & 0,03 & 121 & 0,88 \\
\hline 92 & 3 & 6 & CFE & $\mathrm{BMF}$ & 0,98 & 23,40 & 0,00 & 0,15 & 0,00 & 121 & 0,82 \\
\hline 92 & 5 & 4 & CFA & CSCE & 0,88 & 28,73 & 0,00 & 0,18 & 0,01 & 78 & 0,37 \\
\hline 92 & 5 & 4 & CFA & BMF & 0,89 & 33,07 & 0,00 & 0,19 & 0,00 & 78 & 0.57 \\
\hline 92 & 5 & 4 & CFB & CSCE & 0,89 & 27,95 & 0,00 & 0,13 & 0,01 & 78 & 0,91 \\
\hline 92 & 5 & 4 & CFB & BMF & 0,89 & 30,67 & 0,00 & 0,15 & 0,01 & 78 & 0,98 \\
\hline 92 & 5 & 4 & CFC & CSCE & 0,89 & 23,50 & 0,00 & 0,12 & 0,01 & 78 & 0,48 \\
\hline 92 & 5 & 4 & CFC & BMF & 0,90 & 23,85 & 0,00 & 0,16 & 0,00 & 78 & 0,43 \\
\hline 92 & 5 & 4 & CFD & CSCE & 0,92 & 27,73 & 0,00 & 0,30 & 0,00 & 78 & 0,78 \\
\hline 92 & 5 & 4 & CFD & BMF & 0,93 & 34,94 & 0,00 & 0,30 & 0,00 & 78 & 0,39 \\
\hline 92 & 5 & 4 & CFE & CSCE & 0,95 & 38,54 & 0,00 & 0,04 & 0,55 & 78 & 0,00 \\
\hline 92 & 5 & 4 & CFE & BMF & 0,95 & 36,79 & 0,00 & 0,11 & 0,13 & 78 & 0,00 \\
\hline 92 & 5 & 6 & CFA & CSCE & 0,91 & 30,85 & 0,00 & 0,14 & 0,02 & 115 & 0,01 \\
\hline 92 & 5 & 6 & CFA & BMF & 0,91 & 37,64 & 0,00 & 0,09 & 0,11 & 115 & 0,01 \\
\hline 92 & 5 & 6 & CFB & CSCE & 0,93 & 31,04 & 0,00 & 0,08 & 0,11 & 115 & 0,33 \\
\hline 92 & 5 & 6 & CFB & $\mathrm{BMF}$ & 0,93 & 32,59 & 0,00 & 0,08 & 0,09 & 115 & 0,61 \\
\hline 92 & 5 & 6 & CFC & CSCE & 0,89 & 27,75 & 0,00 & 0,07 & 0,07 & 115 & 0,11 \\
\hline 92 & 5 & 6 & CFC & BMF & 0,90 & 27,09 & 0,00 & 0,10 & 0,00 & 115 & 0,29 \\
\hline 92 & 5 & 6 & CFD & CSCE & 0,93 & 38,50 & 0,00 & 0,16 & 0,00 & 115 & 0,02 \\
\hline 92 & 5 & 6 & CFD & BMF & 0,93 & 43,00 & 0,00 & 0,16 & 0,00 & 115 & 0,10 \\
\hline 92 & 5 & 6 & CFE & CSCE & 0,96 & 34,44 & 0,00 & 0,04 & 0,50 & 115 & 0,00 \\
\hline 92 & 5 & 6 & CFE & $\mathrm{BMF}$ & 0,96 & 34,70 & 0,00 & 0,09 & 0,09 & 115 & 0,00 \\
\hline 92 & 7 & 4 & CFA & CSCE & 0,93 & 31,13 & 0,00 & 0,14 & 0,01 & 77 & 0,30 \\
\hline 92 & 7 & 4 & CFA & BMF & 0,94 & 27,24 & 0,00 & 0,27 & 0,00 & 78 & 0,18 \\
\hline 92 & 7 & 4 & CFB & CSCE & 0,93 & 25,35 & 0,00 & 0,16 & 0,00 & 77 & 0,60 \\
\hline 92 & 7 & 4 & CFB & $\mathrm{BMF}$ & 0,94 & 26,34 & 0,00 & 0,22 & 0,00 & 78 & 0,74 \\
\hline 92 & 7 & 4 & CFC & CSCE & 0,94 & 26,87 & 0,00 & 0,04 & 0,40 & 77 & 0,25 \\
\hline 92 & 7 & 4 & CFC & BMF & 0,94 & 22,87 & 0,00 & 0,15 & 0,00 & 77 & 0,26 \\
\hline 92 & 7 & 4 & CFD & CSCE & 0,97 & 33,39 & 0,00 & 0,16 & 0,00 & 77 & 0,53 \\
\hline 92 & 7 & 4 & CFD & BMF & 0,97 & 28,87 & 0,00 & 0,36 & 0,00 & 78 & 0,24 \\
\hline 92 & 7 & 4 & CFE & CSCE & 0,86 & 31,69 & 0,00 & 0,11 & 0,03 & 77 & 0,39 \\
\hline 92 & 7 & 4 & CFE & BMF & 0,87 & 32,65 & 0,00 & 0,15 & 0,01 & 78 & 0,09 \\
\hline 92 & 7 & 6 & CFA & CSCE & 0,93 & 27,30 & 0,00 & 0,18 & 0,00 & 118 & 0,00 \\
\hline
\end{tabular}


Tabela 14 - Resultados das regressões utilizadas neste estudo (cont.)

\begin{tabular}{|c|c|c|c|c|c|c|c|c|c|c|c|}
\hline Ano & Mês & Periodo & $\bar{Y}$ & $x$ & $\mathbf{R 2}$ & $a$ & ta & $b$ & tb & $\bar{N}$ & Teste Q \\
\hline 92 & 7 & 6 & CFA & BMF & 0,93 & 31,06 & 0,00 & 0,19 & 0,00 & 120 & 0,02 \\
\hline 92 & 7 & 6 & CFB & CSCE & 0,91 & 27,75 & 0,00 & 0,13 & 0,00 & 118 & 0,11 \\
\hline 92 & 7 & 6 & CFB & BMF & 0,92 & 30,01 & 0,00 & 0,14 & 0,00 & 120 & 0,30 \\
\hline 92 & 7 & 6 & CFC & CSCE & 0,95 & 26,32 & 0,00 & 0,06 & 0,11 & 118 & 0,33 \\
\hline 92 & 7 & 6 & CFC & BMF & 0,96 & 22,39 & 0,00 & 0,16 & 0,00 & 120 & 0,41 \\
\hline 92 & 7 & 6 & CFD & CSCE & 0,97 & 35,62 & 0,00 & 0,18 & 0,00 & 118 & 0,23 \\
\hline 92 & 7 & 6 & CFD & BMF & 0,98 & 30,15 & 0,00 & 0,34 & 0,00 & 120 & 0,15 \\
\hline 92 & 7 & 6 & CFE & CSCE & 0,94 & 34,80 & 0,00 & 0,06 & 0,24 & 118 & 0,00 \\
\hline 92 & 7 & 6 & CFE & BMF & 0,94 & 35,15 & 0,00 & 0,09 & 0,13 & 120 & 0,00 \\
\hline 92 & 9 & 4 & CFA & CSCE & 0,91 & 41,65 & 0,00 & $-0,04$ & 0,28 & 82 & 0,00 \\
\hline 92 & 9 & 4 & CFA & BMF & 0,91 & 39,91 & 0,00 & $-0,02$ & 0,75 & 84 & 0,01 \\
\hline 92 & 9 & 4 & CFB & CSCE & 0,93 & 35,55 & 0,00 & 0,01 & 0,71 & 82 & 0,00 \\
\hline 92 & 9 & 4 & CFB & BMF & 0,93 & 34,52 & 0,00 & 0,04 & 0,41 & 84 & 0,00 \\
\hline 92 & 9 & 4 & CFC & CSCE & 0,90 & 33,83 & 0,00 & $-0,04$ & 0,29 & 82 & 0,00 \\
\hline 92 & 9 & 4 & CFC & BMF & 0,90 & 32,19 & 0,00 & $-0,03$ & 0,60 & 84 & 0,01 \\
\hline 92 & 9 & 4 & CFD & CSCE & 0,94 & 41,95 & 0,00 & 0,04 & 0,46 & 82 & 0,00 \\
\hline 92 & 9 & 4 & CFD & BMF & 0,94 & 39,55 & 0,00 & 0,10 & 0,13 & 84 & 0,01 \\
\hline 92 & 9 & 4 & CFE & CSCE & 0,88 & 39,93 & 0,00 & 0,01 & 0,87 & 82 & 0,01 \\
\hline 92 & 9 & 4 & CFE & BMF & 0,89 & 37,04 & 0,00 & 0,07 & 0,30 & 84 & 0,03 \\
\hline 92 & 9 & 6 & CFA & CSCE & 0,95 & 39,06 & 0,00 & 0,00 & 0,96 & 114 & 0,59 \\
\hline 92 & 9 & 6 & CFA & BMF & 0,95 & 39,23 & 0,00 & 0,00 & 0,99 & 116 & 0,55 \\
\hline 92 & 9 & 6 & CFB & CSCE & 0,96 & 33,39 & 0,00 & 0,04 & 0,20 & 114 & 0,02 \\
\hline 92 & 9 & 6 & CFB & BMF & 0,96 & 32,06 & 0,00 & 0,09 & 0,05 & 116 & 0,07 \\
\hline 92 & 9 & 6 & CFC & CSCE & 0,95 & 31,00 & 0,00 & 0,01 & 0,87 & 114 & 0,10 \\
\hline 92 & 9 & 6 & CFC & BMF & 0,95 & 29,22 & 0,00 & 0,04 & 0,40 & 116 & 0,25 \\
\hline 92 & 9 & 6 & CFD & CSCE & 0,97 & 37,96 & 0,00 & 0,09 & 0,04 & 114 & 0,18 \\
\hline 92 & 9 & 6 & CFD & BMF & 0,98 & 35,85 & 0,00 & 0,18 & 0,00 & 116 & 0,30 \\
\hline 92 & 9 & 6 & CFE & CSCE & 0,89 & 36,24 & 0,00 & 0,06 & 0,15 & 114 & 0,01 \\
\hline 92 & 9 & 6 & CFE & BMF & 0,90 & 31,18 & 0,00 & 0,17 & 0,00 & 116 & 0,01 \\
\hline 92 & 12 & 4 & CFA & CSCE & 0,99 & 127,77 & 0,01 & 0,12 & 0,01 & 79 & 0,00 \\
\hline 92 & 12 & 4 & CFA & BMF & 0,99 & 143,90 & 0,01 & 0,13 & 0,04 & 81 & 0,20 \\
\hline 92 & 12 & 4 & CFB & CSCE & 0,99 & 720,00 & 0,04 & 0,18 & 0,00 & 79 & 0,17 \\
\hline 92 & 12 & 4 & CFB & BMF & 0,99 & 640,00 & 0,07 & 0,21 & 0,00 & 81 & 0,74 \\
\hline 92 & 12 & 4 & CFC & CSCE & 0,99 & 237,17 & 0,01 & 0,12 & 0,02 & 79 & 0,64 \\
\hline 92 & 12 & 4 & CFC & BMF & 0,99 & 105,00 & 0,00 & 0,19 & 0,00 & 81 & 0,75 \\
\hline 92 & 12 & 4 & CFD & CSCE & 0,99 & 2159,00 & 0,01 & 0,22 & 0,00 & 79 & 0,26 \\
\hline 92 & 12 & 4 & CFD & BMF & 0,99 & 1754,00 & 0,03 & 0,38 & 0,00 & 81 & 0,22 \\
\hline 92 & 12 & 4 & CFE & CSCE & 0,99 & 133,70 & 0,01 & 0,14 & 0,01 & 79 & 0,06 \\
\hline 92 & 12 & 4 & CFE & BMF & 0,99 & 88,89 & 0,01 & 0,21 & 0,00 & 81 & 0,20 \\
\hline 92 & 12 & 6 & CFA & CSCE & 0,99 & 980,00 & 0,10 & 0,06 & 0,14 & 122 & 0,03 \\
\hline 92 & 12 & 6 & CFA & BMF & 0,99 & 903,70 & 0,13 & 0,09 & 0,07 & 125 & 0,24 \\
\hline 92 & 12 & 6 & CFB & CSCE & 0,99 & 1002,00 & 0,04 & 0,13 & 0,00 & 122 & 0,03 \\
\hline 92 & 12 & 6 & CFB & BMF & 0,99 & 856,24 & 0,09 & 0,18 & 0,00 & 125 & 0,50 \\
\hline 92 & 12 & 6 & CFC & CSCE & 0,99 & 1534,54 & 0,01 & 0,07 & 0,09 & 122 & 0,44 \\
\hline 92 & 12 & 6 & CFC & BMF & 0,99 & 1396,00 & 0,02 & 0,15 & 0,00 & 125 & 0,76 \\
\hline 92 & 12 & 6 & CFD & CSCE & 0,99 & 1457,00 & 0,04 & 0,15 & 0,00 & 122 & 0,39 \\
\hline
\end{tabular}


Tabela 14 - Resultados das regressões utilizadas neste estudo (cont.)

\begin{tabular}{|c|c|c|c|c|c|c|c|c|c|c|c|}
\hline Ano & Mês & Periodo & $\bar{Y}$ & $x$ & R2 & $a$ & ta & $\mathrm{b}$ & tb & $\bar{N}$ & Teste Q \\
\hline 92 & 12 & 6 & CFD & BMF & 0,99 & 1174,00 & 0,08 & 0,31 & 0,00 & 125 & 0,83 \\
\hline 92 & 12 & 6 & CFE & CSCE & 0,99 & 1225,00 & 0,04 & 0,09 & 0,02 & 122 & 0,05 \\
\hline 92 & 12 & 6 & CFE & BMF & 0,99 & 1067,00 & 0,06 & 0,18 & 0,178 & 125 & 0,42 \\
\hline 93 & 3 & 4 & CFA & CSCE & 0,93 & 42,16 & 0,00 & 0,23 & 0,01 & 71 & 0,77 \\
\hline 93 & 3 & 4 & CFB & CSCE & 0,97 & 51,13 & 0,00 & 0,12 & 0,04 & 71 & 0,30 \\
\hline 93 & 3 & 4 & CFC & CSCE & 0,97 & 44,38 & 0,00 & 0,09 & 0,13 & 71 & 0,04 \\
\hline 93 & 3 & 4 & CFD & CSCE & 0,96 & 55,63 & 0,00 & 0,22 & 0,00 & 71 & 0,56 \\
\hline 93 & 3 & 4 & CFE & CSCE & 0,89 & 56,10 & 0,00 & 0,09 & 0,38 & 71 & 0,24 \\
\hline 93 & 3 & 6 & CFA & CSCE & 0,98 & 43,18 & 0,00 & 0,21 & 0,00 & 112 & 0,07 \\
\hline 93 & 3 & 6 & CFB & CSCE & 0,99 & 51,47 & 0,00 & 0,13 & 0,01 & 112 & 0,01 \\
\hline 93 & 3 & 6 & CFC & CSCE & 0,98 & 44,34 & 0,00 & 0,09 & 0,08 & 112 & 0,02 \\
\hline 93 & 3 & 6 & CFD & CSCE & 0,99 & 56,53 & 0,00 & 0,21 & 0,00 & 112 & 0,50 \\
\hline 93 & 3 & 6 & CFE & CSCE & 0,97 & 55,80 & 0,00 & 0,09 & 0,26 & 112 & 0,03 \\
\hline 93 & 5 & 4 & CFA & CSCE & 0,92 & 40,24 & 0,00 & 0,18 & 0,04 & 75 & 0,66 \\
\hline 93 & 5 & 4 & CFA & BMF & 0,92 & 44,06 & 0,00 & 0,17 & 0,09 & 76 & 0,58 \\
\hline 93 & 5 & 4 & CFB & CSCE & 0,96 & 43,24 & 0,00 & 0,04 & 0,53 & 75 & 0,83 \\
\hline 93 & 5 & 4 & CFB & BMF & 0,96 & 41,90 & 0,00 & 0,09 & 0,22 & 76 & 0,42 \\
\hline 93 & 5 & 4 & CFC & CSCE & 0,97 & 32,32 & 0,00 & 0,05 & 0,45 & 75 & 0,01 \\
\hline 93 & 5 & 4 & CFC & BMF & 0,97 & 33,26 & 0,00 & 0,05 & 0,51 & 76 & 0,01 \\
\hline 93 & 5 & 4 & CFD & CSCE & 0,98 & 43,63 & 0,00 & 0,16 & 0,02 & 75 & 0,74 \\
\hline 93 & 5 & 4 & CFD & BMF & 0,98 & 46,97 & 0,00 & 0,17 & 0,04 & 76 & 0,94 \\
\hline 93 & 5 & 4 & CFE & CSCE & 0,92 & 54,62 & 0,00 & $-0,01$ & 0,92 & 75 & 0,03 \\
\hline 93 & 5 & 4 & CFE & BMF & 0,92 & 48,14 & 0,00 & 0,10 & 0,40 & 76 & 0,01 \\
\hline 93 & 5 & 6 & CFA & CSCE & 0,95 & 41,09 & 0,00 & 0,20 & 0,00 & 113 & 0,66 \\
\hline 93 & 5 & 6 & CFA & BMF & 0,95 & 41,44 & 0,00 & 0,23 & 0,00 & 116 & 0,60 \\
\hline 93 & 5 & 6 & CFB & CSCE & 0,97 & 45,87 & 0,00 & 0,10 & 0,05 & 113 & 0,00 \\
\hline 93 & 5 & 6 & CFB & BMF & 0,97 & 42,40 & 0,00 & 0,18 & 0,00 & 116 & 0,01 \\
\hline 93 & 5 & 6 & CFC & CSCE & 0,98 & 32,64 & 0,04 & 0,09 & 0,13 & 113 & 0,04 \\
\hline 93 & 5 & 6 & CFC & BMF & 0,98 & 33,65 & 0,00 & 0,12 & 0,07 & 116 & 0,07 \\
\hline 93 & 5 & 6 & CFD & CSCE & 0,98 & 47,01 & 0,00 & 0,21 & 0,00 & 113 & 0,27 \\
\hline 93 & 5 & 6 & CFD & BMF & 0,98 & 47,53 & 0,00 & 0,26 & 0,00 & 116 & 0,65 \\
\hline 93 & 5 & 6 & CFE & CSCE & 0,94 & 52,19 & 0,00 & 0,07 & 0,35 & 113 & 0,06 \\
\hline 93 & 5 & 6 & CFE & BMF & 0,94 & 44,33 & 0,00 & 0,20 & 0,02 & 116 & 0,02 \\
\hline 93 & 7 & 4 & CFA & CSCE & 0,94 & 51,63 & 0,00 & 0,04 & 0,59 & 82 & 0,42 \\
\hline 93 & 7 & 4 & CFA & BMF & 0,94 & 47,79 & 0,00 & 0,11 & 0,20 & 83 & 0,51 \\
\hline 93 & 7 & 4 & CFB & CSCE & 0,95 & 49,97 & 0,00 & 0,00 & 0,95 & 82 & 0,07 \\
\hline 93 & 7 & 4 & CFB & BMF & 0,95 & 46,07 & 0,00 & 0,07 & 0,39 & 83 & 0,14 \\
\hline 93 & 7 & 4 & CFC & CSCE & 0,91 & 32,73 & 0,00 & 0,07 & 0,33 & 82 & 0,07 \\
\hline 93 & 7 & 4 & CFC & BMF & 0,91 & 29,57 & 0,00 & 0,14 & 0,16 & 83 & 0,07 \\
\hline 93 & 7 & 4 & CFD & CSCE & 0,97 & 53,57 & 0,00 & 0,05 & 0,36 & 82 & 0,03 \\
\hline 93 & 7 & 4 & CFD & BMF & 0,97 & 49,50 & 0,00 & 0,13 & 0,08 & 83 & 0,14 \\
\hline 93 & 7 & 4 & CFE & CSCE & 0,92 & 51,58 & 0,00 & 0,04 & 0,61 & 82 & 0,14 \\
\hline 93 & 7 & 4 & CFE & BMF & 0,92 & 50,82 & 0,00 & 0,06 & 0,55 & 83 & 0,15 \\
\hline 93 & 7 & 6 & CFA & CSCE & 0,92 & 45,72 & 0,00 & 0,13 & 0,05 & 116 & 0,69 \\
\hline 93 & 7 & 6 & CFA & BMF & 0,92 & 46,89 & 0,00 & 0,14 & 0,08 & 118 & 0,73 \\
\hline 93 & 7 & 6 & CFB & CSCE & 0,96 & 49,32 & 0,00 & 0,03 & 0,57 & 116 & 0,19 \\
\hline
\end{tabular}


Tabela 14 - Resultados das regressões utilizadas neste estudo (cont.)

\begin{tabular}{|c|c|c|c|c|c|c|c|c|c|c|c|}
\hline Ano & Mês & Periodo & $\bar{Y}$ & $\bar{x}$ & R2 & a & ta & $b$ & tb & $N$ & Teste Q \\
\hline 93 & 7 & 6 & CFB & BMF & 0,96 & 46,82 & 0,00 & 0,08 & 0,22 & 118 & 0,03 \\
\hline 93 & 7 & 6 & CFC & CSCE & 0,97 & 34,32 & 0,00 & 0,06 & 0,28 & 116 & 0,20 \\
\hline 93 & 7 & 6 & CFC & BMF & 0,97 & 33,46 & 0,00 & 0,09 & 0,20 & 118 & 0,20 \\
\hline 93 & 7 & 6 & CFD & CSCE & 0,97 & 51,74 & 0,00 & 0,10 & 0,06 & 116 & 0,12 \\
\hline 93 & 7 & 6 & CFD & BMF & 0,97 & 49,46 & 0,00 & 0,16 & 0,01 & 118 & 0,44 \\
\hline 93 & 7 & 6 & CFE & CSCE & 0,91 & 55,54 & 0,00 & 0,01 & 0,90 & 116 & 0,05 \\
\hline 93 & 7 & 6 & CFE & BMF & 0,91 & 49,06 & 0,00 & 0,11 & 0,24 & 118 & 0,02 \\
\hline 93 & 9 & 4 & CFA & CSCE & 0,96 & 60,33 & 0,00 & 0,11 & 0,14 & 83 & 0,55 \\
\hline 93 & 9 & 4 & CFA & BMF & 0,96 & 54,55 & 0,00 & 0,17 & 0,07 & 85 & 0,52 \\
\hline 93 & 9 & 4 & CFB & CSCE & 0,96 & 67,95 & 0,00 & 0,03 & 0,63 & 83 & 0,07 \\
\hline 93 & 9 & 4 & CFB & BMF & 0,97 & 61,95 & 0,00 & 0,08 & 0,36 & 85 & 0,19 \\
\hline 93 & 9 & 4 & CFC & CSCE & 0,95 & 69,08 & 0,00 & $-0,02$ & 0,81 & 83 & 0,01 \\
\hline 93 & 9 & 4 & CFC & BMF & 0,95 & 58,48 & 0,00 & 0,04 & 0,70 & 85 & 0,05 \\
\hline 93 & 9 & 4 & CFD & CSCE & 0,97 & 76,38 & 0,00 & 0,07 & 0,32 & 83 & 0,24 \\
\hline 93 & 9 & 4 & CFD & BMF & 0,97 & 58,13 & 0,00 & 0,23 & 0,02 & 85 & 0,65 \\
\hline 93 & 9 & 4 & CFE & CSCE & 0,96 & 60,78 & 0,00 & 0,13 & 0,09 & 83 & 0,65 \\
\hline 93 & 9 & 4 & CFE & BMF & 0,96 & 54,83 & 0,00 & 0,20 & 0,05 & 85 & 0,54 \\
\hline 93 & 9 & 6 & CFA & CSCE & 0,96 & 56,72 & 0,00 & 0,10 & 0,08 & 125 & 0,54 \\
\hline 93 & 9 & 6 & CFA & BMF & 0,96 & 51,13 & 0,00 & 0,18 & 0,02 & 127 & 0,54 \\
\hline 93 & 9 & 6 & CFB & CSCE & 0,97 & 59,30 & 0,00 & 0,03 & 0,53 & 125 & 0,02 \\
\hline 93 & 9 & 6 & CFB & BMF & 0,97 & 51,28 & 0,00 & 0,12 & 0,08 & 127 & 0,20 \\
\hline 93 & 9 & 6 & CFC & CSCE & 0,95 & 52,41 & 0,00 & 0,01 & 0,89 & 125 & 0,34 \\
\hline 93 & 9 & 6 & CFC & BMF & 0,95 & 44,73 & 0,00 & 0,08 & 0,39 & 127 & 0,46 \\
\hline 93 & 9 & 6 & CFD & CSCE & 0,97 & 63,95 & 0,00 & 0,08 & 0,14 & 125 & 0,03 \\
\hline 93 & 9 & 6 & CFD & BMF & 0,98 & 51,97 & 0,00 & 0,23 & 0,00 & 127 & 0,26 \\
\hline 93 & 9 & 6 & CFE & CSCE & 0,97 & 58,45 & 0,00 & 0,11 & 0,06 & 125 & 0,16 \\
\hline 93 & 9 & 6 & CFE & BMF & 0,97 & 52,39 & 0,00 & 0,19 & 0,01 & 127 & 0,16 \\
\hline 93 & 12 & 4 & CFA & CSCE & 0,53 & 47,16 & 0,00 & 0,20 & 0,07 & 78 & 0,00 \\
\hline 93 & 12 & 4 & CFA & BMF & 0,54 & 33,02 & 0,02 & 0,40 & 0,02 & 80 & 0,01 \\
\hline 93 & 12 & 4 & CFB & CSCE & 0,79 & 49,53 & 0,00 & 0,14 & 0,04 & 78 & 0,03 \\
\hline 93 & 12 & 4 & CFB & BMF & 0,79 & 44,30 & 0,00 & 0,23 & 0,03 & 80 & 0,04 \\
\hline 93 & 12 & 4 & CFC & CSCE & 0,76 & 39,78 & 0,00 & 0,19 & 0,03 & 78 & 0,13 \\
\hline 93 & 12 & 4 & CFC & BMF & 0,77 & 33,06 & 0,00 & 0,30 & 0,02 & 80 & 0,14 \\
\hline 93 & 12 & 4 & CFD & CSCE & 0,66 & 63,31 & 0,00 & 0,14 & 0,20 & 78 & 0,44 \\
\hline 93 & 12 & 4 & CFD & BMF & 0,65 & 50,98 & 0,00 & 0,31 & 0,06 & 80 & 0,39 \\
\hline 93 & 12 & 4 & CFE & CSCE & 0,88 & 52,55 & 0,00 & 0,16 & 0,02 & 78 & 0,60 \\
\hline 93 & 12 & 4 & CFE & BMF & 0,88 & 44,50 & 0,00 & 0,28 & 0,01 & 80 & 0,87 \\
\hline 93 & 12 & 6 & CFA & CSCE & 0,87 & 52,46 & 0,00 & 0,13 & 0,11 & 120 & 0,00 \\
\hline 93 & 12 & 6 & CFA & BMF & 0,88 & 6,45 & 0,23 & 0,71 & 0,00 & 120 & 0,01 \\
\hline 93 & 12 & 6 & CFB & CSCE & 0,95 & 54,70 & 0,00 & 0,08 & 0,13 & 120 & 0,14 \\
\hline 93 & 12 & 6 & CFB & BMF & 0,95 & 45,99 & 0,00 & 0,19 & 0,01 & 120 & 0,47 \\
\hline 93 & 12 & 6 & CFC & CSCE & 0,96 & 49,25 & 0,00 & 0,09 & 0,20 & 120 & 0,36 \\
\hline 93 & 12 & 6 & CFC & BMF & 0,96 & 42,47 & 0,00 & 0,18 & 0,08 & 120 & 0,33 \\
\hline 93 & 12 & 6 & CFD & CSCE & 0,94 & 62,58 & 0,00 & 0,13 & 0,10 & 120 & 0,45 \\
\hline 93 & 12 & 6 & CFD & $\mathrm{BMF}$ & 0,94 & 51,43 & 0,00 & 0,28 & 0,01 & 120 & 0,54 \\
\hline 93 & 12 & 6 & CFE & CSCE & 0,94 & 53,93 & 0,00 & 0,13 & 0,03 & 120 & 0,98 \\
\hline
\end{tabular}


Tabela 14 - Resultados das regressões utilizadas neste estudo (cont.)

\begin{tabular}{|c|c|c|c|c|c|c|c|c|c|c|c|}
\hline Ano & Mês & Periodo & $\bar{Y}$ & $\bar{x}$ & $\mathbf{R 2}$ & $\mathbf{a}$ & ta & $b$ & tb & $\mathbf{N}$ & Teste Q \\
\hline 93 & 12 & 6 & CFE & BMF & 0,94 & 48,01 & 0,00 & 0,22 & 0,01 & 120 & 0,99 \\
\hline 94 & 3 & 4 & CFA & CSCE & 0,50 & 66,02 & 0,00 & 0,02 & 0,88 & 73 & 0,54 \\
\hline 94 & 3 & 4 & CFA & BMF & 0,53 & 67,99 & 0,00 & 0,00 & 0,98 & 76 & 0,19 \\
\hline 94 & 3 & 4 & CFB & CSCE & 0,53 & 56,36 & 0,00 & 0,09 & 0,39 & 73 & 0,17 \\
\hline 94 & 3 & 4 & CFB & BMF & 0,58 & 51,74 & 0,00 & 0,15 & 0,36 & 76 & 0,07 \\
\hline 94 & 3 & 4 & CFC & CSCE & 0,28 & 49,01 & 0,00 & 0,11 & 0,14 & 73 & 0,95 \\
\hline 94 & 3 & 4 & CFC & BMF & 0,23 & 43,45 & 0,00 & 0,19 & 0,11 & 76 & 0,44 \\
\hline 94 & 3 & 4 & CFD & CSCE & 0,59 & 80,22 & 0,00 & $-0,01$ & 0,90 & 73 & 0,91 \\
\hline 94 & 3 & 4 & CFD & BMF & 0,60 & 75,39 & 0,00 & 0,04 & 0,81 & 76 & 0,99 \\
\hline 94 & 3 & 4 & CFE & CSCE & 0,70 & 67,67 & 0,00 & 0,01 & 0,89 & 73 & 0,64 \\
\hline 94 & 3 & 4 & CFE & BMF & 0,70 & 59,63 & 0,00 & 0,11 & 0,51 & 76 & 0,59 \\
\hline 94 & 3 & 6 & CFA & CSCE & 0,47 & 61,65 & 0,00 & 0,06 & 0,53 & 112 & 0,00 \\
\hline 94 & 3 & 6 & CFA & $\mathrm{BMF}$ & 0,49 & 50,77 & 0,00 & 0,19 & 0,22 & 115 & 0,00 \\
\hline 94 & 3 & 6 & CFB & CSCE & 0,68 & 55,52 & 0,00 & 0,09 & 0,22 & 112 & 0,95 \\
\hline 94 & 3 & 6 & CFB & BMF & 0,70 & 50,25 & 0,00 & 0,16 & 0,17 & 115 & 0,77 \\
\hline 94 & 3 & 6 & CFC & CSCE & 0,68 & 45,77 & 0,00 & 0,13 & 0,06 & 112 & 0,90 \\
\hline 94 & 3 & 6 & CFC & BMF & 0,65 & 39,68 & 0,00 & 0,23 & 0,07 & 115 & 0,66 \\
\hline 94 & 3 & 6 & CFD & CSCE & 0,66 & 73,36 & 0,00 & 0,05 & 0,59 & 112 & 0,38 \\
\hline 94 & 3 & 6 & CFD & BMF & 0,67 & 60,43 & 0,00 & 0,20 & 0,18 & 115 & 0,34 \\
\hline 94 & 3 & 6 & CFE & CSCE & 0,80 & 60,84 & 0,00 & 0,07 & 0,24 & 112 & 0,38 \\
\hline 94 & 3 & 6 & CFE & BMF & 0,80 & 52,97 & 0,00 & 0,17 & 0,10 & 115 & 0,27 \\
\hline 94 & 5 & 4 & CFA & CSCE & 0,95 & 342,70 & 0,04 & $-0,08$ & 0,55 & 74 & 0,91 \\
\hline 94 & 5 & 4 & CFA & BMF & 0,95 & 130,80 & 0,00 & $-0,01$ & 0,94 & 76 & 0,40 \\
\hline 94 & 5 & 4 & CFB & CSCE & 0,93 & 109,25 & 0,00 & $-0,04$ & 0,78 & 74 & 0,47 \\
\hline 94 & 5 & 4 & CFB & BMF & 0,93 & 77,21 & 0,00 & 0,09 & 0,67 & 76 & 0,35 \\
\hline 94 & 5 & 4 & CFC & CSCE & 0,94 & 62,21 & 0,00 & 0,10 & 0,53 & 74 & 0,95 \\
\hline 94 & 5 & 4 & CFC & BMF & 0,93 & 38,37 & 0,08 & 0,33 & 0,13 & 76 & 0,83 \\
\hline 94 & 5 & 4 & CFD & CSCE & 0,96 & 2939,00 & 0,08 & 0,10 & 0,42 & 74 & 0,52 \\
\hline 94 & 5 & 4 & CFD & BMF & 0,96 & 2646,00 & 0,13 & 0,25 & 0,17 & 76 & 0,59 \\
\hline 94 & 5 & 4 & CFE & CSCE & 0,97 & 3168,00 & 0,04 & $-0,02$ & 0,80 & 74 & 0,76 \\
\hline 94 & 5 & 4 & CFE & BMF & 0,97 & 3022,00 & 0,05 & 0,04 & 0,82 & 76 & 0,81 \\
\hline 94 & 5 & 6 & CFA & CSCE & 0,94 & 160,90 & 0,03 & $-0,02$ & 0,81 & 113 & 0,80 \\
\hline 94 & 5 & 6 & CFA & BMF & 0,94 & 91,43 & 0,00 & 0,06 & 0,72 & 117 & 0,17 \\
\hline 94 & 5 & 6 & CFB & CSCE & 0,93 & 73,93 & 0,00 & 0,10 & 0,37 & 113 & 0,15 \\
\hline 94 & 5 & 6 & CFB & BMF & 0,93 & 64,64 & 0,00 & 0,24 & 0,13 & 117 & 0,15 \\
\hline 94 & 5 & 6 & CFC & CSCE & 0,93 & 52,08 & 0,00 & 0,16 & 0,13 & 113 & 0,93 \\
\hline 94 & 5 & 6 & CFC & BMF & 0,93 & 36,53 & 0,02 & 0,33 & 0,03 & 117 & 0,66 \\
\hline 94 & 5 & 6 & CFD & CSCE & 0,95 & 1817,70 & 0,19 & 0,06 & 0,51 & 113 & 0,78 \\
\hline 94 & 5 & 6 & CFD & $\mathrm{BMF}$ & 0,94 & 1665,51 & 0,24 & 0,20 & 0,14 & 117 & 0,87 \\
\hline 94 & 5 & 6 & CFE & CSCE & 0,97 & 1860,90 & 0,12 & 0,01 & 0,86 & 113 & 0,52 \\
\hline 94 & 5 & 6 & CFE & $\mathrm{BMF}$ & 0,97 & 1740,51 & 0,16 & 0,13 & 0,28 & 117 & 0,47 \\
\hline 94 & 7 & 4 & CFA & CSCE & 0,98 & 216,65 & 0,04 & 0,36 & 0,00 & 78 & 0,66 \\
\hline 94 & 7 & 4 & CFA & BMF & 0,98 & 98,31 & 0,01 & 0,49 & 0,00 & 80 & 0,28 \\
\hline 94 & 7 & 4 & CFB & CSCE & 0,98 & 6267,50 & 0,09 & 0,33 & 0,00 & 78 & 0,42 \\
\hline 94 & 7 & 4 & CFB & $\mathrm{BMF}$ & 0,98 & 196,06 & 0,04 & 0,46 & 0,00 & 80 & 0,18 \\
\hline 94 & 7 & 4 & CFC & CSCE & 0,97 & 7074,00 & 0,08 & 0,23 & 0,00 & 78 & 0,23 \\
\hline
\end{tabular}


Tabela 14 - Resultados das regressões utilizadas neste estudo (cont.)

\begin{tabular}{|c|c|c|c|c|c|c|c|c|c|c|c|}
\hline Ano & Mês & Periodo & $\bar{Y}$ & $x$ & $\mathrm{R} 2$ & $a$ & ta & $b$ & tb & $N$ & Teste $Q$ \\
\hline 94 & 7 & 4 & CFC & $\mathrm{BMF}$ & 0,98 & 97,05 & 0,01 & 0,40 & 0,00 & 80 & 0,12 \\
\hline 94 & 7 & 4 & CFD & CSCE & 0,98 & 6862,00 & 0,16 & 0,49 & 0,00 & 78 & 0,04 \\
\hline 94 & 7 & 4 & CFD & BMF & 0,98 & 48,79 & 0,02 & 0,76 & 0,00 & 80 & 0,00 \\
\hline 94 & 7 & 4 & CFE & CSCE & 0,97 & 6785,00 & 0,13 & 0,37 & 0,00 & 78 & 0,01 \\
\hline 94 & 7 & 4 & CFE & BMF & 0,98 & 173,72 & 0,08 & 0,56 & 0,00 & 80 & 0,00 \\
\hline 94 & 7 & 6 & CFA & CSCE & 0,99 & 4336,45 & 0,10 & 0,36 & 0,00 & 113 & 0,64 \\
\hline 94 & 7 & 6 & CFA & BMF & 0,99 & 4069,00 & 0,10 & 0,49 & 0,00 & 116 & 0,20 \\
\hline 94 & 7 & 6 & CFB & CSCE & 0,98 & 4378,00 & 0,10 & 0,33 & 0,00 & 113 & 0,30 \\
\hline 94 & 7 & 6 & CFB & BMF & 0,99 & 4085,00 & 0,09 & 0,46 & 2,70 & 116 & 0,07 \\
\hline 94 & 7 & 6 & CFC & CSCE & 0,98 & 4685,00 & 0,10 & 0,24 & 0,00 & 113 & 0,10 \\
\hline 94 & 7 & 6 & CFC & BMF & 0,98 & 3820,00 & 0,13 & 0,40 & 0,00 & 116 & 0,06 \\
\hline 94 & 7 & 6 & CFD & CSCE & 0,98 & 4648,00 & 0,17 & 0,48 & 0,00 & 113 & 0,00 \\
\hline 94 & 7 & 6 & CFD & BMF & 0,99 & 3641,00 & 0,19 & 0,73 & 0,00 & 116 & 0,00 \\
\hline 94 & 7 & 6 & CFE & CSCE & 0,98 & 4997,00 & 0,11 & 0,37 & 0,00 & 113 & 0,00 \\
\hline 94 & 7 & 6 & CFE & BMF & 0,99 & 4210,00 & 0,11 & 0,55 & 0,00 & 116 & 0,00 \\
\hline 94 & 9 & 4 & CFA & CSCE & 0,98 & 45,32 & 0,00 & 0,49 & 0,00 & 77 & 0,66 \\
\hline 94 & 9 & 4 & CFA & BMF & 0,97 & 34,39 & 0,01 & 0,67 & 0,00 & 79 & 0,72 \\
\hline 94 & 9 & 4 & CFB & CSCE & 0,97 & 40,00 & 0,00 & 0,49 & 0,00 & 77 & 0,93 \\
\hline 94 & 9 & 4 & CFB & BMF & 0,97 & 29,26 & 0,02 & 0,67 & 0,00 & 79 & 0,83 \\
\hline 94 & 9 & 4 & CFC & CSCE & 0,94 & 40,57 & 0,00 & 0,41 & 0,00 & 77 & 0,18 \\
\hline 94 & 9 & 4 & CFC & BMF & 0,93 & 34,54 & 0,01 & 0,54 & 0,00 & 79 & 0,64 \\
\hline 94 & 9 & 4 & CFD & CSCE & 0,98 & 40,60 & 0,00 & 0,63 & 0,00 & 77 & 0,38 \\
\hline 94 & 9 & 4 & CFD & $\mathrm{BMF}$ & 0,97 & 23,73 & 0,10 & 0,89 & 0,00 & 79 & 0,17 \\
\hline 94 & 9 & 4 & CFE & CSCE & 0,97 & 45,97 & 0,00 & 0,50 & 0,00 & 77 & 0,04 \\
\hline 94 & 9 & 4 & CFE & BMF & 0,96 & 40,04 & 0,02 & 0,66 & 0,00 & 79 & 0,48 \\
\hline 94 & 9 & 6 & CFA & CSCE & 0,99 & 38,91 & 0,00 & 0,50 & 0,00 & 117 & 0,09 \\
\hline 94 & 9 & 6 & CFA & BMF & 0,99 & 21,45 & 0,02 & 0,73 & 0,00 & 120 & 0,10 \\
\hline 94 & 9 & 6 & CFB & CSCE & 0,99 & 30,68 & 0,00 & 0,51 & 0,00 & 117 & 0,71 \\
\hline 94 & 9 & 6 & CFB & BMF & 0,99 & 17,19 & 0,04 & 0,73 & 0,00 & 120 & 0,29 \\
\hline 94 & 9 & 6 & CFC & CSCE & 0,97 & 27,63 & 0,00 & 0,45 & 0,00 & 117 & 0,03 \\
\hline 94 & 9 & 6 & CFC & BMF & 0,97 & 20,88 & 0,02 & 0,61 & 0,00 & 120 & 0,51 \\
\hline 94 & 9 & 6 & CFD & CSCE & 0,99 & 56,52 & 0,00 & 0,55 & 0,00 & 117 & 0,00 \\
\hline 94 & 9 & 6 & CFD & BMF & 0,99 & 10,07 & 0,31 & 0,95 & 0,00 & 120 & 0,00 \\
\hline 94 & 9 & 6 & CFE & CSCE & 0,99 & 40,38 & 0,00 & 0,51 & 0,00 & 117 & 0,00 \\
\hline 94 & 9 & 6 & CFE & BMF & 0,98 & 26,12 & 0,03 & 0,72 & 0,00 & 120 & 0,02 \\
\hline 94 & 12 & 4 & CFA & CSCE & 0,87 & 52,10 & 0,01 & 0,44 & 0,00 & 66 & 0,73 \\
\hline 94 & 12 & 4 & CFA & BMF & 0,86 & 46,75 & 0,05 & 0,55 & 0,00 & 69 & 0,60 \\
\hline 94 & 12 & 4 & CFB & CSCE & 0,89 & 41,57 & 0,02 & 0,46 & 0,00 & 66 & 0,76 \\
\hline 94 & 12 & 4 & CFB & BMF & 0,89 & 34,60 & 0,12 & 0,58 & 0,00 & 69 & 0,85 \\
\hline 94 & 12 & 4 & CFC & CSCE & 0,66 & 44,58 & 0,07 & 0,42 & 0,00 & 66 & 0,89 \\
\hline 94 & 12 & 4 & CFC & BMF & 0,69 & 23,47 & 0,36 & 0,61 & 0,00 & 69 & 0,66 \\
\hline 94 & 12 & 4 & CFD & CSCE & 0,88 & 51,19 & 0,00 & 0,60 & 0,00 & 66 & 0,79 \\
\hline 94 & 12 & 4 & CFD & BMF & 0,88 & 44,34 & 0,03 & 0,75 & 0,00 & 69 & 0,37 \\
\hline 94 & 12 & 4 & CFE & CSCE & 0,76 & 60,13 & 0,00 & 0,45 & 0,00 & 66 & 0,67 \\
\hline 94 & 12 & 4 & CFE & BMF & 0,74 & 46,74 & 0,00 & 0,60 & 0,00 & 69 & 0,73 \\
\hline
\end{tabular}


Tabela 14 - Resultados das regressões utilizadas neste estudo (cont.)

\begin{tabular}{|c|c|c|c|c|c|c|c|c|c|c|c|}
\hline Ano & Mês & Periodo & $\bar{Y}$ & $x$ & R2 & $a$ & ta & b & tb & $\mathrm{N}$ & Teste Q \\
\hline 94 & 12 & 6 & CFA & CSCE & 0,90 & 56,25 & 0,00 & 0,43 & 0,00 & 101 & 0,56 \\
\hline 94 & 12 & 6 & CFA & BMF & 0,89 & 59,50 & 0,01 & 0,51 & 0,00 & 105 & 0,50 \\
\hline 94 & 12 & 6 & CFB & CSCE & 0,91 & 48,35 & 0,00 & 0,44 & 0,00 & 101 & 0,74 \\
\hline 94 & 12 & 6 & CFB & BMF & 0,89 & 51,69 & 0,02 & 0,52 & 0,00 & 105 & 0,77 \\
\hline 94 & 12 & 6 & CFC & CSCE & 0,81 & 54,40 & 0,00 & 0,38 & 0,00 & 101 & 0,96 \\
\hline 94 & 12 & 6 & CFC & BMF & 0,80 & 51,27 & 0,01 & 0,48 & 0,00 & 105 & 0,87 \\
\hline 94 & 12 & 6 & CFD & CSCE & 0,93 & 61,70 & 0,00 & 0,56 & 0,00 & 101 & 0,56 \\
\hline 94 & 12 & 6 & CFD & BMF & 0,92 & 70,99 & 0,00 & 0,63 & 0,00 & 105 & 0,47 \\
\hline 94 & 12 & 6 & CFE & CSCE & 0,86 & 67,63 & 0,00 & 0,42 & 0,00 & 101 & 0,81 \\
\hline 94 & 12 & 6 & CFE & BMF & 0,85 & 78,27 & 0,00 & 0,46 & 0,00 & 105 & 0,73 \\
\hline 95 & 3 & 4 & CFA & CSCE & 0,78 & 39,42 & 0,20 & 0,48 & 0,00 & 53 & 0,55 \\
\hline 95 & 3 & 4 & CFA & BMF & 0,76 & 34,78 & 0,25 & 0,59 & 0,00 & 58 & 0,41 \\
\hline 95 & 3 & 4 & CFB & CSCE & 0,77 & 30,52 & 0,33 & 0,49 & 0,00 & 53 & 0,36 \\
\hline 95 & 3 & 4 & CFB & BMF & 0,75 & 26,81 & 0,39 & 0,60 & 0,00 & 58 & 0,34 \\
\hline 95 & 3 & 4 & CFC & CSCE & 0,90 & 55,54 & 0,05 & 0,39 & 0,00 & 53 & 0,74 \\
\hline 95 & 3 & 4 & CFC & $\mathrm{BMF}$ & 0,89 & 45,80 & 0,10 & 0,52 & 0,00 & 58 & 0,68 \\
\hline 95 & 3 & 4 & CFD & CSCE & 0,92 & 65,84 & 0,00 & 0,47 & 0,00 & 53 & 0,19 \\
\hline 95 & 3 & 4 & CFD & BMF & 0,90 & 67,71 & 0,01 & 0,55 & 0,00 & 58 & 0,95 \\
\hline 95 & 3 & 4 & CFE & CSCE & 0,85 & 40,17 & 0,15 & 0,51 & 0,00 & 53 & 0,19 \\
\hline 95 & 3 & 4 & CFE & BMF & 0,85 & 25,80 & 0,33 & 0,68 & 0,00 & 58 & 0,49 \\
\hline 95 & 3 & 6 & CFA & CSCE & 0,93 & 63,72 & 0,00 & 0,37 & 0,00 & 87 & 0,32 \\
\hline 95 & 3 & 6 & CFA & $\mathrm{BMF}$ & 0,92 & 37,67 & 0,01 & 0,57 & 0,00 & 93 & 0,08 \\
\hline 95 & 3 & 6 & CFB & CSCE & 0,94 & 47,94 & 0,00 & 0,41 & 0,00 & 87 & 0,44 \\
\hline 95 & 3 & 6 & CFB & BMF & 0,93 & 28,83 & 0,03 & 0,59 & 0,00 & 93 & 0,53 \\
\hline 95 & 3 & 6 & CFC & CSCE & 0,81 & 44,76 & 0,03 & 0,43 & 0,00 & 87 & 0,12 \\
\hline 95 & 3 & 6 & CFC & BMF & 0,82 & 35,70 & 0,06 & 0,57 & 0,00 & 93 & 0,44 \\
\hline 95 & 3 & 6 & CFD & CSCE & 0,97 & 119,91 & 0,00 & 0,24 & 0,00 & 87 & 0,94 \\
\hline 95 & 3 & 6 & CFD & BMF & 0,96 & 118,12 & 0,00 & 0,30 & 0,01 & 93 & 0,43 \\
\hline 95 & 3 & 6 & CFE & CSCE & 0,88 & 49,82 & 0,00 & 0,47 & 0,00 & 87 & 0,75 \\
\hline 95 & 3 & 6 & CFE & BMF & 0,89 & 28,14 & 0,01 & 0,67 & 0,00 & 93 & 0,68 \\
\hline 95 & 5 & 4 & CFA & CSCE & 0,75 & 82,55 & 0,00 & 0,32 & 0,01 & 61 & 0,97 \\
\hline 95 & 5 & 4 & CFA & BMF & 0,75 & 65,77 & 0,04 & 0,47 & 0,01 & 63 & 0,97 \\
\hline 95 & 5 & 4 & CFB & CSCE & 0,73 & 79,58 & 0,00 & 0,31 & 0,01 & 61 & 0,91 \\
\hline 95 & 5 & 4 & CFB & BMF & 0,74 & 66,29 & 0,05 & 0,43 & 0,01 & 63 & 0,96 \\
\hline 95 & 5 & 4 & CFC & CSCE & 0,67 & 110,09 & 0,00 & 0,18 & 0,10 & 61 & 0,97 \\
\hline 95 & 5 & 4 & CFC & BMF & 0,70 & 95,19 & 0,00 & 0,30 & 0,06 & 63 & 0,96 \\
\hline 95 & 5 & 4 & CFD & CSCE & 0,74 & 55,63 & 0,01 & 0,52 & 0,00 & 61 & 0,97 \\
\hline 95 & 5 & 4 & CFD & BMF & 0,73 & 26,35 & 0,33 & 0,78 & 0,00 & 63 & 0,85 \\
\hline 95 & 5 & 4 & CFE & CSCE & 0,68 & 71,13 & 0,00 & 0,39 & 0,00 & 61 & 0,87 \\
\hline 95 & 5 & 4 & CFE & BMF & 0,73 & 40,04 & 0,04 & 0,62 & 0,00 & 63 & 0,83 \\
\hline 95 & 5 & 6 & CFA & CSCE & 0,87 & 52,91 & 0,03 & 0,43 & 0,00 & 91 & 0,78 \\
\hline 95 & 5 & 6 & CFA & BMF & 0,87 & 44,78 & 0,10 & 0,56 & 0,00 & 96 & 0,77 \\
\hline 95 & 5 & 6 & CFB & CSCE & 0,87 & 41,96 & 0,10 & 0,45 & 0,00 & 91 & 0,53 \\
\hline 95 & 5 & 6 & CFB & BMF & 0,86 & 37,97 & 0,17 & 0,56 & 0,00 & 96 & 0,65 \\
\hline 95 & 5 & 6 & CFC & CSCE & 0,90 & 63,98 & 0,01 & 0,36 & 0,00 & 91 & 0,85 \\
\hline 95 & 5 & 6 & CFC & BMF & 0,90 & 56,16 & 0,02 & 0,48 & 0,00 & 96 & 0,84 \\
\hline
\end{tabular}


Tabela 14 - Resultados das regressões utilizadas neste estudo (cont.)

\begin{tabular}{|c|c|c|c|c|c|c|c|c|c|c|c|}
\hline Ano & Mês & Periodo & $\mathrm{Y}$ & $\bar{x}$ & $R 2$ & $a$ & ta & b & tb & $\mathbf{N}$ & Teste Q \\
\hline 95 & 5 & 6 & CFD & CSCE & 0,87 & 57,48 & 0,01 & 0,51 & 0,00 & 91 & 0,76 \\
\hline 95 & 5 & 6 & CFD & BMF & 0,86 & 33,08 & 0,09 & 0,74 & 0,00 & 96 & 0,92 \\
\hline 95 & 5 & 6 & CFE & CSCE & 0,87 & 38,89 & 0,07 & 0,51 & 0,00 & 91 & 0,43 \\
\hline 95 & 5 & 6 & CFE & BMF & 0,88 & 20,02 & 0,34 & 0,72 & 0,00 & 96 & 0,75 \\
\hline 95 & 7 & 4 & CFA & CSCE & 0,80 & 95,46 & 0,00 & 0,27 & 0,00 & 78 & 0,13 \\
\hline 95 & 7 & 4 & CFA & BMF & 0,81 & 76,62 & 0,00 & 0,43 & 0,00 & 80 & 0,06 \\
\hline 95 & 7 & 4 & CFB & CSCE & 0,84 & 76,74 & 0,00 & 0,33 & 0,00 & 78 & 0,55 \\
\hline 95 & 7 & 4 & CFB & $\mathrm{BMF}$ & 0,86 & 62,26 & 0,00 & 0,47 & 0,00 & 80 & 0,67 \\
\hline 95 & 7 & 4 & CFC & CSCE & 0,94 & 87,14 & 0,00 & 0,16 & 0,05 & 78 & 0,72 \\
\hline 95 & 7 & 4 & CFC & BMF & 0,94 & 85,77 & 0,00 & 0,26 & 0,03 & 80 & 0,58 \\
\hline 95 & 7 & 4 & CFD & CSCE & 0,91 & 55,74 & 0,00 & 0,51 & 0,00 & 78 & 0,26 \\
\hline 95 & 7 & 4 & CFD & BMF & 0,92 & 42,47 & 0,00 & 0,69 & 0,00 & 80 & 0,23 \\
\hline 95 & 7 & 4 & CFE & CSCE & 0,83 & 104,82 & 0,00 & 0,23 & 0,00 & 78 & 0,23 \\
\hline 95 & 7 & 4 & CFE & BMF & 0,85 & 93,39 & 0,00 & 0,34 & 0,00 & 80 & 0,35 \\
\hline 95 & 7 & 6 & CFA & CSCE & 0,79 & 103,93 & 0,00 & 0,22 & 0,00 & 102 & 0,15 \\
\hline 95 & 7 & 6 & CFA & BMF & 0,79 & 94,37 & 0,00 & 0,32 & 0,00 & 106 & 0,03 \\
\hline 95 & 7 & 6 & CFB & CSCE & 0,82 & 89,29 & 0,00 & 0,26 & 0,00 & 102 & 0,46 \\
\hline 95 & 7 & 6 & CFB & BMF & 0,82 & 80,10 & 0,00 & 0,36 & 0,00 & 106 & 0,36 \\
\hline 95 & 7 & 6 & CFC & CSCE & 0,92 & 98,20 & 0,00 & 0,21 & 0,01 & 102 & 0,97 \\
\hline 95 & 7 & 6 & CFC & BMF & 0,92 & 78,29 & 0,00 & 0,36 & 0,00 & 106 & 0,78 \\
\hline 95 & 7 & 6 & CFD & CSCE & 0,90 & 56,77 & 0,00 & 0,51 & 0,00 & 102 & 0,45 \\
\hline 95 & 7 & 6 & CFD & BMF & 0,91 & 39,02 & 0,00 & 0,71 & 0,00 & 106 & 0,28 \\
\hline 95 & 7 & 6 & CFE & CSCE & 0,79 & 92,90 & 0,00 & 0,29 & 0,00 & 102 & 0,82 \\
\hline 95 & 7 & 6 & CFE & $\mathrm{BMF}$ & 0,81 & 81,65 & 0,00 & 0,41 & 0,00 & 106 & 0,85 \\
\hline 95 & 9 & 4 & CFA & CSCE & 0,89 & 136,15 & 0,00 & 0,03 & 0,72 & 81 & 0,28 \\
\hline 95 & 9 & 4 & CFA & BMF & 0,89 & 128,38 & 0,00 & 0,08 & 0,44 & 86 & 0,07 \\
\hline 95 & 9 & 4 & CFB & CSCE & 0,90 & 126,49 & 0,00 & 0,06 & 0,39 & 81 & 0,69 \\
\hline 95 & 9 & 4 & CFB & BMF & 0,90 & 118,29 & 0,00 & 0,12 & 0,17 & 86 & 0,36 \\
\hline 95 & 9 & 4 & CFC & CSCE & 0,97 & 98,21 & 0,00 & 0,13 & 0,02 & 81 & 0,41 \\
\hline 95 & 9 & 4 & CFC & BMF & 0,97 & 8,25 & 0,00 & 0,22 & 0,00 & 86 & 0,09 \\
\hline 95 & 9 & 4 & CFD & CSCE & 0,96 & 109,62 & 0,00 & 0,21 & 0,00 & 81 & 0,28 \\
\hline 95 & 9 & 4 & CFD & BMF & 0,96 & 101,81 & 0,00 & 0,30 & 0,00 & 86 & 0,26 \\
\hline 95 & 9 & 4 & CFE & CSCE & 0,94 & 104,66 & 0,00 & 0,21 & 0,00 & 81 & 0,43 \\
\hline 95 & 9 & 4 & CFE & BMF & 0,95 & 95,24 & 0,00 & 0,31 & 0,00 & 86 & 0,68 \\
\hline 95 & 9 & 6 & CFA & CSCE & 0,89 & 133,32 & 0,00 & 0,06 & 0,38 & 119 & 0,12 \\
\hline 95 & 9 & 6 & CFA & BMF & 0,90 & 57,97 & 0,00 & 0,52 & 0,00 & 124 & 0,01 \\
\hline 95 & 9 & 6 & CFB & CSCE & 0,89 & 119,90 & 0,00 & 0,11 & 0,09 & 119 & 0,96 \\
\hline 95 & 9 & 6 & CFB & BMF & 0,89 & 67,33 & 0,00 & 0,44 & 0,00 & 124 & 0,64 \\
\hline 95 & 9 & 6 & CFC & CSCE & 0,96 & 100,97 & 0,00 & 0,14 & 0,02 & 119 & 0,92 \\
\hline 95 & 9 & 6 & CFC & BMF & 0,97 & 97,65 & 0,00 & 0,19 & 0,02 & 124 & 0,88 \\
\hline 95 & 9 & 6 & CFD & CSCE & 0,95 & 108,08 & 0,00 & 0,24 & 0,00 & 119 & 0,09 \\
\hline 95 & 9 & 6 & CFD & BMF & 0,96 & 23,71 & 0,00 & 0,78 & 0,00 & 124 & 0,19 \\
\hline 95 & 9 & 6 & CFE & CSCE & 0,93 & 97,43 & 0,00 & 0,26 & 0,00 & 119 & 0,16 \\
\hline 95 & 9 & 6 & CFE & BMF & 0,94 & 82,83 & 0,00 & 0,39 & 0,00 & 124 & 0,32 \\
\hline 95 & 12 & 4 & CFA & CSCE & 0,96 & 65,74 & 0,00 & 0,38 & 0,00 & 80 & 0,57 \\
\hline 95 & 12 & 4 & CFA & BMF & 0,96 & 51,60 & 0,00 & 0,53 & 0,00 & 83 & 0,68 \\
\hline
\end{tabular}


Tabela 14 - Resultados das regressões utilizadas neste estudo (cont.)

\begin{tabular}{|c|c|c|c|c|c|c|c|c|c|c|c|}
\hline Ano & Mês & Periodo & $Y$ & $\bar{x}$ & $\mathbf{R 2}$ & a & ta & b & tb & $\mathrm{N}$ & Teste $\mathbf{Q}$ \\
\hline 95 & 12 & 4 & CFB & CSCE & 0,95 & 69,78 & 0,00 & 0,34 & 0,00 & 80 & 0,06 \\
\hline 95 & 12 & 4 & CFB & BMF & 0,95 & 44,90 & 0,00 & 0,55 & 0,00 & 83 & 0,07 \\
\hline 95 & 12 & 4 & CFC & CSCE & 0,88 & 84,94 & 0,00 & 0,22 & 0,00 & 80 & 0,32 \\
\hline 95 & 12 & 4 & CFC & BMF & 0,85 & 69,90 & 0,00 & 0,35 & 0,00 & 83 & 0,66 \\
\hline 95 & 12 & 4 & CFD & CSCE & 0,97 & 76,13 & 0,00 & 0,35 & 0,00 & 80 & 0,28 \\
\hline 95 & 12 & 4 & CFD & BMF & 0,96 & 67,60 & 0,00 & 0,46 & 0,00 & 83 & 0,28 \\
\hline 95 & 12 & 4 & CFE & CSCE & 0,97 & 104,92 & 0,00 & 0,15 & 0,00 & 80 & 0,66 \\
\hline 95 & 12 & 4 & CFE & BMF & 0,96 & 101,89 & 0,00 & 0,19 & 0,00 & 83 & 0,65 \\
\hline 95 & 12 & 6 & CFA & CSCE & 0,93 & 95,92 & 0,00 & 0,21 & 0,00 & 120 & 0,86 \\
\hline 95 & 12 & 6 & CFA & BMF & 0,93 & 90,90 & 0,00 & 0,27 & 0,00 & 125 & 0,38 \\
\hline 95 & 12 & 6 & CFB & CSCE & 0,93 & 101,38 & 0,00 & 0,15 & 0,00 & 120 & 0,57 \\
\hline 95 & 12 & 6 & CFB & BMF & 0,93 & 95,62 & 0,00 & 0,21 & 0,00 & 125 & 0,01 \\
\hline 95 & 12 & 6 & $\mathrm{CFC}$ & CSCE & 0,89 & 94,98 & 0,00 & 0,15 & 0,00 & 120 & 0,74 \\
\hline 95 & 12 & 6 & $\mathrm{CFC}$ & $\mathrm{BMF}$ & 0,89 & 90,42 & 0,00 & 0,20 & 0,01 & 125 & 0,53 \\
\hline 95 & 12 & 6 & CFD & CSCE & 0,96 & 90,30 & 0,00 & 0,28 & 0,00 & 120 & 0,99 \\
\hline 95 & 12 & 6 & CFD & BMF & 0,96 & 80,97 & 0,00 & 0,38 & 0,00 & 125 & 0,99 \\
\hline 95 & 12 & 6 & CFE & CSCE & 0,97 & 103,45 & 0,00 & 0,17 & 0,00 & 120 & 0,83 \\
\hline 95 & 12 & 6 & CFE & BMF & 0,97 & 99,41 & 0,00 & 0,23 & 0,00 & 125 & 0,93 \\
\hline 96 & 3 & 4 & CFA & CSCE & 0,97 & 104,11 & 0,00 & 0,26 & 0,00 & 67 & 0,30 \\
\hline 96 & 3 & 4 & CFA & BMF & 0,97 & 85,30 & 0,00 & 0,33 & 0,00 & 71 & 0,67 \\
\hline 96 & 3 & 4 & CFB & CSCE & 0,97 & 129,24 & 0,01 & 0,26 & 0,00 & 67 & 0,75 \\
\hline 96 & 3 & 4 & CFB & BMF & 0,97 & 95,66 & 0,00 & 0,28 & 0,00 & 71 & 0,63 \\
\hline 96 & 3 & 4 & CFC & CSCE & 0,95 & 121,52 & 0,00 & 0,20 & 0,07 & 67 & 0,18 \\
\hline 96 & 3 & 4 & CFC & BMF & 0,93 & 81,96 & 0,00 & 0,32 & 0,03 & 71 & 0,00 \\
\hline 96 & 3 & 4 & CFD & CSCE & 0,98 & 3192,30 & 0,15 & 0,28 & 0,00 & 67 & 0,69 \\
\hline 96 & 3 & 4 & CFD & BMF & 0,98 & 2646,03 & 0,23 & 0,32 & 0,00 & 71 & 0,98 \\
\hline 96 & 3 & 4 & CFE & CSCE & 0,98 & 2456,67 & 0,24 & 0,15 & 0,02 & 67 & 0,67 \\
\hline 96 & 3 & 4 & CFE & BMF & 0,98 & 2062,26 & 0,28 & 0,24 & 0,00 & 71 & 0,33 \\
\hline 96 & 3 & 6 & CFA & CSCE & 0,96 & 88,05 & 0,00 & 0,30 & 0,00 & 106 & 0,09 \\
\hline 96 & 3 & 6 & CFA & BMF & 0,96 & 75,67 & 0,00 & 0,36 & 0,00 & 112 & 0,69 \\
\hline 96 & 3 & 6 & CFB & CSCE & 0,96 & 99,48 & 0,00 & 0,26 & 0,00 & 106 & 0,75 \\
\hline 96 & 3 & 6 & $\mathrm{CFB}$ & $\mathrm{BMF}$ & 0,95 & 86,37 & 0,00 & 0,28 & 0,00 & 112 & 0,60 \\
\hline 96 & 3 & 6 & CFC & CSCE & 0,94 & 103,78 & 0,00 & 0,21 & 0,00 & 106 & 0,03 \\
\hline 96 & 3 & 6 & CFC & $\mathrm{BMF}$ & 0,92 & 84,91 & 0,00 & 0,28 & 0,01 & 112 & 0,00 \\
\hline 96 & 3 & 6 & CFD & CSCE & 0,98 & 1896,58 & 0,28 & 0,33 & 0,00 & 106 & 0,89 \\
\hline 96 & 3 & 6 & CFD & BMF & 0,97 & 97,54 & 0,00 & 0,36 & 0,00 & 112 & 0,96 \\
\hline 96 & 3 & 6 & CFE & CSCE & 0,97 & 145,59 & 0,02 & 0,15 & 0,00 & 106 & 0,78 \\
\hline 96 & 3 & 6 & CFE & BMF & 0,97 & 108,45 & 0,00 & 0,23 & 0,00 & 112 & 0,56 \\
\hline 96 & 5 & 4 & CFA & CSCE & 0,94 & 116,23 & 0,00 & 0,14 & 0,10 & 52 & 0,81 \\
\hline 96 & 5 & 4 & CFA & BMF & 0,95 & 97,34 & 0,00 & 0,26 & 0,02 & 53 & 0,98 \\
\hline 96 & 5 & 4 & CFB & CSCE & 0,93 & 107,90 & 0,00 & 0,17 & 0,07 & 52 & 0,89 \\
\hline 96 & 5 & 4 & CFB & $\mathrm{BMF}$ & 0,94 & 87,69 & 0,00 & 0,30 & 0,02 & 53 & 0,98 \\
\hline 96 & 5 & 4 & CFC & CSCE & 0,92 & 98,93 & 0,10 & 0,14 & 0,31 & 52 & 0,95 \\
\hline 96 & 5 & 4 & CFC & BMF & 0,93 & 82,99 & 0,12 & 0,24 & 0,17 & 53 & 0,92 \\
\hline 96 & 5 & 4 & CFD & CSCE & 0,94 & 124,97 & 0,00 & 0,16 & 0,15 & 52 & 0,98 \\
\hline 96 & 5 & 4 & CFD & BMF & 0,96 & 106,76 & 0,00 & 0,28 & 0,04 & 53 & 0,98 \\
\hline
\end{tabular}


Tabela 14 - Resultados das regressões utilizadas neste estudo (cont.)

\begin{tabular}{|c|c|c|c|c|c|c|c|c|c|c|c|}
\hline Ano & Mês & Periodo & $\bar{Y}$ & $x$ & R2 & $\mathbf{a}$ & ta & $b$ & tb & $N$ & Teste Q \\
\hline 96 & 5 & 4 & CFE & CSCE & 0,93 & 130,90 & 0,00 & 0,08 & 0,38 & 52 & 0,93 \\
\hline 96 & 5 & 4 & CFE & BMF & 0,94 & 117,38 & 0,00 & 0,17 & 0,16 & 53 & 0,88 \\
\hline 96 & 5 & 6 & CFA & CSCE & 0,96 & 104,12 & 0,00 & 0,17 & 0,01 & 87 & 0,38 \\
\hline 96 & 5 & 6 & CFA & BMF & 0,97 & 83,81 & 0,00 & 0,32 & 0,00 & 91 & 0,96 \\
\hline 96 & 5 & 6 & CFB & CSCE & 0,95 & 100,86 & 0,00 & 0,17 & 0,02 & 87 & 0,92 \\
\hline 96 & 5 & 6 & CFB & BMF & 0,96 & 85,72 & 0,00 & 0,28 & 0,01 & 91 & 0,70 \\
\hline 96 & 5 & 6 & CFC & CSCE & 0,93 & 95,88 & 0,00 & 0,12 & 0,23 & 87 & 0,68 \\
\hline 96 & 5 & 6 & CFC & BMF & 0,93 & 86,56 & 0,00 & 0,22 & 0,15 & 91 & 0,02 \\
\hline 96 & 5 & 6 & CFD & CSCE & 0,96 & 115,02 & 0,00 & 0,19 & 0,02 & 87 & 0,99 \\
\hline 96 & 5 & 6 & CFD & BMF & 0,97 & 101,67 & 0,00 & 0,28 & 0,01 & 91 & 0,99 \\
\hline 96 & 5 & 6 & CFE & CSCE & 0,95 & 120,23 & 0,00 & 0,10 & 0,11 & 87 & 0,98 \\
\hline 96 & 5 & 6 & CFE & $\mathrm{BMF}$ & 0,96 & 106,98 & 0,00 & 0,20 & 0,02 & 91 & 0,95 \\
\hline 96 & 7 & 4 & CFA & CSCE & 0,72 & $-4388,70$ & 0,34 & 0,04 & 0,79 & 46 & 0,93 \\
\hline 96 & 7 & 4 & CFA & $\mathrm{BMF}$ & 0,71 & $-4273,89$ & 0,36 & 0,06 & 0,82 & 47 & 0,78 \\
\hline 96 & 7 & 4 & CFB & CSCE & 0,64 & $-4292,22$ & 0,32 & 0,00 & 0,99 & 46 & 0,97 \\
\hline 96 & 7 & 4 & CFB & BMF & 0,63 & $-4246,43$ & 0,33 & 0,10 & 0,69 & 47 & 0,70 \\
\hline 96 & 7 & 4 & CFC & CSCE & 0,83 & 67,99 & 0,15 & 0,10 & 0,72 & 46 & 0,05 \\
\hline 96 & 7 & 4 & CFC & $\mathrm{BMF}$ & 0,81 & 78,54 & 0,22 & 0,06 & 0,89 & 47 & 0,01 \\
\hline 96 & 7 & 4 & CFD & CSCE & 0,62 & 138,32 & 0,00 & $-0,13$ & 0,42 & 46 & 0,29 \\
\hline 96 & 7 & 4 & CFD & BMF & 0,62 & 112,53 & 0,04 & 0,00 & 0,99 & 47 & 0,27 \\
\hline 96 & 7 & 4 & CFE & CSCE & 0,57 & $-3880,35$ & 0,37 & $-0,05$ & 0,75 & 46 & 0,63 \\
\hline 96 & 7 & 4 & CFE & $\mathrm{BMF}$ & 0,57 & $-3949,40$ & 0,36 & 0,06 & 0,80 & 47 & 0,42 \\
\hline 96 & 7 & 6 & CFA & CSCE & 0,88 & 91,16 & 0,11 & 0,17 & 0,11 & 79 & 0,97 \\
\hline 96 & 7 & 6 & CFA & BMF & 0,89 & 80,37 & 0,00 & 0,36 & 0,03 & 81 & 0,99 \\
\hline 96 & 7 & 6 & CFB & CSCE & 0,88 & $-1008,65$ & 0,76 & 0,17 & 0,12 & 79 & 0,99 \\
\hline 96 & 7 & 6 & CFB & BMF & 0,89 & 66,96 & 0,10 & 0,38 & 0,02 & 81 & 0,96 \\
\hline 96 & 7 & 6 & CFC & CSCE & 0,94 & $-600,91$ & 0,56 & 0,17 & 0,30 & 79 & 0,58 \\
\hline 96 & 7 & 6 & CFC & BMF & 0,93 & 46,07 & 0,62 & 0,16 & 0,55 & 81 & 0,18 \\
\hline 96 & 7 & 6 & CFD & CSCE & 0,88 & 127,63 & 0,00 & 0,09 & 0,43 & 79 & 0,99 \\
\hline 96 & 7 & 6 & CFD & BMF & 0,90 & 100,80 & 0,00 & 0,31 & 0,07 & 81 & 0,99 \\
\hline 96 & 7 & 6 & CFE & CSCE & 0,87 & 40,06 & 0,88 & 0,07 & 0,54 & 79 & 0,99 \\
\hline 96 & 7 & 6 & CFE & BMF & 0,88 & 90,90 & 0,22 & 0,17 & 0,30 & 81 & 0,99 \\
\hline 96 & 9 & 4 & CFA & CSCE & 0,96 & 56,70 & 0,11 & 0,22 & 0,16 & 58 & 0,95 \\
\hline 96 & 9 & 4 & CFA & BMF & 0,96 & 49,92 & 0,10 & 0,38 & 0,06 & 60 & 0,92 \\
\hline 96 & 9 & 4 & CFB & CSCE & 0,96 & 49,80 & 0,10 & 0,25 & 0,09 & 58 & 0,92 \\
\hline 96 & 9 & 4 & CFB & BMF & 0,97 & 35,55 & 0,16 & 0,49 & 0,01 & 60 & 0,35 \\
\hline 96 & 9 & 4 & CFC & CSCE & 0,78 & 32,63 & 0,37 & 0,30 & 0,20 & 58 & 0,04 \\
\hline 96 & 9 & 4 & CFC & BMF & 0,75 & 27,14 & 0,40 & 0,44 & 0,10 & 60 & 0,01 \\
\hline 96 & 9 & 4 & CFD & CSCE & 0,95 & 69,00 & 0,07 & 0,27 & 0,18 & 58 & 0,88 \\
\hline 96 & 9 & 4 & CFD & BMF & 0,95 & 60,53 & 0,08 & 0,45 & 0,08 & 60 & 0,80 \\
\hline 96 & 9 & 4 & CFE & CSCE & 0,96 & 58,13 & 0,17 & 0,19 & 0,30 & 58 & 0,96 \\
\hline 96 & 9 & 4 & CFE & BMF & 0,96 & 37,03 & 0,33 & 0,47 & 0,06 & 60 & 0,91 \\
\hline 96 & 9 & 6 & CFA & CSCE & 0,97 & 69,98 & 0,03 & 0,14 & 0,20 & 78 & 0,93 \\
\hline 96 & 9 & 6 & CFA & BMF & 0,97 & 60,66 & 0,04 & 0,29 & 0,07 & 80 & 0,92 \\
\hline 96 & 9 & 6 & CFB & CSCE & 0,96 & 66,32 & 0,02 & 0,16 & 0,14 & 78 & 0,95 \\
\hline 96 & 9 & 6 & CFB & BMF & 0,97 & 49,34 & 0,04 & 0,37 & 0,01 & 80 & 0,68 \\
\hline
\end{tabular}


Tabela 14 - Resultados das regressões utilizadas neste estudo (cont.)

\begin{tabular}{|c|c|c|c|c|c|c|c|c|c|c|c|}
\hline Ano & Mês & Periodo & $Y$ & $x$ & $R 2$ & $a$ & ta & $\mathrm{b}$ & tb & $N$ & Teste Q \\
\hline 96 & 9 & 6 & CFC & CSCE & 0,91 & 51,05 & 0,08 & 0,19 & 0,27 & 78 & 0,16 \\
\hline 96 & 9 & 6 & CFC & BMF & 0,90 & 51,54 & 0,12 & 0,25 & 0,33 & 80 & 0,03 \\
\hline 96 & 9 & 6 & CFD & CSCE & 0,95 & 90,54 & 0,01 & 0,16 & 0,26 & 78 & 0,83 \\
\hline 96 & 9 & 6 & CFD & BMF & 0,95 & 78,00 & 0,01 & 0,32 & 0,11 & 80 & 0,76 \\
\hline 96 & 9 & 6 & CFE & CSCE & 0,97 & 69,76 & 0,08 & 0,12 & 0,33 & 78 & 0,74 \\
\hline 96 & 9 & 6 & CFE & BMF & 0,97 & 50,29 & 0,17 & 0,36 & 0,07 & 80 & 0,68 \\
\hline 96 & 12 & 4 & CFA & CSCE & 0,87 & 67,15 & 0,00 & 0,27 & 0,03 & 69 & 0,87 \\
\hline 96 & 12 & 4 & CFA & BMF & 0,86 & 64,83 & 0,00 & 0,32 & 0,06 & 72 & 0,92 \\
\hline 96 & 12 & 4 & CFB & CSCE & 0,86 & 41,39 & 0,01 & 0,35 & 0,00 & 69 & 0,33 \\
\hline 96 & 12 & 4 & CFB & BMF & 0,87 & 35,55 & 0,03 & 0,48 & 0,00 & 72 & 0,11 \\
\hline 96 & 12 & 4 & $\mathrm{CFC}$ & CSCE & 0,70 & 88,43 & 0,00 & $-0,05$ & 0,74 & 69 & 0,05 \\
\hline 96 & 12 & 4 & CFC & BMF & 0,74 & 69,02 & 0,00 & 0,10 & 0,60 & 72 & 0,53 \\
\hline 96 & 12 & 4 & CFD & CSCE & 0,74 & 50,58 & 0,01 & 0,42 & 0,00 & 69 & 0,10 \\
\hline 96 & 12 & 4 & CFD & BMF & 0,81 & $-10,78$ & 0,18 & 1,01 & 0,00 & 72 & 0,88 \\
\hline 96 & 12 & 4 & CFE & CSCE & 0,93 & 70,66 & 0,00 & 0,20 & 0,01 & 69 & 0,87 \\
\hline 96 & 12 & 4 & CFE & BMF & 0,94 & 67,06 & 0,00 & 0,27 & 0,01 & 72 & 0,88 \\
\hline 96 & 12 & 6 & CFA & CSCE & 0,91 & 60,42 & 0,00 & 0,27 & 0,01 & 93 & 0,99 \\
\hline 96 & 12 & 6 & CFA & BMF & 0,91 & 55,33 & 0,00 & 0,38 & 0,01 & 97 & 0,99 \\
\hline 96 & 12 & 6 & CFB & CSCE & 0,93 & 46,88 & 0,00 & 0,30 & 0,00 & 93 & 0,82 \\
\hline 96 & 12 & 6 & CFB & BMF & 0,94 & 39,06 & 0,01 & 0,44 & 0,00 & 97 & 0,70 \\
\hline 96 & 12 & 6 & CFC & CSCE & 0,72 & 71,37 & 0,00 & 0,04 & 0,70 & 93 & 0,19 \\
\hline 96 & 12 & 6 & CFC & BMF & 0,76 & 61,30 & 0,00 & 0,14 & 0,32 & 97 & 0,84 \\
\hline 96 & 12 & 6 & CFD & CSCE & 0,89 & 58,74 & 0,00 & 0,36 & 0,01 & 93 & 0,69 \\
\hline 96 & 12 & 6 & CFD & BMF & 0,90 & 35,99 & 0,04 & 0,64 & 0,00 & 97 & 0,79 \\
\hline 96 & 12 & 6 & CFE & CSCE & 0,94 & 65,24 & 0,00 & 0,19 & 0,07 & 93 & 0,57 \\
\hline 96 & 12 & 6 & CFE & BMF & 0,94 & 50,84 & 0,01 & 0,37 & 0,01 & 97 & 0,43 \\
\hline 97 & 3 & 4 & CFA & CSCE & 0,97 & 57,02 & 0,00 & 0,43 & 0,00 & 33 & 0,87 \\
\hline 97 & 3 & 4 & CFA & BMF & 0,98 & 43,50 & 0,00 & 0,56 & 0,00 & 36 & 0,88 \\
\hline 97 & 3 & 4 & CFB & CSCE & 0,98 & 45,95 & 0,07 & 0,39 & 0,00 & 33 & 0,82 \\
\hline 97 & 3 & 4 & CFB & BMF & 0,97 & 7,73 & 0,06 & 0,65 & 0,00 & 36 & 0,77 \\
\hline 97 & 3 & 4 & CFC & CSCE & 0,94 & 107,78 & 0,11 & 0,08 & 0,55 & 33 & 0,78 \\
\hline 97 & 3 & 4 & CFC & BMF & 0,93 & 77,44 & 0,10 & 0,17 & 0,31 & 36 & 0,77 \\
\hline 97 & 3 & 4 & CFD & CSCE & 0,99 & 57,98 & 0,07 & 0,59 & 0,00 & 33 & 0,80 \\
\hline 97 & 3 & 4 & CFD & BMF & 0,99 & 1,49 & 0,70 & 0,92 & 0,00 & 36 & 0,82 \\
\hline 97 & 3 & 4 & CFE & CSCE & 0,98 & 3740,50 & 0,40 & 0,30 & 0,01 & 33 & 0,85 \\
\hline 97 & 3 & 4 & CFE & BMF & 0,99 & 3879,00 & 0,33 & 0,33 & 0,00 & 36 & 0,89 \\
\hline 97 & 3 & 6 & CFA & CSCE & 0,97 & 81,85 & 0,00 & 0,30 & 0,00 & 67 & 0,99 \\
\hline 97 & 3 & 6 & CFA & BMF & 0,97 & 63,29 & 0,00 & 0,43 & 0,00 & 71 & 0,98 \\
\hline 97 & 3 & 6 & CFB & CSCE & 0,97 & 43,45 & 0,01 & 0,38 & 0,00 & 67 & 0,91 \\
\hline 97 & 3 & 6 & CFB & BMF & 0,96 & 25,59 & 0,00 & 0,55 & 0,00 & 71 & 0,13 \\
\hline 97 & 3 & 6 & CFC & CSCE & 0,89 & 74,68 & 0,05 & 0,12 & 0,32 & 67 & 0,99 \\
\hline 97 & 3 & 6 & CFC & BMF & 0,90 & 64,42 & 0,01 & 0,19 & 0,11 & 71 & 0,95 \\
\hline 97 & 3 & 6 & CFD & CSCE & 0,99 & 104,87 & 0,15 & 0,56 & 0,00 & 67 & 0,49 \\
\hline 97 & 3 & 6 & CFD & BMF & 0,99 & $-0,09$ & 0,97 & 0,93 & 0,00 & 71 & 0,99 \\
\hline 97 & 3 & 6 & CFE & CSCE & 0,97 & 1703,28 & 0,59 & 0,31 & 0,00 & 67 & 0,99 \\
\hline 97 & 3 & 6 & CFE & BMF & 0,98 & 2204,31 & 0,44 & 0,33 & 0,00 & 71 & 0,98 \\
\hline
\end{tabular}


Tabela 14 - Resultados das regressões utilizadas neste estudo (cont.)

\begin{tabular}{ccclllrlcccc}
\hline Ano & Mês & Periodo & Y & X & R2 & \multicolumn{1}{c}{$\mathbf{a}$} & ta & b & tb & N & Teste Q \\
\hline 97 & 7 & 4 & CFA & CSCE & 0,69 & 61,50 & 0,00 & 0,45 & 0,00 & 37 & 0,76 \\
97 & 7 & 4 & CFA BMF & 0,62 & 2,35 & 0,94 & 0,82 & 0,00 & 38 & 0,75 \\
97 & 7 & 4 & CFB & CSCE & 0,07 & 124,04 & 0,00 & 0,08 & 0,12 & 37 & 0,71 \\
97 & 7 & 4 & CFB BMF & 0,20 & 91,26 & 0,00 & 0,24 & 0,00 & 38 & 0,96 \\
97 & 7 & 4 & CFC & CSCE & 0,55 & 29,72 & 0,40 & 0,22 & 0,06 & 37 & 0,39 \\
97 & 7 & 4 & CFC BMF & 0,60 & 0,62 & 0,99 & 0,41 & 0,02 & 38 & 0,46 \\
97 & 7 & 4 & CFD CSCE & 0,80 & 123,20 & 0,00 & 0,34 & 0,00 & 36 & 0,32 \\
97 & 7 & 4 & CFD BMF & 0,83 & 86,94 & 0,01 & 0,58 & 0,00 & 37 & 0,36 \\
97 & 7 & 4 & CFE CSCE & 0,60 & 65,15 & 0,03 & 0,34 & 0,00 & 37 & 0,96 \\
97 & 7 & 4 & CFE BMF & 0,64 & 36,67 & 0,21 & 0,54 & 0,00 & 38 & 0,97 \\
97 & 7 & 6 & CFA CSCE & 0,81 & 64,99 & 0,00 & 0,44 & 0,00 & 49 & 0,88 \\
97 & 7 & 6 & CFA BMF & 0,76 & 10,83 & 0,63 & 0,78 & 0,00 & 51 & 0,74 \\
97 & 7 & 6 & CFB CSCE & 0,14 & 123,04 & 0,00 & 0,08 & 0,01 & 49 & 0,95 \\
97 & 7 & 6 & CFB BMF & 0,20 & 106,52 & 0,00 & 0,17 & 0,00 & 51 & 0,98 \\
97 & 7 & 6 & CFC CSCE & 0,72 & 31,48 & 0,34 & 0,22 & 0,03 & 49 & 0,49 \\
97 & 7 & 6 & CFC BMF & 0,75 & $-4,59$ & 0,90 & 0,43 & 0,01 & 51 & 0,52 \\
97 & 7 & 6 & CFD CSCE & 0,89 & 117,17 & 0,00 & 0,38 & 0,00 & 48 & 0,95 \\
97 & 7 & 6 & CFD BMF & 0,90 & 73,25 & 0,00 & 0,65 & 0,00 & 50 & 0,83 \\
97 & 7 & 6 & CFE CSCE & 0,63 & 61,91 & 0,03 & 0,36 & 0,00 & 49 & 0,70 \\
97 & 7 & 6 & CFE BMF & 0,66 & 23,78 & 0,40 & 0,61 & 0,00 & 51 & 0,96 \\
\hline
\end{tabular}




\section{REFERÊNCIA BIBLIOGRÁFICA}

Anuário Estatístico Coffee Business 1997 e 1998. Rio de Janeiro.

ASSIS, M. Palestra realizada no $1^{\circ}$ Seminário Internacional do Café, Rio de Janeiro (RJ), jan/97.

BARROS, G. S. C. Economia da Comercialização Agrícola. Piracicaba, FEALQ, $1987.306 \mathrm{p}$.

BERNSTEIN, P. Desafio aos Deuses: A Fascinante História do Risco. 3.ed. Rio de Janeiro: Editora Campus, 1997. 389p.

BESSADA, O. O Mercado Futuro e de Opções. Rio de Janeiro, Record, 1995. 297 p.

EDERINGTON, L. H. The hedging performance of the new futures markets. Journal of Finance. v.34, n.1, p.157-171, 1979.

EMMET, E. Reduction in hedging risk from adjusting for autocorrelation in the residuals of a price level regression. Journal of Future Markets. v.11, n.3, p.371-384, 1991.

GUJARATI, D. N. Basic Econometrics. 3.ed. : McGraw-Hill, 1995. 838p. 
HULL, J. Introduction to Future and Options Market. 2.ed. New Jersey: Prentice Hall, 1995. 444p.

KMENTA, J. Elementos de Econometria: Teoria Econométrica Básica. 2.ed. São Paulo: Atlas, 1988. 711 p.

LENCE, S. H.; HAYENGA, M. L.; PATTERSON, M. D. Storage profitability and hedge ratio estimation. Journal of Future Markets. v.16, n.6, p.655-676, 1996.

LENCE, S. H.; HAYES, D. J. The empirical minimum-variance hedge ratio. American Journal of Agricultural Economics. v.76, n.1, p.94-104, 1994.

LEUTHOLD, R. M.; JUNKUS, J. C.; CORDIER, J. E. The Theory and Practice of Futures Markets. Lexington Books, 1989.

LIEN, D. D. The effect of cointegration relationship on futures hedging: a note. Journal of Future Markets. v.16, n.7, p.773-780, 1996.

LU, R. LEUTHOLD, R. M. Cointegration relations between spot and futures prices for storable commodities: implications for hedging and forecasting. OFOR Paper Number 94-12, 1994.

MYERS, R. J.; THOMPSON, R. J. Generalized optimal hedge ratio estimation. American Journal of Agricultural Economics. v.71, n.4, p.858-868, 1989. 
OUATTARA, K; SCHROEDER, T. C; SORENSON, L. O. Potential use of futures markets for international marketing of Cote d'Ivoire coffe. Journal of Futures Markets. v.10, n.2, p. 113-121, 1990.

PURCELL, W. D. Agricultural Futures and Options: Principles and Strategies. New York: Macmillian, 1991.363p.

ROCHELLE, T.C.P.; CASTRO, E.T.P.; MARQUES, P.V. Relações Contratuais no Complexo Soja. Piracicaba, 1995, 14 p.

SHAFER, C. E. Hedge ratios and basis behavior: an intuitive insight. Journal of Futures Markets. v.13, n.8, p.837-847, 1993. 